\title{
RACIAL/ETHNIC INEQUALITY AMONG OLDER WORKERS: FOCUSING ON WHITES, BLACKS, AND LATINOS WITHIN THE CUMULATIVE ADVANTAGE/DISADVANTAGE FRAMEWORK
}

by

\section{Eunhee Choi}

Bachelor of Political Science \& Social Work, Kyunghee University, 2004

Master's in Social Work, Yonsei University, 2007

Submitted to the Graduate Faculty of

The School of Social Work in partial fulfillment

of the requirements for the degree of

Doctor of Philosophy

University of Pittsburgh 


\section{UNIVERSITY OF PITTSBURGH \\ SCHOOL OF SOCIAL WORK}

This dissertation was presented

by

Eunhee Choi

It was defended on

August 12, 2013

Dissertation Co-Advisor: Valire Carr Copeland Associate Dean of Academic Affairs, University of Pittsburgh School of Social Work

Dissertation Co-Advisor: Fengyan Tang, Associate Professor, University of Pittsburgh School of Social Work

Ray Engel, Associate Professor, University of Pittsburgh School of Social Work

Steven M. Albert, Professor and Chair, University of Pittsburgh Department of Behavior and Community Health Sciences Graduate School of Public Health 
Copyright $(\subset$ by Eunhee Choi

2013 


\title{
RACIAL/ETHNIC INEQUALITY AMONG OLDER WORKERS: FOCUSING ON WHITES, BLACKS, AND LATINOS WITHIN THE CUMULATIVE ADVANTAGE/DISADVANTAGE FRAMEWORK
}

\author{
Eunhee Choi, M.S.W., Ph.D. \\ University of Pittsburgh, 2013
}

\begin{abstract}
As the number of older workers increases, scholars from variable fields have made an effort to understand what makes the current older generation want to remain in the labor market; however, our knowledge of older minority workers is fragmentary. The experience of older minority workers, defined as Blacks and Latinos in this study, may differ from that of their White counterparts because of persistent racial/ethnic differences among older workers, especially in four domains: 1) financial resources for retirement, 2) health, 3) career patterns, and 4) education. Existing literature has little to offer for older minority workers because of limited methodological approaches and a dearth of appropriate theories. Thus, this study aims to identify factors that explain older Americans' labor market participation after retirement age and whether there are racial/ethnic differences among those factors. It also presents fragmentary knowledge from existing studies within the framework of the cumulative advantage/disadvantage (CAD) theory.
\end{abstract}

Using the 1,114 pre-retirement aged workers from the 2004 and 2008 datasets of the Health and Retirement Study (HRS), probit analysis was run to estimate the analytic model. 
Racially separate analyses were performed to treat race as a major indicator for the outcome (workers' labor market status after age 65) and to systematically compare factors by race.

The results showed that, after adjusting for covariates, factors influencing older individuals' employment after age 65 were conditioned by race. Whereas health and the meaning of work most influence Whites, financial resources (particularly home ownership) most affect Blacks, while health alone most concerns Latinos. Overall, this study suggests that access to the labor market - as opposed to personal preference, financial necessity, or job dissatisfactionmost influences the labor market participation of minorities.

These findings of this study highlight the role of race, suggesting that one universal model cannot fully explain older individuals' labor market participation among different race/ethnic groups. Furthermore, this study's inclusion of Latinos expanded the scope of the existing literature, finding that both Black and Latino workers experience a lifetime accumulation of disadvantages. However, their employment experiences differ significantly: while class differences potentially exist among Black workers, Latinos can be more disadvantaged as a whole, experiencing substantial barriers related to education level and language in the workplace.

This study helps to correct theoretical limitations in studies of older workers by using the more revealing $\mathrm{CAD}$ framework to interpret results. Racial/ethnic inequality among older workers should be understood not as sudden occurrences in old age, but as a byproduct of the interplay between the individual's lifetime experiences in the labor market and the social structures that impose cumulative advantages/disadvantages on the individual. This study also 
contributes to the field of social work by stressing the importance of both financial and nonfinancial factors to better comprehend issues surrounding older workers. 


\section{TABLE OF CONTENTS}

TABLE OF CONTENTS VII

PREFACE XV

I. INTRODUCTION 1

A. TRENDS OF WORKING AFTER RETIREMENT AGE 1

B. IGNORED DIFFERENCES AMONG OLDER WORKERS BY RACE/ETHNICITY ... 1

C. THEORETICAL LIMITATIONS IN UNDERSTANDING OLDER MINORITY WORKERS

D. METHODOLOGICAL LIMITATIONS OF EXISTING RESEARCH. 5

E. STUDY PURPOSE ............................................................................................ 7

II. LITERATURE REVIEW ................................................................................. 10

A. BACKGROUND OF OLDER WORKERS ......................................................... 10

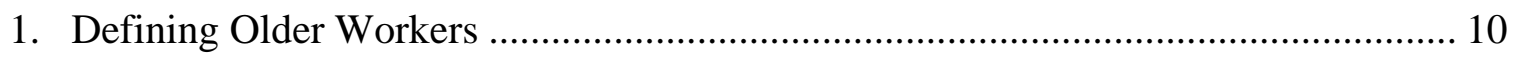

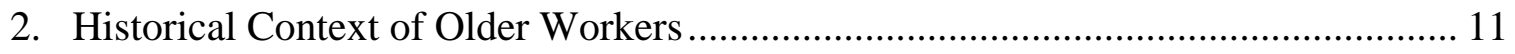


B. FINANCIAL RESOURCES FOR RETIREMENT ..................................................... 14

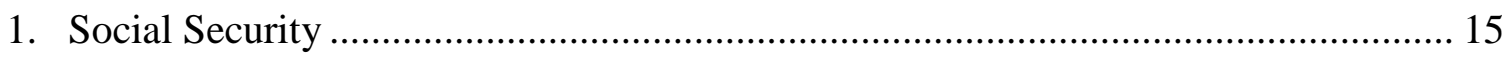

2. Employer-Sponsored Pensions ……………………...................................... 19

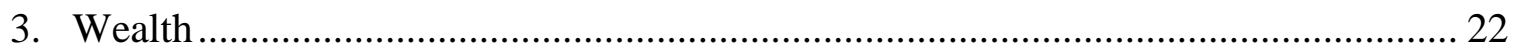

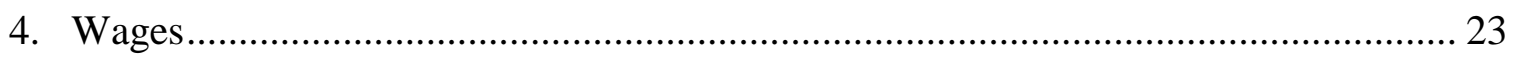

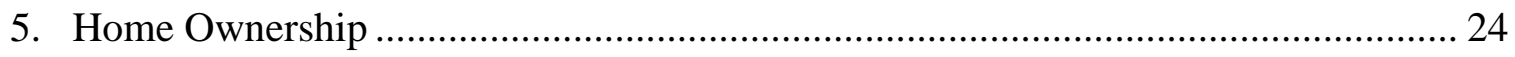

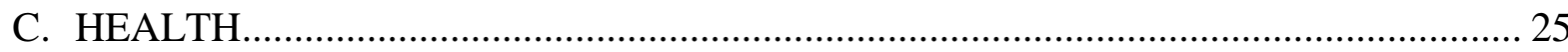

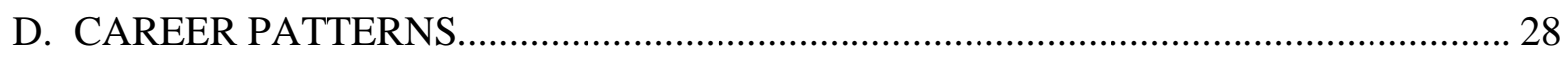

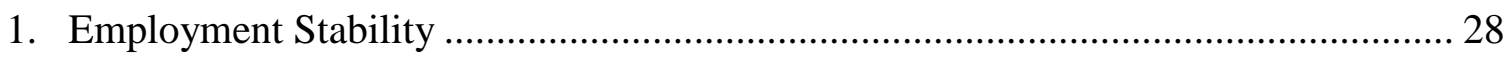

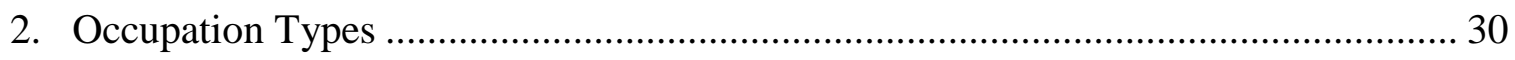

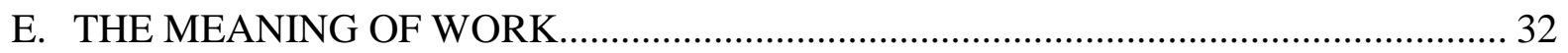

F. THE ATTRIBUTES OF PRERETIREMENT WORK …………................................... 35

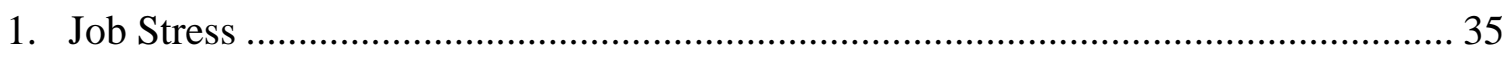

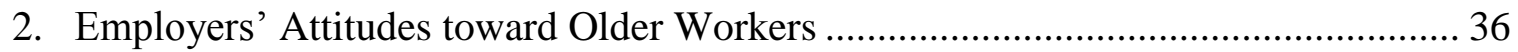

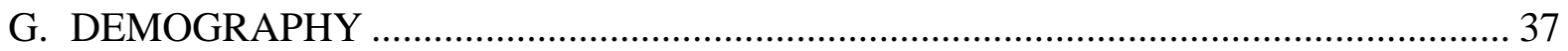

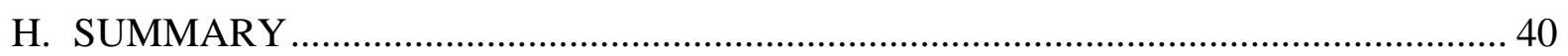

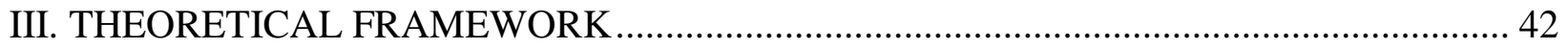

A. THEORETICAL BACKGROUND OF UNDERSTANDING SOCIAL INEQUALITY 42

1. Marx and Weber: Inequality is Fundamentally Detrimental ..................................... 42

2. Durkheim \& the Functionalists: Inequality is Necessary and Inevitable .................... 44 
3. Need for an Alternative Theory for Older Minority Workers

B. HISTORICAL CONTEXT OF MINORITY WORKERS IN THE U.S

C. INTRODUCTION OF CUMULATIVE ADVANTAGE/DISADVANTAGE THEORY52

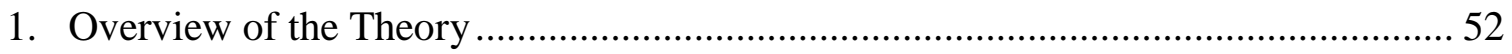

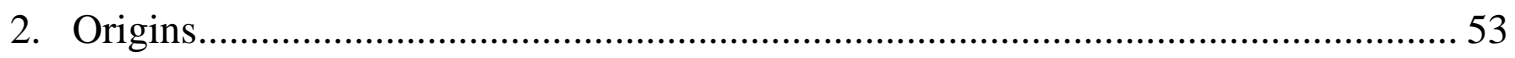

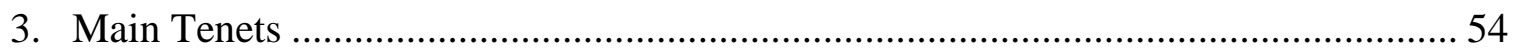

4. The Emergence of CAD Theory in Studies on Aging .............................................. 55

5. Significance of Race/Ethnicity in Understanding Social Inequality in the U.S. ........ 56

D. APPLYING CAD THEORY TO RACIAL/ETHNIC INEQUALITY IN OLD AGE ..... 57

1. Minorities' Cumulative Disadvantages in Financial Resources for Retirement and

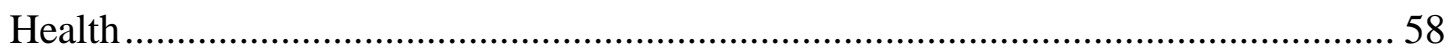

2. Significance of Career Patterns............................................................................ 59

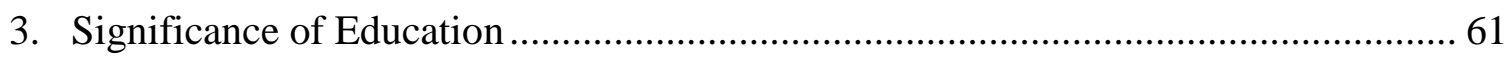

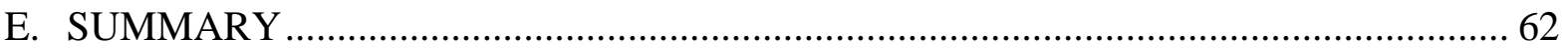

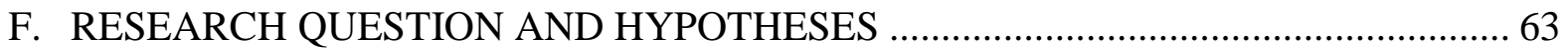

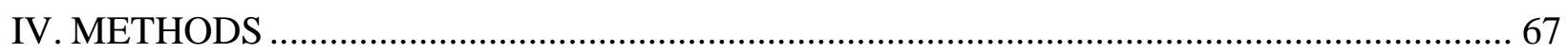

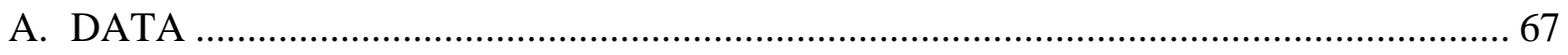

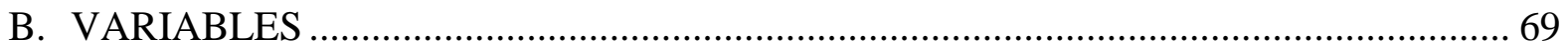

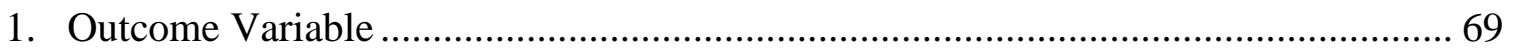

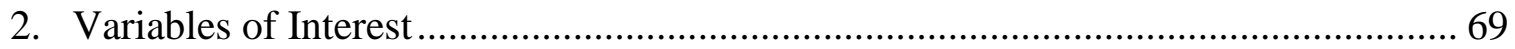




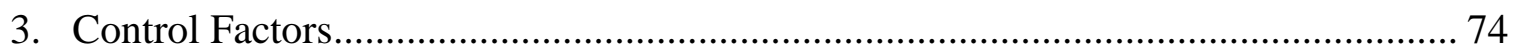

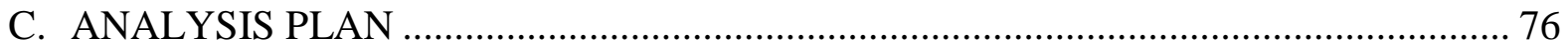

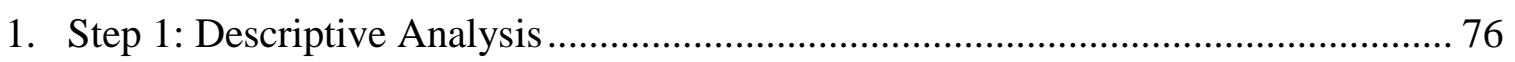

2. Step 2: Missing Value Imputation ........................................................................ 77

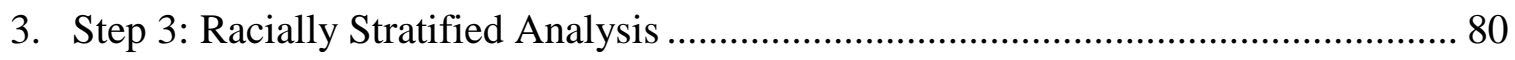

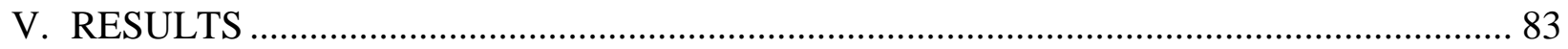

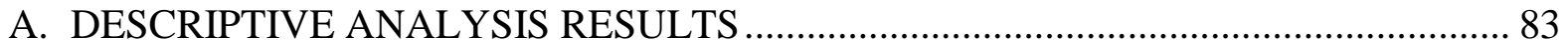

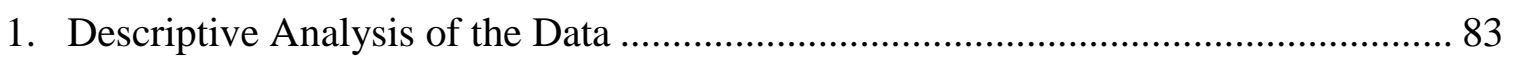

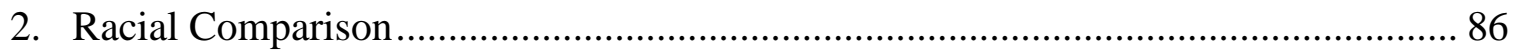

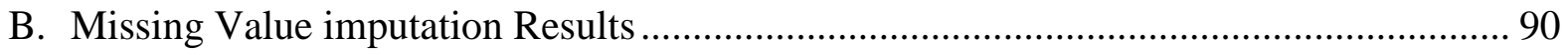

1. Step 2-1 Results: Checking Missing Values............................................................ 90

2. Step 2-2 Results: Checking Missing Patterns ............................................................. 92

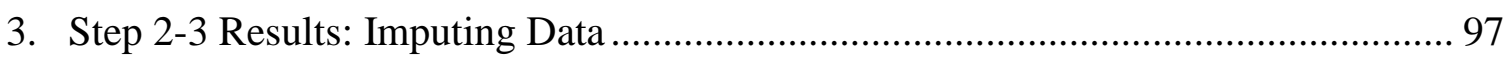

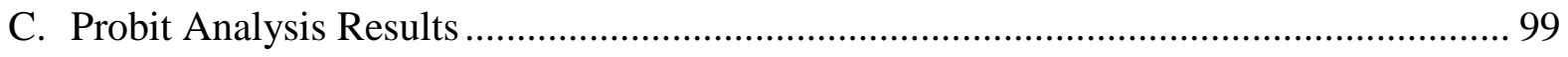

1. Step 3-1: Comparing significant factors across races .................................................. 99

2. Step 3-2: Comparing magnitude of significant factors across races......................... 101

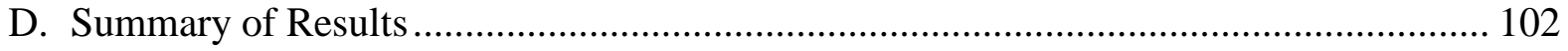

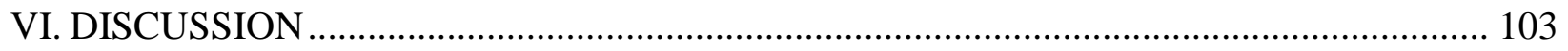

A. RACIAL/ETHNIC INEQUALITY AMONG OLDER WORKERS ………….............. 103

1. Racial Inequality in Pre-retirement Conditions .......................................................... 103 
2. Racial Differences in Factors Affecting Labor Market Participation after Retirement Age 104

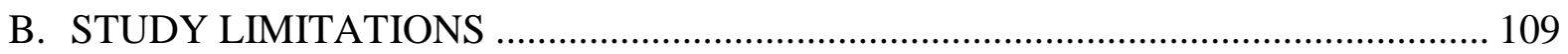

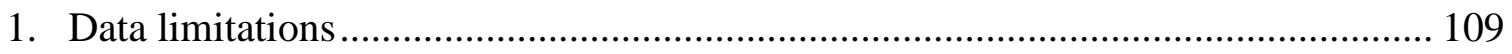

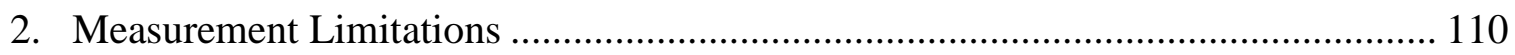

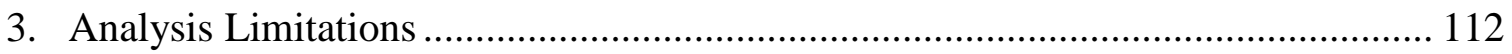

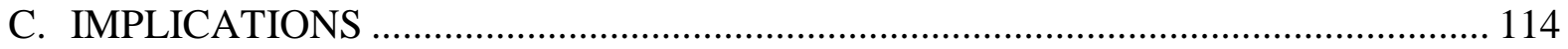

1. Implications for Future Research....................................................................... 114

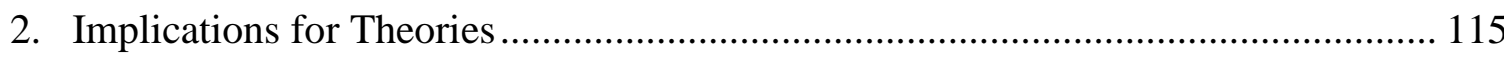

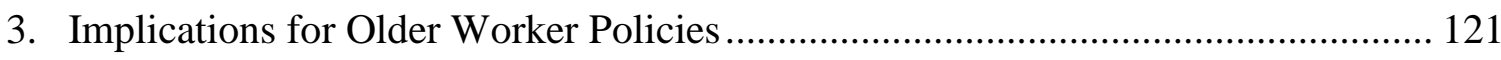

4. Implications for Social Work Practice ................................................................ 128

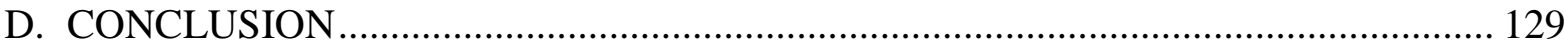

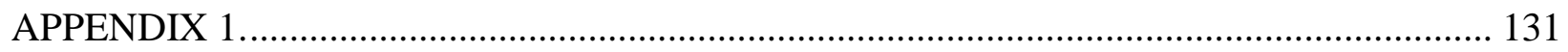

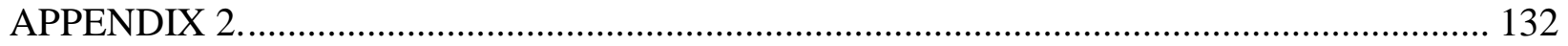

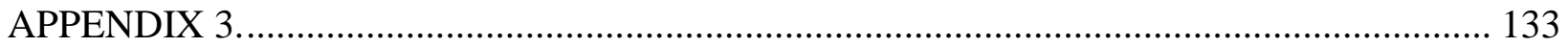

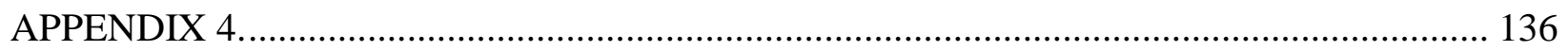

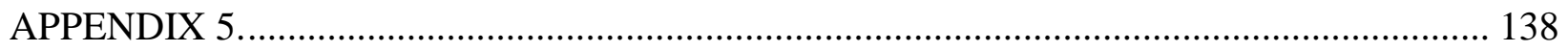

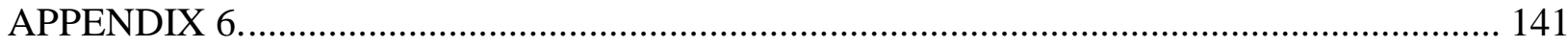




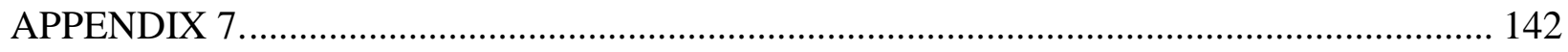

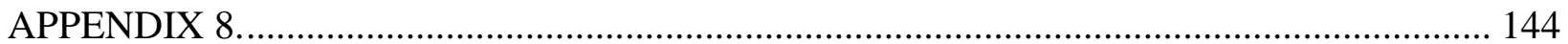

APPENDIX 9

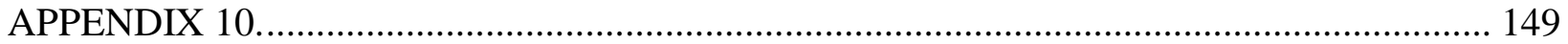

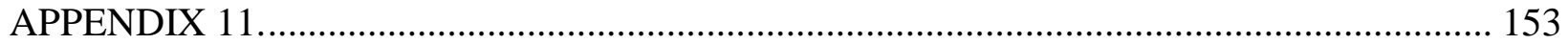

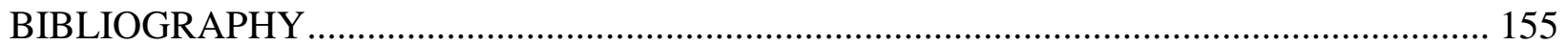




\section{LIST OF TABLES}

Table 1. Coding schemes for categorizing occupations................................................. 73

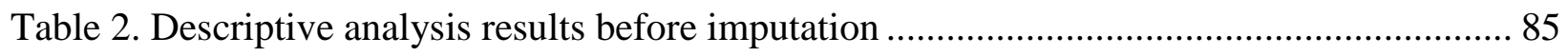

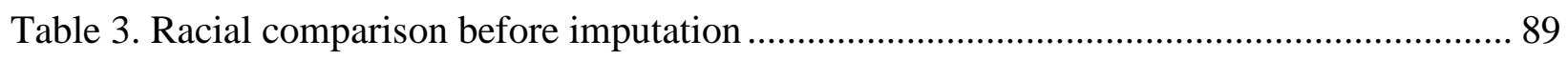

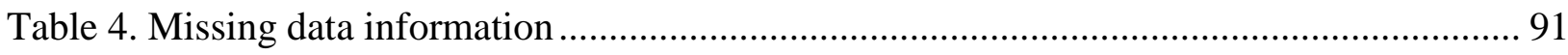

Table 5. Checking independence of patterns of missing for work status and race .................... 93

Table 6. Comparing the missing patterns of meaning of work with other covariates ................ 96

Table 7. Comparing descriptive statistics before and after imputation ................................. 98

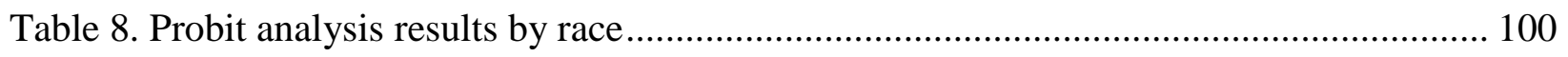

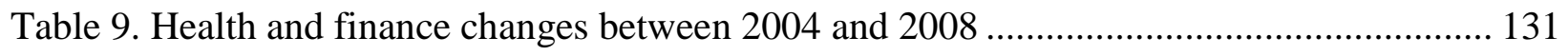

Table 10. Multinomial logit analysis results using three-level outcome (retired, part-time, and

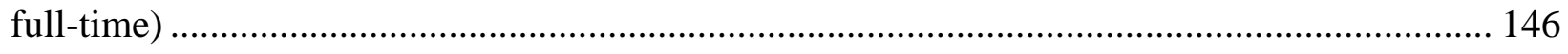

Table 11. VIF information for imputed data by race ..................................................... 148

Table 12. Comparisons between this study's sample and those excluded from this study ......... 149

Table 13. Multinomial logit analysis results comparing retirees, workers, and the

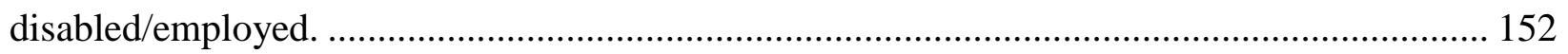

Table 14. Correlations between meaning of work and selected study variables ..................... 154 


\section{LIST OF FIGURES}

Figure 1. The conceptual model of this study... 


\section{PREFACE}

Many people deserve acknowledgement and thanks for their support, allowing me to reach this pivotal point in my life. Even with my passion and devotion to my dissertation, its path was more difficult than I ever imagined, but I feel so blessed to have these people in my life. Without them, none of this would have been possible.

I would first like to thank my dissertation co-chairs, Dr. Fengyan Tang and Dr. Valire Carr Copeland, the heart of this dissertation. Dr. Tang was my motivation for coming to the University of Pittsburgh, as I wanted to learn more about productive aging. She generously included me in her projects and provided significant opportunities for growth. I deeply thank her for her guidance throughout my Ph.D. training. Dr. Copeland, who also happened to be Ph.D. program director, has witnessed my growth academically and personally from the beginning. I truly appreciate her gifts of guidance, perseverance, and wisdom, which have enabled me to complete this work. I especially thank her for her great support in my job market search despite her considerable academic responsibilities. Thanks to both of my chairs' insight and input, which they were always willing to share, I have built a strong scholarly foundation, expanding my views not only on methodologies, but also on theories, historical perspectives, and how to write logically and concisely. I would also like to thank my committee members, Dr. Ray Engel and Dr. Steven Albert. I appreciate Dr. Engel's sharp insight, time and wisdom, all of which truly helped me improve my study. Thanks as well to Dr. Albert. Besides his kindness and 
caring, I learned from him the fascinating world of interdisciplinary research, and how to incorporate health and social work perspectives into my studies of aging. These skills gained from my chairs and committee members are priceless. It is a great privilege to have received a Ph.D. under their guidance.

I am grateful to Dr. William Elliott, who let me explore to my full potential. His tremendous help taught me how to become a productive and passionate researcher, how to teach online courses, and how to better communicate in academia. Despite the distance, he continues to provide me with his mentorship and wisdom. I truly appreciate the time he has spent supporting me and the dedication with which he has helped advance my career. I am also thankful to Dr. Rachel Fusco for her sincere, warm, caring support and encouragement, and for helping me endure all the difficult times during my PhD. program. I also want to give my sincere thank-you to the faculty at the University of Pittsburgh for their dedication to my doctoral education, including Dr. Gary Koeske, Dr. Katie Greeno, Dr. Christina Newhill, Dr. Aaron Mann, Dr. Helen Petracchi, Dr. John Wallace, and Dr. Kevin Kim. I also extend my thanks to Mary Pat Elhattab for her kindness and consistent willingness to help.

I am indebted to Sunggeun, beyond a friend, who is an intellectual colleague and a perpetual problem solver. Embarking on the Ph.D. journey together, we have witnessed each other's growth. He was always willing to help and gave me extensive yet sincere and generous support. I am deeply grateful to Tom Mcworther and Lynne Sunderman, my editors. They are more than just editors, but mentors and friends, giving me strength and assurance, both within and beyond academia. I would like to acknowledge the ongoing support and friendship from my colleagues in the doctoral program: Hyunzee, Grace, Janice, Yoonmi, Nari, Terri, Addie, Karen, Lisa, Yeonjung Hyuna, Andrea, Amada, Courtney, Kevin, Rachel, Daniel, Eunji, Heath, Ilsung, 
Hyojung, and many others. I wish you all the best, my dear colleagues! Moreover, I am appreciative of my dearest friends, Yoonjung, Hanna, Boeun, Jihee, and pastor Lym, who spiritually encourage me, not just for my dissertation, but also for my life. Their prayers have meant so much. Also, I cannot express how blessed I am to have Chen, my soft place when my personal and academic life got too hard to bear.

Finally, I could not have gotten here without my loving family: my aunt in Japan—my greatest friend who understands everything about me, my aunt and uncles in Korea—who care about me like her own daughter, and grandmother-who loves me so much. Most of all, I dedicate this dissertation to my mother and father, who have given me wings to fly with to reach my full potential and have taught me to do my best in life and to be honest with others. I love you all very much. I thank God for his blessings and grace. 


\section{INTRODUCTION}

\section{A. TRENDS OF WORKING AFTER RETIREMENT AGE}

The number of Americans who stay in the labor market beyond the traditional retirement age of 65 has been steadily increasing. From 1990 to 2010, the number of older workers grew from 11.9 $\%$ to $17.4 \%$; today, six million of the 39 million older Americans remain in the labor market (U.S. Bureau of Labor Statistics, 2011). Scholars from various fields have made an effort to understand what makes the current older generation want to stay in the labor market longer. According to their findings, financial and health factors play the most influential roles: individuals with fewer financial resources for retirement (French, 2005; Gustman \& Steinmeier, 2009; Quinn \& Kozy, 1996) and better health (Currie \& Madrian, 1999; Deschryvere, 2004) are more likely to work in old age. In addition to these individual-level factors, the U.S. government's pro-work policies—such as increasing the delayed retirement credits which entails more Social Security benefits for those who delay retirement until age 70-appear to have contributed to the growing popularity of working among older people (French, 2005; Gustman \& Steinmeier, 2009).

\section{B. IGNORED DIFFERENCES AMONG OLDER WORKERS BY RACE/ETHNICITY}

Although racial/ethnic differences in America have been recognized as a serious social issue and are routinely documented, our knowledge of older minority workers remains fragmentary. The proportion of older minority workers—-defined as Blacks and Latinos in this study—is relatively small: among the six million older workers in the U.S. today, Blacks and Latinos ${ }^{1}$ comprise only

\footnotetext{
${ }^{1}$ This study uses the term "Latinos" instead of "Hispanics" to be consistent with the data that this study uses for analysis.
} 
7\% each (U.S. Bureau of Labor Statistics, 2011). In particular, even though many researchers have examined factors that influence older people's labor market participation, they have not actively investigated what factors uniquely affect older minorities. The experience of older minorities may differ from that of their White counterparts due to persistent racial/ethnic differences among older workers, in four domains in particular, 1) financial status, 2) health, 3) career patterns, and 4) education. First, compared to older Whites, older minorities generally have fewer financial resources for retirement (Choudhury \& Bridges, 2009; Purcell, 2009b). When comparing the household wealth among near-retirees ages 51 to 61 , Blacks $(\$ 305,000)$ and Latinos $(\$ 331,000)$ have substantially lower wealth than Whites $(\$ 819,000)$ (AARP, 2011).

Second, older minority workers are more likely to have poorer health than older White workers. Although older Americans are becoming healthier in general, this improvement in health has not been universal across races (Taylor, 2008). It is well-documented that minorities of all ages experience a higher risk of morbidity, disability, and mortality compared to Whites (Hayward, Friedman, \& Chen, 1996; Hogan, Kim, \& Perrucci, 1997; Porell, 2009) and these risks are even higher among older minorities with low income.

Third, career patterns exhibit racial/ethnic differences. Despite the decrease in the proportion of physically demanding jobs in the U.S. labor market (R. W. Johnson, 2004) and the reduction of occupational segregation during the past decades (Gilbert, 2002), Blacks and Latinos historically account for a disproportionate share of low-skilled, low-paying, physically demanding, and intermittent positions (Flippen \& Tienda, 2000; Williams, Costa, Odunlami, \& Mahammed, 2008). According to a nationwide household survey of older workers ages 50-69, more than half of Blacks (52\%) and Latinos (58\%) have physically demanding or low-skilled jobs, such as service worker and laborer, compared to older Whites (33\%) (AARP, 2009). Also, 
older Latino workers differ from their Black counterparts in terms of job types. For example, many older Latino employees work in agriculture. In 2007, 21\% of Latinos ages 50 to 69 worked in these industries, compared with $14 \%$ of Whites and $10 \%$ of Blacks. In addition, older Latinos are notably underrepresented in managerial, professional, and technical occupations. Only 18\% of employed Hispanic men ages 50 to 69 worked in either management, professional, or technical positions, compared to $41 \%$ of Whites and $24 \%$ of Blacks. Furthermore, Latinos are less likely to work in the service sector. Only $26 \%$ of employed older Latino men worked in services, compared with 30\% of Whites and 35\% of Blacks (AARP, 2009).

Finally, educational attainment among older workers differs by race/ethnicity as well. Among individuals ages 50 to $74,30 \%$ of Whites completed a four-year college or higher as compared with only $15 \%$ of Blacks and $12 \%$ of Latinos (AARP, 2011). Particularly with Latinos, immigration status plays a significant role in their educational attainment. In 2007, $57 \%$ of Latinos aged 50 to 69 were foreign-born, compared to only $9 \%$ of their non-Hispanic counterparts; furthermore, of those foreign-born Latinos, 55\% did not speak English well (AARP, 2009).

These racial disparities may signal that, beyond the challenges of employment and educational discrimination minorities experience at younger ages, these minority workers may suffer from continuing racial/ethnic inequality over a life time (Hogan et al., 1997).

These stark racial/ethnic differences among older workers also point out that one universal model may not fully explain older people's labor market participation among different race groups. Therefore, it is necessary to examine factors which significantly explain older Americans' labor market participation after retirement age and whether there are racial/ethnic differences in the factors. 


\section{THEORETICAL LIMITATIONS IN UNDERSTANDING OLDER MINORITY WORKERS}

Theoretical limitations appear to hinder our understanding of older minority workers. For instance, economists, who have conducted many of the studies on older workers, usually do not use social theories.

Although studies from other disciplines, such as sociology, psychology, or social work, apply certain theories, these theories have not adequately accounted for the experience of older Black and Latino workers. To illustrate, disengagement theory from the 1960s - the earliest psychosocial theory on aging (Knapp, 2009) — asserts that older people inevitably withdraw from meaningful roles, relationships, and society (Cumming \& Henry, 1961) and tend to seek isolation as preparation for death (Lindberg \& Carstensen, 2007). Although disengagement theory provided fundamentals for developing formal theories of aging, especially in the area of lifespan development (Knapp, 2009), and offered systematic explanations for early retirement (Donoghue, 2008), it has received considerable criticism (Lynott \& Lynott, 2002). Gerontologists nowadays generally believe that isolation or disengagement is unnecessary and may even negatively impact older people (Maurer, 2001). Also, today's many older individuals are capable of keeping active and desire to stay in their families, communities, and society (Hochschild, 1975). Thus, the increasing number of older workers itself would seem to contradict the premise of disengagement theory due to social, political, economic, and cultural changes in society.

Moreover, activity theory and role theory - which highlight the positive aspects of aging - are commonly used in studies of older workers. In some ways, these theories are helpful to understand the current older generations' different expectations toward retirement since they 
offer a change from the conventionally negative view of aging to a new norm of aging about ways to spend old age well (Butler \& Gleason, 1994). These theories also recognize the immense potential of older people (Friedan, 1993), by viewing older workers as those who voluntarily choose to work based on their need for and interest in personal growth as well as their willingness to contribute to society (Butler \& Gleason, 1994; Friedan, 1993; Hinterlong, Morrow-Howell, \& Sherraden, 2001). However, they are not suitable for older minority workers. Despite their contributions, these theories have limits concerning older minority workers because they primarily focus on staying active as a new norm of successful aging and leave out the important role finances play in an individual's decision to delay retirement (Choi, 2001). These theories are fundamentally based on the assumption that working after retirement age is a matter of personal preference. Even though some older people choose to work because they do enjoy work and desire meaningful activity (Mutchler, 2002), others, often minorities with few economic resources for retirement and poor health, may work to survive, not to gain personal growth or to make a productive contribution to society.

In addition to a dearth of appropriate theories, theories commonly used in older worker studies fail to consider effects of social structure, which substantially impacts members of racial and ethnic minorities. Thus, given these theoretical limitations in understanding older minority workers, it is not appropriate for this study to use conventional theories for older workers.

\section{METHODOLOGICAL LIMITATIONS OF EXISTING RESEARCH}

Experts in racial/ethnic health disparity criticize the analytical approach which studies of racial/ethnic disparity typically take: treating race as a binary (dummy) variable which is statistically controlled for in multivariate analysis or including interaction terms between race 
and other variables of interest (Jones, 2001; LaVeist, 2002). However, these two common approaches are limited in comparing racial/ethnic differences. Having a simple race variable in the analytical model only produces adjusted means of the dependent variable for each race group (Kaufman \& Cooper, 2001; LaVeist, 1994). Also, simulation studies strongly suggest that interaction terms do not accurately compare groups because the unobserved variation is not the same across groups (Hoetker, 2007). Consequently, these methods fail to consider raceassociated differences as key elements, providing no insight into the role of race in the analysis (Jones, 2001; Kaufman \& Cooper, 2001; LaVeist, 1994; Robins, Hernan, \& Brumback, 2000). For instance, in studying racial/ethnic differences among older workers, some studies (e.g., Hayward et al, 1996; Mutchler, Burr, Pienta, \& Massagli, 1997) treated race not as an important clue but as a simple characteristic of a person to adjust for confounding effects. Although one study (Bound, Waidmann, Schoenbaum, Bingenheimer, 2003) successfully designed a separate analysis among races, its analytic model failed to comprehensively consider important determinants of working in old age. As a result, racial differences remain poorly explained.

In addition, most studies investigating the racial/ethnic differences have focused on Black-White differences. Such an approach has neglected Latinos-the fastest growing population in the U.S. Although older Latino workers are similar with older Black workers in exhibiting lifetime histories of unstable employment, poor health, and high poverty rate (Flippen \& Tienda, 2000; Zsembik \& Singer, 1990), they are somewhat different from Black workers. Their low education level — even lower than that of Blacks — and lack of fluency in English often give them additional barriers to having jobs with high-pay, pension coverage, and health benefits (Flippen \& Tienda, 2000). 


\section{E. STUDY PURPOSE}

This study aims to examine factors that significantly explain older Americans' labor market participation after retirement age and whether there are racial differences in the factors. This study particularly focuses on workers approaching retirement and excludes those who are disabled and unemployed because these two groups differ in many aspects.

In regard with a theoretical framework, this study introduces a new conceptual framework of cumulative advantage/disadvantage theory (CAD). CAD theory, although not yet empirically applied to the older worker population, can help us to understand how groups become disparate in later life for two reasons. First, CAD theory emphasizes the process by which the social system generates inequality and how unfavorable positions in early life lead to an accumulation of disadvantages in later age (Crystal \& Shea, 1990; Shuey \& Willson, 2008). Based upon CAD theory, this study suggests that staying in the labor market beyond retirement age may not simply result from individual preference per se but also from social structures, which reflect underlying racial inequality within older workers. Second, CAD theory helps this study to frame fragmentary knowledge from existing research into four essential factors: financial resources for retirement, health, career patterns, and education. Although most studies of older workers focus on factors in late life, it is especially important to pay attention to the role of career patterns - defined by employment stability (long- or short-term employment history) and occupation types (white- or blue-collar jobs)—which involve earlier work experiences during the course of life. Career patterns play a significant role in shaping one's work behaviors in later life (Hayward, Friedman, \& Chen, 1998; Mutchler, Burr, Pienta, \& Massagli, 1997; Raymo, Warren, Sweeney, Hauser, \& Ho, 2009). This is because working in old age is not a simple product of the immediate circumstances prior to retirement, but is embedded in the 
broader context of an individual's career (Hayward et al., 1998; Mutchler et al., 1997; Raymo et al., 2009). For example, literature shows that individuals who have mostly worked part-time are more likely to experience disadvantages in accumulating financial resources for retirement due to their ineligibility to participate in pension schemes (Ginn \& Arber, 1998). In contrast, a stable employment history with privileged jobs is more likely to provide potential for growth in compensation, job security, protection from unemployment, a smaller risk of occupational injury, and retirement benefits - all of which enable workers to increase their opportunities for saving (E. Brown, 2009; Crystal, Shea, \& Krishnaswami, 1992). Thus, this study will test whether the cumulative advantage/disadvantage framework can better explain older minority workers' labor market participation.

In terms of methodology, this study uses the 2004 and 2008 waves of the Health and Retirement Study (HRS) datasets and performs racially separate analyses-stratifying the data by race, running the identical analytic model separately on the White, Black, and Latino populations, and comparing the results by race. Such an analytic approach is expected to overcome the failure of existing studies to systematically compare the factors by race because it treats race as a major indicator for an outcome and actively investigates race-related differences (Jones, 2001; LaVeist, 2002). Also, this approach of separate analysis across groups eliminates the potential bias coming from differences in the unobserved variation in groups (Allison, 1999; Hoetker, 2007). Thus, this study expects to more effectively illuminate the racial/ethnic differences within the factors predicting the labor market participation of older people.

Comparing the differences within the factors predicting older people's labor market participation will help researchers and policy makers better understand not only the experiences of older minority workers but also racial disparities playing out in the personal and structural 
systems in the U.S. Also, it is expected that CAD theory provides useful explanations for framing and evaluating our knowledge for practice. Furthermore, it will provide insight into how the current system perpetuates the racial/ethnic inequality among older workers. Thus, this study expects to produce empirical evidence to establish short-term and long-term implications for effective interventions and policies that serve older minority workers.

The examination of this issue is timely, as all age groups of the minority population in the U.S. are expected to increase substantially. From 2008 to 2050, the number of Blacks is estimated to grow from 9 to $12 \%$, and Latinos from 7 to $18 \%$ of the total U.S. population (Federal Interagency Forum on Aging-Related Statistics, 2010). If we fail to understand these racial gaps in the labor market participation among older workers, this problem is likely to continue into the next generation of older minorities. 


\section{LITERATURE REVIEW}

This chapter provides a review of the literature within and across disciplines to address various factors affecting older people's labor force participation after retirement age ${ }^{2}$. It begins by providing the background of older workers (defining and the historical background of older workers). Then, this chapter proceeds with a review of factors that have been identified to explain older people's labor market participation, including 1) retirement income, 2) health status, 3) career patterns, 4) the meaning of work, 5) the attributes of preretirement work, and 6) demography.

\section{A. BACKGROUND OF OLDER WORKERS}

\section{Defining Older Workers}

"Older workers" are generally defined in relation to "retirement age." Unfortunately, these concepts are not defined universally because individuals retire at different ages (Shaw \& Hill, 2002). Accordingly, scholars use diverse age thresholds to define older workers depending on their research foci. For example, some may define older workers as aged 62 and above, which is reported as Americans' average retirement age (National Institute on Aging, 2007). Some researchers use the age of 65, which is the eligibility age for full Social Security benefits (Choi, 2001; French, 2005). Others include 55 and over to incorporate those who retire earlier than the conventional retirement age of 62 or 65 (Gustman \& Steinmeier, 2009) or use a broader age threshold of 50 or 51 or above to examine work transitions in old age (Au, Mitchell, \& Phillips,

\footnotetext{
${ }^{2}$ Note that the term "older people's labor market participation after retirement age" is expressed in various form throughout the study, such as "working in old age," "working in later life," "the likelihood of working in old age," "older people's continuing labor market participation," or "labor force participation in old age."
} 
2005; Cahill, Giandrea, \& Quinn, 2006; Flippen \& Tienda, 2000; McGarry, 2004; Quinn \& Kozy, 1996; Tunceli, Bradley, Nerenz, Williams, Pladevall, \& Elston Lafata, 2005).

Older workers in this study are defined as those who: 1) stay in the labor market either part-, full-time, or are self-employed; and 2) have reached the age of 65.

\section{Historical Context of Older Workers}

\section{The Origin of Retirement}

Today, retirement is a normative stage of life course (Ekerdt, 2002); however, surprisingly, the concept of retirement was institutionalized only at the beginning of the 1900s (Atchley, 1982). Prior to the $20^{\text {th }}$ century, with low life expectancy, people continued to work until death, with only a few privileged and wealthy people able to leave the labor market in old age in advance of disability (Ekerdt, 2002).

The emergence of a pension system, both in public and private forms, contributed to institutionalizing retirement. Around 1900, the first public pension plan in the U.S., the veteran's pension, provided benefits for Civil War participants (Costa, 1998; Scocpol, 1992), which may have led many recipients to leave the labor force (O'Rand, 2002). On the other hand, the first private pension plan had the explicit goal of making aged workers leave the company. In 1875, the American Express company initiated the first private pension plan in the U.S. to control the age structure of its workers (O'Rand, 2002). Between 1900 and the 1930s, a solid foundation for the system of retirement was gradually constructed in the U.S. (Jacoby, 1985).

The passage of the Social Security Acts in 1935 solidified the institutionalization of retirement (Costa, 1998). Congress set 65 as the eligible age to receive Social Security benefits, 
eventually creating strong incentives to retire by age 65 and the regulation of mandatory retirement $^{3}$ (Costa, 1998; Henretta, 1992). Today, as a result of the emergence of public and private pensions, retirement has become a common transition among workers in industrialized societies (O'Rand, 2002).

\section{Increasing Number of Older Workers}

Until the mid-1980s, older Americans' labor market participation had declined for a century, thanks to generous public and private retirement programs; however, since then, the number of older workers has started to increase, especially during the past two decades (Cahill et al., 2006; Clark \& Quinn, 2002; Walsh, 2001). From 1990 to 2010, their labor force participation rate increased from $11.9 \%$ to $17.4 \%$; today, six million of the 39 million Americans 65 plus are still in the labor market (U.S. Bureau of Labor Statistics, 2011).

This growing popularity of working after retirement age can be explained by four reasons: 1) better health of today's older population, 2) older people's desire to work longer, 3) financial shortfalls in the retirement income system and 4) the enactment of policies reducing barriers to work during retirement. First, the current older cohort is healthier than previous ones. Current life expectancy is 77.9 years, about 10 years longer than in 1950 (National Center for Health Statistics, 2011). Also, in 2010 among people age 65 and over, 75\% rated their health as good, very good, or excellent (Federal Interagency Forum on Aging-Related Statistics, 2010). It may seem obvious and, indeed, research supports that healthy older people can and desire to work (Munnell \& Sass, 2008b).

\footnotetext{
${ }^{3}$ Note that the mandatory retirement existed until the mid-80s.
} 
Second, an increasing number of older people desire to work beyond retirement. A survey of 800 workers shows that $70 \%$ desire to work past the retirement ages of 62 and 65 (Reynolds, Reidley, \& Van Horn, 2005).

Third, the failing system of retirement income-Social Security, employer-sponsored pensions, and private savings-have contributed to Americans' financial difficulties in retirement. The financial shortfall of the Social Security fund has led to creating new regulations, such as reduced benefits and raised eligibility age (Cahill et al., 2006). Moreover, since the mid1970s, the predominant type of pension has switched from defined-benefit (DB) to definedcontribution (DC) plans, such as 401(k)s. This means a shift from shared to individual risk and responsibility, which makes it difficult and unpredictable for workers to accumulate adequate retirement assets. Furthermore, private savings rates are at the same levels as during the Great Depression according to the United States National Income and Product Accounts (U.S. Department of Commerce Bereau of Economic Analysis, 2005). As a result of this failing system of retirement income, with possible cutbacks in Medicare and Medicaid, there has been an increase of older people who reluctantly delay their retirement and stay in the labor market (Cahill et al., 2006).

Finally, building pro-work policies toward retirement has reduced the barriers to work during retirement. For instance, the Age Discrimination in Employment Act of 1967 and its amendments in 1978 and 1986 have eliminated mandatory retirement for American workers (Clark \& Quinn, 2002). As a consequence, the age barrier preventing older people from working longer has been eased (Burtless \& Quinn, 2000). Also, the Social Security earnings test, 
designed to reduce retirement benefits for individuals who continued working, was eliminated ${ }^{4}$ in 2000 for those older than the full retirement age (65) (Curl \& Hokenstad, 2006; Gustman \& Steinmeier, 2009; Song \& Manchester, 2007). This regulation change removed Social Security recipients' penalty and provided a new incentive to work longer for additional earnings that could supplement their Social Security benefits (Quinn \& Kozy, 1996; Song \& Manchester, 2007).

In sum, the interdependence of changing demography, individual preference, the failing system of retirement income, and government's pro-work policies have contributed to the popularity of working after the average retirement age and even the number of older workers is expected to grow even further in the future (Munnell \& Sass, 2008a).

\section{B. FINANCIAL RESOURCES FOR RETIREMENT}

Financial resources are vital for retirement. Scholars, mainly from the field of economics, have produced a considerable volume of studies on how diverse types of financial resources for retirement influence labor market participation in old age. Financial resources for retirement in this study include 1) Social Security, 2) employer-sponsored pensions, 3) wages, 4) wealth, and 5) home ownership. This section demonstrates the significance of each type of resource in understanding older people's labor market participation and then reviews the relationships between these factors and working after retirement age.

\footnotetext{
${ }^{4}$ Note that the earnings test still applies to those who receive Social Security benefits before the eligibility age (Song \& Manchester, 2007)
} 


\section{Social Security}

Social Security was established in 1935 under the Social Security Act as part of President Roosevelt's New Deal to prepare social protection against old age, poverty, unemployment, and being widows and fatherless children. Social Security provides three types of programs: the Old Age, Survivor, and Disability Insurance (OASDI). In addition to basic retirement benefits, Social Security expanded its benefits to workers' survivors and dependents in 1939 and to workers with severe disabilities in 1956. The fundamental structure of Social Security, although Congress has made several amendments to the Social Security regulations, has remained the same since its establishment. Eligibility for receiving any type of Social Security benefits includes having a specified amount of work in covered employment. Eligible beneficiaries may claim early retirement benefits at age 62 (Wacker, 2000).

Social Security is the most fundamental source of income for retirees. Currently, $91 \%$ of older people receive Social Security benefits and $40 \%$ of retirees' annual income comes from Social Security (Wacker, Roberto, \& Piper, 2002). However, Social Security is not intended to provide one's entire income for retirement (Segal, 2010). In 2006, while the median annual household income of older people was $\$ 27,798$ (DeNavas-Walt, Proctor, \& Smith, 2008), the average Social Security payments in 2006 were only $\$ 1,044$ a month, or $\$ 12,258$ a year (Social Security Administration, 2008).

The amount of Social Security benefits affects older people's labor market participation. According to French (2005), individuals who receive less Social Security benefits tend to stay longer in the labor force. In his simulation using data from the Panel Study of Income Dynamics (PSID) for the years 1968-1997, he estimated that a $20 \%$ decline in Social Security benefits 
lengthened workers' overall labor force participation by three months. Such findings point out that a lack of Social Security benefits can lead to older individuals' continuing labor force participation.

Social Security policies also affect an older individual's labor market participation. The U.S. government has made three major changes in Social Security regulations: 1) the increase in eligibility age, 2) the increase in the delayed retirement credit, and 3) the elimination of the earnings test. First, the Social Security Amendments of 1983 increased the eligible age for receiving Social Security benefits from 65 to 67 (The U.S. Social Security Administration, 2011b). To illustrate, individuals born before 1942 (age 69 or older in 2011) are eligible to receive full retirement benefits at age 65; those born between 1943 to 1959 (age 52 to 68 in 2011) will receive at age 66; and those born in 1960 and later (age 50 or older in 2011) will start receiving at age 67 (Social Security Online, 2011).

Second, the same amendments increased the delayed retirement credits, which provides increased rates of Social Security benefits for people who delay their full retirement until age 70 (The U.S. Social Security Administration, 2011a).

Finally, in 2000, the U.S. government eliminated the Social Security earnings test ${ }^{5}$, which was designed to reduce retirement benefits of individuals who continued working beyond age 65 . (Curl \& Hokenstad, 2006; Gustman \& Steinmeier, 2009; Song \& Manchester, 2007). This removal signifies that Social Security recipients who still remain in the labor market can earn additional earnings that supplement their Social Security benefits without any penalties charged (Song \& Manchester, 2007).

\footnotetext{
${ }^{5}$ Again, note that the earnings test still applies to those who receive Social Security benefits before the eligibility age (Song \& Manchester, 2007)
} 
These changes in the regulations have contributed to increasing labor market participation of people age 65 or older (French, 2005; Gustman \& Steinmeier, 2009). Using combined data from the Current Population Survey (CPS) and the Health and Retirement Study (HRS) between 1992 and 2004, Gustman and Steinmeier (2009) found that men aged 65-69 were $6 \%$ more likely to stay in the labor force in 2004 than those in 1992 . After controlling for confounding factors such as age, health status, and pension, the changes in Social Security regulations still accounted for $17 \%$ of the overall increase in older workers.

Similar to these findings, French's simulation (2005) also indicated that the elimination of the Social Security earnings test has in fact encouraged extended labor market activity among older individuals, which is more influential than the effect of the amount of Social Security benefits that older people receive.

Although Social Security benefits are almost universal today, racial gaps in Social Security still remain. It should be recognized that Congress has made an efforts to reduce the racial gaps in Social Security. For example, taxable earning replacement rates, one of the Social Security benefit formulas, was created in 1939 to replace the higher proportion of preretirement earnings for people with lower earnings ${ }^{6}$ while balancing with equity — the benefits increase with contributions (Martin \& Weaver, 2005). As a result, taxable earnings replacement rates are lowest for Whites and higher for minority subgroups (Choudhury \& Bridges, 2009). Also, the percentage of people receiving Social Security benefits increased from 69\% in 1962 to $89 \%$ in 2004 (Choudhury \& Bridges, 2009). This effort, however, has not fully reduced the racial gaps

\footnotetext{
${ }^{6}$ Note that the social atmosphere on the Social Security recipients of race/ethnic minorities has changed as well. From 1935 to 1980, the Social Security application form (SS-5) only allowed classification of a person's race into "White," "Negro," or "Other" categories. However since 1980, the race/ethnicity categories of the form have expanded to six: "White (non-Hispanic)," "Black (non-Hispanic)," "Hispanic," "Asian, Asian-American, or Pacific Islander," "American Indian or Alaska Native," and "Unknown” (Scott, 1999).
} 
in Social Security benefits. Older minorities are still less covered by Social Security than older Whites. In 2004, the percentage of people 65 or above receiving Social Security benefits was $91 \%$ for Whites, $85 \%$ for Blacks and 76\% for Latinos (U.S. Census Bureau, 2004).

Furthermore, among the recipients, minorities tend to receive lower amounts of Social Security benefits compared to Whites (Choudhury \& Bridges, 2009). Also, the average annual Social Security benefits in 2004 were $\$ 10,621$ for Whites, $\$ 8,828$ for Blacks, and $\$ 8,497$ for Latinos (U.S. Census Bureau, 2004). These racial/ethnic differences stem from gaps in indexed taxable earnings during their lifetimes (Williamson \& McNamara, 2004). Individuals' Social Security benefits are decided by their lifetime taxable earnings in employment covered by Social Security: those with higher indexed taxable earnings receive a higher amount of Social Security wealth and annualized payouts (Biggs, Sarney, \& Tamborini, 2009). Therefore, minorities with weak earnings histories tend to be underserved or left out of the Social Security system. Latino groups, in particular, show relatively smaller increase in their Social Security wealth over decades than any other minority subgroups. This is mainly because a substantial portion of the Latino population are foreign-born: in calculating lifetime taxable earnings, Social Security law excludes immigrants' earnings gained outside the U.S ${ }^{7}$ (Choudhury \& Bridges, 2009). Even with this gap in benefits, minorities are more dependent on Social Security than Whites (Choi, 1997). Although Social Security is not intended to provide one's entire income for retirement (Segal, 2010), the three-legged system of retirement income-Social Security, private pensions, and personal savings—-seem more like a one-legged system for many minorities (Hogan et al., 1997).

\footnotetext{
${ }^{7}$ Latinos who work illegally in the U.S. are not included in the scope of this study since the datasets that this study uses does not include that group.
} 


\section{Employer-Sponsored Pensions}

As Social Security alone is not enough to fully support retirement, employer-sponsored pensions have supplemented older Americans' retirement. The history of pension in the U.S. started from the Civil Service Retirement Act enacted in 1920, which provided pension benefits to federal civilian workers. Today, the American pension system is regulated by the Employee Retirement Income Security Act (ERISA) established in 1974 (Wacker et al., 2002).

Pension influences labor market participation in old age in three ways: pension eligibility, the amount of pension benefits, and pension types.

\section{Pension eligibility}

Pension eligibility influences older people's labor market participation. Not all retirees receive pension benefits from their previous employers; in the U.S., around 50\% of private sector employees are covered by a pension (Wacker et al., 2002). Empirical studies suggest that those eligible for pension benefits tend to retire earlier than those who are not eligible (Munnell, Cahill, \& Jivan, 2003; Munnell, Triest, \& Jivan, 2004; Quinn \& Kozy, 1996). For example, Munnell, Triest, and Jivan (2004) investigated the impact of pensions on timing of retirement using data from the first six waves $(1992,1994,1996,1998,2000$, and 2002) of the Health and Retirement Study (HRS). They found that compared to workers with pensions, those without pensions were more likely to stay longer in the labor market. They surmised that financial incentives from pensions may lead workers to leave the labor market earlier than those without pensions. 


\section{Amount of pension benefits}

Research consistently shows that individuals who receive inadequate pension benefits are more likely to stay employed in old age (Munnell et al., 2004; Pienta \& Hayward, 2002). For instance, using the 1992 HRS data, Pienta and Hayward (2002) examined workers' future expectations to work beyond age 62. They discovered that near-retirees' expectations to work beyond age 62 were higher for those with smaller pensions, which was found for both men and women.

\section{Type of pensions}

There are mainly two pension types: defined benefit (DB) and defined contribution (DC) plans. DB plans, also referred to as "traditional pension plans," provide employees with a guaranteed level of retirement income based on years of service, age of retirement, and levels of income over the working years (Segal, 2010). DB plans promise retirees a steady income from retirement to death or, in some cases to their spouse's death (Wacker et al., 2002). In contrast, DC plans do not guarantee future benefits; it is the employee's responsibility to choose how to invest their pension funds (Segal, 2010). The 401(k) plan is the most common and frequently employed DC plan in the U.S. (Barocas, 1994). If DC plan's investments go well in the private market, the employees retire with sufficient financial resources. However, if the investments are not successful, the employees may retire with less than they had before entering the plan. Thus, DC plans may provide promising assets for retirement, but at the same time, they can be riskier than DB plans.

Further, these two types of pensions differ in terms of age restriction. DB plans often contain strong age-specific financial incentives to leave the job, while DC plans are age-neutral 
by design, which often reduces barriers for people who want to work beyond retirement age (Segal, 2010).

Pension plans in the U.S. have gradually shifted from DB to DC plans. The number of DB plan participants has dropped as companies have opted for the 401(k) type of DC plans. In 1980, among private-sector workers with retirement benefits, only eight percent had DC plans, but that number had increased to $27 \%$ by 1998 and to $53 \%$ in 2005, whereas $10 \%$ had DB plans and the remaining 27\% invested in both DB and DC plans in 2005 (Employee Benefit Research Institute, 2007). This shift is attributed to those employers with DB plans, who must make sure they have enough money to pay guaranteed amounts of pension benefits to their retired workers, and have the burden of paying pension benefits due to prolonged longevity, consequently resulting in a switch to DC plans in which the retirees are responsible for all investment risk (Crenshaw, 2004). Thus, the shift from DB to DC plans means a shift from shared to individual risk and responsibility (Segal, 2010).

This shift in pension plans has also affected older people's retirement timing. Substantial research has demonstrated that workers with DC plans tend to work longer than those with DB plans (Cahill et al., 2006; Clark \& Quinn, 2002; Friedberg, 2005; Munnell et al., 2004; Purcell, 2009a; Sapozhnikov \& Triest, 2007). For example, Friedberg and Webb (2005) used the first four waves $(1992,1994,1996$, and 1998) of the HRS datasets to examine how the decline in DB plan participants has influenced retirement timing. They found that workers with DC plans retired on average almost two years later compared to those with DB plans, when controlling for relevant confounding factors. They interpreted this change as mainly due to the absence of agerelated incentives in DC plans. They concluded that the change in pension plans in the U.S. is partly responsible for the increase in the number of older workers after decades of decline. 
In short, labor market participation in old age is influenced by pension in three ways: pension eligibility, pension types, and the amount of pension benefits.

Pension benefits exhibit racial/ethnic differences. Older minorities are less likely to work for employers offering pensions (Herz, Meisenheimer, \& Weinstein, 2000). The statistics from the Current Population Survey show that among salaried and waged workers, 56\% of Whites participate in any pension plans, compared with $46 \%$ of Blacks and 32\% of Latinos. (AARP, 2009). Furthermore, even among those participating in pensions, minorities' amount of pension wealth is smaller than that of Whites. In 2004 , median pension wealth was $\$ 186,600$ for Whites, $\$ 168,000$ for Blacks, and \$103,500 for Latinos (Butrica \& Johnson, 2010).

\section{Wealth}

Wealth in this study is defined as household wealth that includes business assets, stocks, bonds, individual retirement accounts (IRAs), and bank accounts, but it excludes actuarial present value of future benefits from Social Security and/or pensions and net home equity. Wealth represents not only the resources that household members have accumulated but also any resources passed on across generations (Shuey \& Willson, 2008).

It appears that the amount of wealth individuals have does not influence their probability of working in old age (Au, Mitchell, \& Phillops, 2005; Cahill et al., 2006). According to Cahill and his colleagues (2006b), this is perhaps because individuals with less wealth plan to work after retirement for financial reasons, while those with more wealth also desire to work in old age for non-financial purposes. In fact, management or professional positions comprise the biggest

portion of the occupations in which workers age 65 or above participate (Holder \& Clark, 
2008a). Due to a lack of empirical evidence, however, any conclusions on the influence of wealth is tentative.

Wealth exhibits racial/ethnic differences. When we compare the household wealth of near-retirees (age 51 to 61) -including the value of homes, other real estate, financial assets, the expected values of Social Security and employer-sponsored pensions-Blacks $(\$ 305,000)$ and Latinos (\$331,000) have substantially lower wealth than Whites (\$819,00) (AARP, 2011).

\section{Wages}

How do wages from preretirement work influence older people's likelihood of working? Although one's inclination to work in old age is negatively related with retirement wealth, its relationship with wages seems more complicated: some research show a negative connection (S. Kim \& Feldman, 2000), others, interestingly, claim a U-shaped relationship (Cahill et al., 2006; Munnell et al., 2004).

Kim and Feldman (2000) showed wages' negative relationship with one's preference to work in old age. They collected 371 samples from professors at the University of California who accepted early retirement incentive offers in 1994 and examined their current job status as well as factors influencing work status. They found that individuals with lower salary at the time they retired were more likely to work after their early retirement. This finding indicates that workers with lower wages often work longer in order to gain additional retirement income (Munnell et al., 2004).

On the other hand, Cahill, Giandrea, and Quinn (2006) examining samples age 51 to 61 argued that individuals remaining in the labor market are those with both low- and high-wages. They explained that low-wage individuals keep working out of financial necessity, whereas those 
at the upper end of the wage distribution, many of whom could have afforded retirement, often choose to work for quality-of-life reasons. Or perhaps workers with higher compensation stay longer in the labor market because of their intention to keep the high compensation that they currently receive (Munnell et al., 2004).

\section{Home Ownership}

Although slim in quantity, some research does document that home ownership reduces the likelihood of working in old age (Cahill et al., 2006; Doling \& Horsewood, 2003; Munnell et al., 2004). For instance, Cahill and his colleagues (2006) estimated that home ownership, although it does not influence one's chance of having a full-time job in old age, significantly impacts the likelihood of having "bridge jobs"-jobs that bridge the gap between full-time career employment and complete labor force withdrawal. They reported that both older men and women with home ownership were less likely to have bridge jobs in old age. Also, Doling and Horsewood (2003), who specifically focused on the role of home ownership on labor market participation among older workers in European countries, explained that home ownership may offer the ability to live rent-free, which facilitates early retirement.

It is, however, inconclusive whether the effects of homeownership differ by race. Bould (1980) suggested that although the overall effects of financial factors are stronger for minorities than for Whites in explaining early retirement decisions, the influence of home ownership was not significant for either Whites or Blacks (Bould, 1980). On the other hand, Choi (1994) showed that Black home renters tend to retire earlier than Black homeowners. This is because, according to Cahill and his colleagues (2006), those at the upper end of the wealth and wages distribution, many of whom could afford retirement, often choose to continue working for 
various reasons, including the intrinsic reward from working and keeping their higher pecuniary rewards. Interestingly, retirement may cost more to them financially than keeping their higher wages and perks (Mutchler, Burr, Massagli, \& Pienta, 1999). Similarly, the most common job category for workers age 65 or older, regardless of race, is management or professional positions (Holder \& Clark, 2008b).

In summary, financial resources for retirement are the most popularly investigated area in topics concerning older workers. It is well established how different types of financial resources for retirement influence older people's labor market participation. Given the review of literature, older workers are usually those who receive less benefit from Social Security and DC pension plans, and those who have home ownership. However, the influence of wage and wealth appear to be inconclusive.

\section{HEALTH}

Along with financial factors, health has been found to be another powerful factor affecting the labor force participation of older people. This subsection provides a review of empirical studies on the relationship between health and labor market participation in old age.

It is well established that poor health usually reduces older people's chances of remaining in the labor market; those with poor health are more likely to retire as soon as they become eligible to receive retirement benefits from either Social Security or pensions (Currie \& Madrian, 1999; Deschryvere, 2004). Currie and Madrian (1999) provided a comprehensive literature review on the effects of health on older people's employment. Summarizing 30 studies conducted between 1975 and 1997, they reported evidence that health plays an important role in older people's work decisions. However, they were unable to reach a consensus on the 
magnitude of health effects because the conceptual definition of health varies widely from study to study. For example, the varying health measures include depression (Ruhm, 1992), medical conditions (Stern, 1989), mortality (Bound, 1991; Parsons, 1982), ADL (Activities of Daily Living) limitation (Ettner, 1997), alcohol/cigarette consumption (Bound, Schoenbaum, \& Waidmann, 1996), obesity (Bound, Schoenbaum, \& Waidmann, 1995; Bound et al., 1996), and medication usage (Ruhm, 1992). Moreover, Currie and Madrian (1999) reported that the magnitude of health effects might be sensitive to the sampled individuals' age, cohort, gender, and family circumstances.

Deschryvere (2004) updated the literature review of Currie and Madrian (1999) by further including recent studies conducted in the U.S. as well as in European countries. Although his study reinforced the findings of Currie and Madrian (1999), his work also failed to find consensus on the magnitude of health effects. He stated that this is because estimating the effect of health is sensitive to the different health measures and estimation methods used in each study.

More recent studies have replicated previous studies' findings: older people stay in the labor market only if they are healthy enough to work (Cai \& Kalb, 2006; Tunceli et al., 2005). Tunceli and his health research team (2005) examined the effect of diabetes on labor market outcomes. By using the Wave 1 (1992) HRS data, they first selected 7,055 workers aged 51 to 61 who were diverse in race (including Whites, Blacks, Latinos, and others) and in occupation (service sector, white collar, and blue collar). Then, they constructed a study group with diabetes $(n=490)$ and a comparison group without diabetes $(n=6,565)$. Finally, using the Wave 2 (1994), they estimated the respondents' chances of staying in the labor market in old age and compared these estimated chances between the study and comparison groups. They found that compared to the comparison group, the study group showed a $4 \sim 7 \%$ smaller probability of working. Thus, 
they concluded that diabetes substantially decreases the employment rates for people ages 51 to 61.

Cai and Kalb (2006) suggested that health affects employment across all age and gender groups. They employed data from the 2001 wave of the Household, Income and Labour Dynamics in Australia (HILDA) and used multiple health measures - including self-rated health (excellent, good, fair, bad, very bad), the Short Form 36 (SF-36), and asking whether respondents have long-term conditions, impairment or disability (e.g., limited use of fingers or arms, or problems with eye sight, physical impairments which restrict everyday activities and have lasted for six months or more). Their results indicated that better health increases one's possibility of working across all age and gender groups, including males aged 15-49, males aged 50-64, females aged 15-49, and females aged 50-60. Interestingly, the researchers pointed out that the health effect is greater for the older group.

For both Whites and minorities, health is an extremely important factor in determining work status in old age (Bound et al., 1996). However, a considerable amount of research, using a variety of health measures, has reported that older minority workers show poorer health and higher mortality compared to older White workers (Hayward et al., 1996; Hogan et al., 1997; Porell, 2009). Yet, the racial differences in the magnitude of health effects appear inconclusive. Some argue that the effect of health is stronger among minorities than among Whites (Bound et al., 1996). In other words, when comparing only those in poor health, Blacks are reported to have a higher likelihood of leaving the workforce than Whites (Bound et al., 1996).

Conversely, Williamson and McNamara (2004) indicated that the effect of health is weaker for minorities. This means that minorities' employment is relatively less influenced by their health compared to Whites. They explained that minorities are less likely to find stable 
employment regardless of their health conditions (Williamson \& McNamara, 2004). Given the inconclusive results, further investigation is required to see how health differently affects labor market participation between older Whites and minorities.

\section{CAREER PATTERNS}

Does continuing labor market participation in old age reflect a simple product of the immediate circumstances prior to retirement, or is it embedded in the broader context of the career? Most studies of older workers focus on factors in late life; however, we should also pay attention to the role of career patterns that involve earlier work experiences during the course of life and that career patterns play a significant role in shaping one's work behaviors in later life (Hayward et al., 1998; Mutchler et al., 1997; Raymo et al., 2009). This section defines career patterns as 1) employment stability and 2) occupation types and provides a review of how career patterns influence labor market participation in old age.

\section{Employment Stability}

Not all workers are stably employed with one employer during their lifetime. Employment histories may involve multiple transitions among employment, unemployment, and nonparticipation (Mutchler et al., 1997). Among near-retirement aged workers, some hold a long and stable career while others have short-term and unstable patterns of employment throughout their lives (Hayward et al., 1998). The Baby Boomers, in particular, commonly have work histories with multiple transitions in and out of the labor force or with many different employers (Han \& Moen, 1999).

The degree of employment stability (also called "job tenure" in economics lingo) can be categorized as either long- or short-term. A long-term employment history, also called a career or 
stable work pattern, refers to an attachment to a single employer for a substantial portion of an individual's working life (Feldman, 2007; Ruhm, 1990b). On the other hand, a short-term employment pattern, also called an intermittent or unstable employment pattern, refers to workers with frequent job turnover during their lifespan (Schochet \& Rangarajan, 2004; Wu, 2011).

The consideration of employment stability is crucial due to its connection to wage growth during working life. Workers with unstable employment patterns, caused by either voluntary or involuntary reasons, are often disadvantaged in the labor market stemming from the loss of income during the time of unemployment (Wu, 2011). Further, intermittent career patterns hinder accumulating work experiences and seniority over time, which are closely associated with wage growth in a life time (Holzer \& Lalonde, 2005).

Even with its significance, employment stability has not been actively examined in studies of older workers. Although slim in quantity, existing studies suggest a positive relationship between the degree of employment stability and the probability of work in old age (S. Kim \& Feldman, 2000; Raymo et al., 2009; Singh \& Verma, 2003). Singh and Verma (2003) recruited 1,805 respondents from Bell Canada (Canada's largest telecommunication firm), who were offered four different early retirement incentive packages between 1985 and 1995 for the purpose of headcount reduction. They found that those who had greater tenure were likely to go back to the labor market (for new employers). They interpreted that longer tenure reflects competence, attachment to work, and stamina (good health), all of which can positively affect their return-to-work decision. 
Similarly, Kim and Feldman (2000) also reported a positive relationship between the degree of employment stability and the chance to work in old age. Their sample came from the faculty members at the University of California system, who accepted early retirement incentives in 1994. In their investigation on the antecedents of going back to the labor market, they found that the professors who had more years of service in the UC system were more likely to engage in post-retirement work.

\section{Occupation Types}

Occupation types can be classified into white-collar and blue-collar occupations. Whitecollar occupations usually involve high status occupations characterized by great substantive complexity; on the other hand, blue-collar occupations represent low status occupations with low autonomy, and repetitive, dangerous, physically demanding positions (Raymo et al., 2009).

Even though workers may change occupations during their life course, they generally stay within one collar boundary because it is difficult to cross the boundaries of collar colors in both directions (Hayward et al., 1998; Jacobs, 1983). Jacobs (1983) explains that this is because the different educational requirements between the two occupation types.

Empirical studies show conflicting findings regarding the relationship between occupation types and the likelihood of working in old age. Some reported that workers who mostly have blue-collar occupations tend to leave the labor market earlier (Hayward, 1986; Hayward et al., 1998; Raymo et al., 2009; Singh \& Verma, 2003). For example, Singh and Verma (2003) assessed Bell Canada workers who accepted early retirement incentive packages between 1985 and 1995 to examine who had returned to the labor market sometime later. They 
found that those who had returned to the labor market were those who had managerial positions, rather than positions of clerks, sales, technicians, or operators.

Conversely, others viewed that those who mostly have blue-collar jobs tend to stay in the labor market beyond retirement age (Mein, Martikainen, Stansfeld, Brunner, Fuhrer, \& Marmot, 2000). Mein and her colleagues (2000) used longitudinal data from 1988 to 1995 on 2,532 males and females aged 50 to 59.5 years who had worked as civil servants at the British Civil Service-one of the largest employers in the public sector in the U.K. Including a diverse range of occupations and salaried levels, they aimed to examine the factors predicting early retirement. Their results indicated that both men and women who took white-collar positions, such as administrators, were more likely to retire earlier than those who had a blue-collar position, such as clerical and support. Perhaps blue-collar workers' longer attachment to the labor market is explained by their less amount of money accumulated for retirement (Mein et al., 2000).

Blacks and Latinos historically account for a disproportionate share in low-skilled, lowpaying, physically demanding, and intermittent positions (Ferraro \& Farmer, 1996; Flippen \& Tienda, 2000; Williams et al., 2008; Williams \& Jackson, 2005). Moreover, minorities, even those with good health, are more likely to experience difficulties finding jobs, compared to Whites (Williamson \& McNamara, 2004). Accordingly, career patterns seem to affect labor market participation differently between older Whites and minorities. To illustrate, good jobs with prestige and/or high pay tend to keep older Black men at work, whereas they make no difference to Whites (Choi, 1994). 
In sum, the literature review on career patterns show that older workers are usually characterized by those who have greater employment stability during the course of life. However, the impact of occupation types is inconclusive.

\section{E. THE MEANING OF WORK}

Work is not just a simple source of income: it is also a central life activity that provides important social and psychological fulfillment (Mor-Barak, 1995). Classical economics studies usually view that working in old age is a voluntary continuation of a career based on a worker's calculation of retirement income (Flippen \& Tienda, 2000); however, older people are also interested in non-financial aspects of work. According to AARP's survey on 1,500 nationally representative workers ages 45 to $74,21 \%$ rated psychological or social fulfillment (such as enjoying working or feeling productive) as the most important single reason for working (RoperASW, 2002). Thus, to understand the predictors of working into old age, we must understand how older people perceive work.

\section{Description of the meaning of work to older people}

What does work mean besides a source of income? This study defines the meaning of work as one's psychological or social fulfillment (Morse \& Weiss, 1955). To older people, work has a number of meanings, including: 1) providing social interaction, 2) keeping self-identity, 3) having a meaningful activity, and 4) satisfying the need of "generativity." First, work is a source of social interaction with coworkers, which is especially meaningful to older people who lose a major social network after retirement (Mor-Barak, 1995; Smyer \& Pitt-Catsouphes, 2007). According to a survey performed on a sample of 5,111 nationally representative workers aged 60 to $70,43 \%$ rated the statement "Working in retirement will keep me connected with others" as 
very important, in comparison to $41 \%$ who rated monetary reasons as very important (Total Merrill, 2006).

Second, work protects the self-image of older people who often lose social roles once they are no longer employed. Research documents that work is a major component of forming older people's identity (Mutchler, 2002), offers a source of keeping self-esteem and a sense of pride (Mor-Barak, 1995; Noonan, 2005), and gives feelings of accomplishment and being useful (Morse \& Weiss, 1955; Noonan, 2005; Smyer \& Pitt-Catsouphes, 2007).

Third, work provides a meaningful activity to older people (Morse \& Weiss, 1955; Noonan, 2005). Noonan's qualitative work (2005), which interviewed 45 older workers age 55 or above to ask about their current work experiences, gives insight into how older workers perceive work. Respondents reported that they value their work because of the meaningful activities that their work gives. Noonan quoted several responses: "I like being busy,"; "I wouldn't know what else to do with my life,"; "I would not get up every day without a purpose,"; "I have to do something...I cannot sit and vegetate, I will die...I've been lucky in the sense that I've been busy all the time,"; "I will never retire. I will always be doing something...because I think that's what we're here for" (p.231).

Lastly, to older people, work often serves as a way to teach, train, and share skills with younger generations. According to Erickson's psychosocial theory of development (1975), older people experience a stage of "generativity versus stagnation," expressing their need to pass on the knowledge and skills that they have achieved in their lives. Mor-Barak's factor analysis on the constructs of the meaning of work (1995) showed that generativity is one of the most important components explaining how older people perceive work. 
The relationship between the meaning of work and older people's labor market participation

Although the investigation on the meaning of work is varied, existing studies show that near-retirees who value the meaning of work are more likely to stay in the labor market after retirement age (H. Kim \& DeVaney, 2005; Singh \& Verma, 2003; Smyer \& Pitt-Catsouphes, 2007). For instance, Kim and Devaney (2005) used the 1992 and 2000 HRS datasets and compared how two groups of older people - retirees and full-time employees-perceive the meaning of work differently. Their results showed that compared to retirees, full-time workers considered the meaning of work more important than money. Based on this difference, they concluded that older individuals who value work have a higher tendency to remain in the labor force.

Singh and Verma (2003) confirmed the positive influence of the meaning of work on older people's labor market participation. They followed workers who retired early from a large telecommunications firm in Canada and tracked their work status a few years later, reporting that those with high attachment to work were more likely to return to full-time work.

It appears that there are racial differences in the influence of the meaning of work. According to Choi (1994), among overall factors determining older people's employment in later life, Black males were more likely to be influenced by variables which reflect economic circumstances, whereas White males were more likely to be influenced by their preference to work past retirement. Perhaps this is because financial resources can play a more central role for minorities (Burr, Massagli, Mutchler, \& Pienta, 1996).

In summary, to older people, work means something beyond a source of income, such as socially interacting, keeping self-identity, having a meaningful activity, and fulfilling the need 
for generativity. This review of empirical studies regarding the meaning of work shows that those who value the meaning of work are more likely to remain in the labor market beyond retirement age.

\section{F. THE ATTRIBUTES OF PRERETIREMENT WORK}

The final area that this study reviews is the attribute of preretirement work. Work experiences near retirement can directly influence labor market participation after retirement age. This section focuses on two elements of preretirement work: 1) job stress and 2) employers' attitudes toward older workers.

\section{Job Stress}

Stressful jobs often reduce older individuals' commitment to work and induce them to leave their jobs (Herzog, House, \& Morgan, 1991). Although job stress is often measured by a worker's subjective assessment of the psychological stress from their jobs, such as stress from psychosocial demands and from a lack of decision latitude (Herzog et al., 1991), it is also represented by the level of physical demands (Filer \& Petri, 1988; Herzog et al., 1991; R. W. Johnson, 2004). Especially for older people, physically demanding jobs can cause high stress. Even though the number of jobs with physical demands has significantly decreased in the U.S (RoperASW, 2002), non-physical demands of today's jobs are often more time-consuming and emotionally stressful (R. W. Johnson, 2004).

The effect of job stress on older people's labor force participation needs careful examination because near-retirement workers who are not financially ready for retirement may keep working, even if their jobs are stressful. Some research reported that job stress is not significant when controlling for financial factors (Weckerle \& Shultz, 1999). Others, however, 
argued that job stress is still a significant factor inducing older people to exit the labor market (Ekerdt, Kosloski, \& DeViney, 2000; Filer \& Petri, 1988). Ekerdt (2000) stated that stressful jobs can lead older workers to consider retirement more often. A similar study by Filer and Petri (1988), which analyzed retirement-aged workers from the 1980 Census data, indicated that those who perceived high job stress were more likely to retire early.

There are interesting differences in job stress experienced by race. According to statistics from nationally representative data among salaried and waged workers age 50 to 69 , job stress is most experienced by Whites (62.1\%) as opposed to Blacks (53.4\%) and Latinos (49.0\%) (AARP, 2009).

In sum, more research is necessary to clarify whether the job stress from workers' preretirement employment is a significant determinant of working after retirement age.

\section{Employers' Attitudes toward Older Workers}

Workers may feel that their employers treat older workers differently from younger workers. Based on a survey results of 800 randomly-selected people in the stratified regions in the U.S., around $40 \%$ of workers of all ages agreed that employers treat older workers differently from younger workers (Reynolds et al., 2005).

Older workers who perceive they are treated differently from younger workers, either by their employers or co-workers, may leave the labor market early (Weckerle \& Shultz, 1999). Although little empirical evidence exists, it uniformly indicates that workers who experience or observe negative attitudes toward older workers in their workplace tend to have low expectations of working past retirement age (Adams, 2002; Kosloski, Ekerdt, \& Deviney, 2001). Using the 1992 HRS datasets, Kosloski, Ekerdt, and Deviney (2001) found that workers who experienced 
discrimination by one's employers or perceived age-related social pressure to leave the firm reported a higher probability of retiring at ages 62 or 65 . Consistent with this finding, Adams (2002) also reported similar results. He used the 1992 and 1994 HRS datasets and examined whether employers' age-discriminatory promotion decisions could harm older workers. He found that workers with a greater likelihood of early retirement were those who felt that their firms did favor younger workers in promotion decisions. He explained that the age-discriminatory actions in workplaces not only reduce wage growth but also discourage older workers' work commitment, leading to their early withdrawal from the labor force.

In terms of racial/ethnic differences, surprisingly, subjective experiences of employers' discrimination toward older workers are most felt by older Whites (13\%) and Latinos (14\%), compared to Blacks (8\%) (AARP, 2008). Further investigation is necessary to understand these differences by race.

In summary, the attributes from preretirement work significantly shape older people's labor market participation. Older individuals who stay employed beyond retirement age are usually those who experience equal treatment based on age and less stress in their preretirement workplace.

\section{G. DEMOGRAPHY}

This section reviews the influences of demographic characteristics-including age, gender, marital status, and education — on working after retirement age. These demographic factors are crucial elements in understanding labor force participation in old age. 
Age is a potent factor determining older people's labor market participation, as the number of older workers decreases with age. In 2008, the number of workers was 3.3 million (29.4\% of the total population age 65-69) for those age 65 to $69,1.5$ million (16.9\%) for those age 70 to 74, and 1.2 million (7.0\%) for those age 75 and over (U.S. Bureau of Labor Statistics, 2011). Substantial research also reported that older people's inclination to work actually decreases as people age (Hayward et al., 1998; S. Kim \& Feldman, 2000; Quinn \& Kozy, 1996; Singh \& Verma, 2003; Szinovacz \& Deviney, 2000).

It is important to note that the employment rates of older Americans decrease at age 62 and age 65, which are the eligibility ages for the Social Security early retirement and full retirement benefits. According to statistics, the employment rates among people in their 50s are $70 \%$ for men and $60 \%$ for women; however, by age 65 , employment rates drop to $50 \%$ for both men and women (National Institute on Aging, 2007).

Gender $^{8}$

Currently, older women's employment rates are lower than older men's. In 2008, the employment rates of women age 65 or above was $12.7 \%$ while that of men in the same age was

\footnotetext{
${ }^{8}$ Research documents that the retirement experiences of women differ from that of men in three substantial ways. First, older women's labor market participation is influenced by their personal circumstances, such as family caregiving obligations (Reitzes, Mutran, \& Fernandez, 1996), their husbands' employment (Ruhm, 1996), and their husbands' pensions rather than their own (Henretta, O'Rand, \& Chan, 1993).

Second, older women tend to experience disadvantages in the labor market during the course of life, which include discontinuous work histories, lower incomes, and concentration in industries without pension coverage (Even \& Macpherson, 1994). These patterns explain women's smaller Social Security and pension benefits (Even \& Macpherson, 1994), which further influence their employment after retirement age.

Finally, women who are overrepresented in service-sector jobs have fortunately gained a greater stability in the labor market since the demand of those jobs has increased in the U.S. (DeViney \& O'Rand, 1988).
} 
20.5\% (U.S. Bureau of Labor Statistics, 2011). However, it should be noted that women's labor force participation in general has greatly increased. The workforce participation rate of women ages 35 to 44, both married and single, was less than 20\% in 1990; however, it increased to $45 \%$ in 1960, 65\% in 1980, and reached $70 \%$ in 2000 (Munnell \& Sass, 2008a). This suggests that women approaching retirement, around the late 50s and early 60s, have more work experiences compared to previous cohorts (Munnell \& Sass, 2008a) and that the role of most women in society has expanded from housewives to contributors to the labor market.

Empirical studies examining the relationship between gender and labor market participation in old age suggest that women are less likely to stay in the labor market compared to men (Munnell et al., 2004; Singh \& Verma, 2003).

\section{Marital status ${ }^{9}$}

Empirical studies show conflicting findings on the relationship between marital status and older people's work status (Kilty \& Berling, 1985; S. Kim \& Feldman, 2000; Singh \& Verma, 2003). Some have found that married people are more likely to work in old age (Kilty \& Berling, 1985), while others report no significant relationship between the two (S. Kim \& Feldman, 2000; Singh \& Verma, 2003).

Perhaps these conflicting results can be understood in light of the current statistics showing the relationship between marital status and working in old age. According to the National Institute on Aging (2007), married people (56.9\%) are more likely to stay in the labor

\footnotetext{
${ }^{9}$ Despite the fact that marital status is not a major predictor in this study, it is important to note that when making the decision to work in old age, married people do not just make a personal decision but also take into account their spouse's situations - such as spouse's financial needs and resources (Henretta et al., 1993), and spouse's inability to work - either due to poor health or involuntary retirement (Szinovacz \& Deviney, 2000). Thus, a couple's joint circumstances may obligate one either to remain in the labor force for the purpose of complementing the spouse's income or to retire early in order to be a caregiver.
} 
market past retirement age than their non-married counterparts $(53.2 \%)$, but the difference is negligible.

\section{Education}

Numerous studies have documented that educational attainment increases the chances of working in old age, which is applied to both men and women (Griffin \& Beryl, 2008; Munnell et al., 2004; Singh \& Verma, 2003; Williamson \& McNamara, 2004). For example, Williamson and McNamara (2004), who analyzed individuals age between 60 and 80 from the 1998 HRS datasets, indicated that those with higher education were more likely to remain in the workforce in later life ${ }^{10}$.

Minorities tend to have lower education than Whites. Among individuals age 50 to 74 , $30 \%$ of Whites complete a four-year college degree or higher, compared with only $15 \%$ of Blacks and 12\% of Latinos (AARP, 2011).

\section{H. SUMMARY}

This chapter seeks to identify factors influencing older people's continuous labor force participation and demonstrates six groups of factors influencing that participation: financial resources for retirement (Social Security, pensions, wealth, household income, and home ownership), health, career patterns (employment stability and job types), the meaning of work, and the attributes of preretirement work. However, noticeable racial/ethnic differences were found within these factors; compared to older Whites, older minorities are more likely to have fewer financial resources for retirement, poorer health, weaker earning histories, and less

\footnotetext{
${ }^{10}$ Further discussion on the relationship between education and older people's continuous labor market participation will be discussed in detail in Chapter 3.
} 
compensation from work. This chapter also observes that minorities facing retirement are generally situated in unfavorable conditions in terms of financial resources for retirement, health, career patterns, and education, compared to their White counterparts. 


\section{THEORETICAL FRAMEWORK}

This study employs cumulative advantage/disadvantage (CAD) theory to frame its research questions and to formulate the subsequent hypotheses. This chapter 1) provides theoretical background on social inequality, 2) discusses the historical background of minority workers in the U.S., 3) offers a brief review of CAD's theoretical origins, main tenets, and its applications in aging and race studies, and finally, 4) reviews CAD theory's application for racial/ethnic inequality in old age, with a focus on financial resources for retirement, health, career patterns, and education. This chapter then concludes by laying out this study's research question and subsequent hypotheses.

\section{A. THEORETICAL BACKGROUND OF UNDERSTANDING SOCIAL INEQUALITY}

In examining racial/ethnic differences among older workers, it is first necessary to understand social inequality. How did such inequality emerge and how do theorists explain it? Social class, one of the most widely used concepts in sociology, is helpful to comprehend racial/ethnic inequality. We must grasp early theories to understand social inequality because the contributions of Marx, Weber, Durkheim, and the functionalists, the most important theorists in sociology, provide the fundamental foundation for understanding social inequality.

\section{Marx and Weber: Inequality is Fundamentally Detrimental}

In defining the concept of social class, Marx used the term "class" and "class structure" in his famous writings, The German Ideology (1845/1970), and Capital (1867-1894/1990); however, the book in which he provided the concept's most explicit descriptions is The Communist Manifesto (1848/2002) (Levine, 2006). He argued that there is a repeated tendency in history in all societies that divides people into two unequal social classes: patrician and slave; 
lord and serf; capitalist and wage laborer. He stated that classes always exist in relation to a hierarchy of social and economic privilege. As a result, the tensions between the social classes cause social conflict between these classes, which always give rise to a new system to overthrow the old - the perpetual struggle over the means of production. Thus, he asserted that the history of all existing societies is the uninterrupted history of class struggle between contending classes (Marx, 1848/2002).

In a capitalist society, according to Marx, the root of basic inequality comes from capitalist (bourgeois) exploitation of the working class (proletarians) (Morrison, 2006). Marx put emphasis on the importance of property-the ownership of the means of production-as the sole determinant of this class division (Marx, 1848/2002). The system of capitalism, in which capitalists try to increase production while cutting costs and reducing workers' wages down to sustenance level, promotes the intense struggle between the classes (Sernau, 2001). Ultimately, Marx claimed that as the capitalist class becomes richer and smaller, the working class becomes larger and more miserable and the system ultimately collapses (Marx, 1848/2002).

Some contemporary sociologists have found Max Weber more suitable for explaining today's inequality in the U.S. (Tiryakian, 1975). Weber's initial arguments on social class are well reflected in his book Economy and Society (Weber, 1922/1978). Since Weber's description on social class was made sixty years after Marx expressed his central arguments, Weber was able to observe whether Marx's theories were historically accurate and whether they fit the class situation of the modern period (Levine, 2006).

Although Weber adopted many of Marx's ideas, his perspectives on social class differ from Marx's arguments to some extent. For example, Weber agreed with some of Marx's premises, such as economics as the core function of society, the importance of property relations 
in the creation of social classes, and the significance of social conflict as the main impetus for social change (Sernau, 2001). However, these two theorists have different opinions on the determinants of social class: whereas Marx regarded private ownership as the sole determinant of social class, Weber theorized that, in addition to property ownership, a person's class is also determined by education credentials, which provides individuals with life chances — which help individuals to gain skills and abilities and then to sell them on the market to earn income and wages (Weber, 1922/1978). In addition to capitalists and working classes, Weber identifies a new class of educated and trained personnel—including technicians, civil servants, teachers, and other white-collar workers-who do not own any property but still can obtain income because of their education and credentials (Weber, 1922/1978).

In addition to these perspectives on social class, Weber's views on social inequality are also distinct from Marx's in explaining factors contributing to the creation of social inequality. Weber agreed with Marx that inequality results from unequal property ownership, but further emphasized the role of status and power (Allen \& Chung, 2000). Weber stated that power is generated from three different sources: economic power from class, social power from status, and political power from parties (Levine, 2006).

Marx and Weber, the founders of the radical perspective, despite some differences, provide essential fundamentals to the explanation of social inequality in modern societies. This goes as well for discussing the impact of race, class, and gender on retirement in old age.

\section{Durkheim \& the Functionalists: Inequality is Necessary and Inevitable}

Not all theorists agree that the underlying inequality of society is unjust. While recognizing the existence of class conflict, theorists with the conservative perspective, such as 
Durkheim and the functionalists, argue that the differences in each individual's worth ultimately make societies function (Sernau, 2001).

Emile Durkheim, a French sociologist, utilized the conservative view to empirically investigate the consequences of social inequality. He was particularly interested in how a society remains orderly without collapsing (Durkheim, 1893/1960). A central argument of Durkheim is the division of labor, in which tasks are divided by specialists. In explaining social solidarity, which is further supported by religion and social cohesion (Durkheim, 1893/1960), Durkheim saw inequality as a necessary part of maintaining the functional order of a society, which locates people in the workplace and stimulates them to work hard (Sernau, 2001). Durkheim's interest in social solidarity contributed to the formulation of functionalism in the U.S. (Sernau, 2001).

The American functionalists Kingsley Davis and Wilbert E. Moore argued that stratification and inequalities are vital for the survival of a society (Davis \& Moore, 1945). They stated that all societies are composed of distinct positions that hold unique values for the survival of the society (Davis \& Moore, 1945), and that "societies insure that the most important positions are conscientiously filled by the most qualified persons" (p. 243). Accordingly, the system of stratified rewards is required to encourage people to fulfill the duties of their positions (Davis \& Moore, 1945). Consequently, the universal existence of social inequality in all societies is validated as a means of functioning societies (Levine, 2006).

In sum, there are mainly two perspectives on social class: radical and conservative (Sernau, 2001). Karl Marx and Max Weber, who represent the radical perspective, posit that social inequality is fundamentally detrimental and harmful to society (Sernau, 2001). The conservative perspective, espoused by Emile Durkheim and other functionalists, stresses that 
inequality is necessary for societies to function (Levine, 2006). The philosophical debates between these two perspectives have lasted since the 1800s, providing fundamental foundations for understanding social inequality (Allen \& Chung, 2000). In sum, the contributions of Marx, Weber, Durkheim, and the functionalists - the most important theorists in sociology — provide the fundamental foundation in understanding social inequality. As the heart of sociology, economics, political science, and social science, their theories offer a framework for analyzing social class, gender, race, and inequality in today's society. Therefore, it is important first to understand these early classical theories of inequality as lenses_through which to view work, retirement, and employment.

\section{Need for an Alternative Theory for Older Minority Workers}

\section{Beyond Classical Theories of Inequality}

Although classical theories provide foundational background for understanding inequality, these theories are limited in guiding this study because their analyses on inequality are fundamentally based on social class, not race (Allen \& Chung, 2000; Morrison, 2006; Sernau, 2001). In America, social inequality is not solely explained by social class any longer. It is compounded with diverse aspects, such as race/ethnicity, gender, age, and nationality (Allen \& Chung, 2000; Sernau, 2001). Also, a number of scholars underline the unique significance of race in explaining inequality (Allen \& Chung, 2000; DuBois, 1903; Levine, 2006). For instance, Dubois (1903) states that racial/ethnic inequality cannot be exclusively explained by economic dimensions, and boldly claims that serious social problems in U.S. society stem from the problem of stratification based on skin color. 
Social inequality is not a fixed or singular concept but rather a multidimensional one that constantly evolves in different contexts. For instance, America's unique racial/ethnic disparity was formed by the history of slavery of Blacks and the conquest and exploitation of Mexicans (Allen \& Chung, 2000). Although Weber argues for the beneficial influence of education, we need to consider that people of color in the U.S. have historically been given unequal access to education. As mentioned earlier, enslaved Blacks, before the Civil War, were prohibited from educational access by law to maintain white dominance (M. C. Brown \& Yates, 2005; Halpern, 1995) . Furthermore, though the Freemen's Bureau established schools for Blacks, and though freed Blacks eagerly received education, schools for Blacks were segregated and funded poorly because of the resistance of former slave owners who were afraid of losing their political and economic power (K. V. Johnson \& Watson, 1993). Even the Civil Rights era was not able to completely rectify Black Americans' unequal access to education. In many urban areas, Black and Latino children, than their White counterparts, are still more likely to attend urban schools that report lower average test scores, inferior classroom conditions, less qualified teachers, and more limited curricula—leading to racial differences in rates of high school dropouts and college enrollment (Williams \& Collins, 2002), which in turn lead to racial differences in employment. Clearly, Weber's argument on education does not fully account for Americans racism today. Therefore, it is necessary to use an alternative conceptual model that accounts for race/ethnicity's continuing significance for individuals' outcomes and embraces the disadvantages that minorities experience in contemporary U.S. society.

\section{Beyond Rational Choice Theory}

Economists' view of older workers is primarily based on rational choice theory, which has a long history in the field of economics and according to which individuals rationally 
calculate and compare the future returns of retirement versus working longer, and choose the one with greater payoffs (Molm, 2005). For instance, whether to work or not is a rational choice for all older workers; some workers retire early due to generous pension benefits, others decide to stay in the labor market longer to maximize their annuities before retirement (Singh \& DeNoble, 2003).

Although rational choice theory has contributed to our understanding of older workers by examining the influence of diverse financial resources on retirement (e.g., Social Security, pensions, wealth, or wages) (Baugh \& Sullivan, 2009), this theory may not describe many minority workers who have no choice but to work because of financial hardship or who need to work but cannot due to deteriorating health or an involuntary exit out of the labor market.

\section{Beyond Activity Theory and Role Theory}

Conventionally used theories in empirical studies of older workers, such as activity theory and role theory, are limited in explaining racial/ethnic inequality among older workers. Activity theory assumes that except for inevitable changes in biology and health, older people have the same psychological and social needs as middle-aged people. Therefore, from the perspective of activity theory, those aging optimally are ones who successfully manage the shrinkage of their social networks by staying active (Havighurst, 1968). Role theory posits that work is central to one's identity (George, 1993). This theory is often used to explain how working in old age may decrease depression symptoms among older people. These two theories have contributed to the older population's different expectations toward retirement-to be healthier and more active in old age. However, these theories are limited in guiding this study because they fail to consider financial aspects, which play a dominant role in many older individuals' decisions on whether to stay in or leave the labor market (Choi, 2001). 
Thus, in understanding racial/ethnic inequality among older workers, it is necessary to use a theoretical framework that focuses on how race continues to significantly influence labor market participation in old age.

\section{B. HISTORICAL CONTEXT OF MINORITY WORKERS IN THE U.S}

Racial/ethnic inequality existing in the contemporary U.S. is not a simple result of social class but a confluence of class and institutionalized discrimination based on race and ethnicity/national

origin - the majority's systematic exclusion of minorities from resources and power (Omi \& Winant, 2006). This section provides a review of the historical background of minority workers in the U.S. that shows how persistent oppression based on race/ ethnicity continues to operate today.

Origins of minority workers in the U.S.

The entry of Blacks and Latinos into the U.S. was different; however, both groups were exploited for economic growth. They were a cheap source of labor to help build the economic infrastructure of the country's less developed regions (Glenn, 1991). Starting in 1619, with the first arrival of a slave ship to the U.S., Africans were forcibly transported to and enslaved in the U.S. to produce sugar and tobacco crops (Scarpitti \& Andersen, 1992). The institution of the slavery system in the U.S. evolved as a class system in which White supremacy profited from Black slaves (Scarpitti \& Andersen, 1992). Moreover, to maintain white dominance, the majority of Blacks, under the system of slavery and segregation, were prohibited from educational access by law before the Civil War (M. C. Brown \& Yates, 2005; Halpern, 1995). Latino Americans, another group providing the cheap labor, originated as an ethnic group through migration, U.S. 
territorial expansion, and conquest, with Mexico's defeat in the Mexican American War in 1846 (Glenn, 1991; Nelson \& Tienda, 1984).

\section{Post Civil War era}

After the Civil War, although the Emancipation Proclamation in 1862 freed Blacks from the 200-year long slavery system in the U.S., Black workers, mostly uneducated and unskilled, faced difficulties in finding jobs due to the sudden change in their status (Trattner, 1999). To provide temporary relief for newly freed Black workers, the Federal government under President Lincoln established the Freedmen's Bureau, formally known as the Bureau of Refugees, Freedmen, and Abandoned Lands in 1865 (Segal, 2010), the first federal welfare agency in the U.S. (Baker, 2003). This Bureau provided diverse services of employment, settlement, health, and education for Blacks — such as supervising their written contracts with employers, leasing abandoned properties, employing doctors to reduce freed Blacks' mortality rate, and encouraging the foundation of schools for Blacks (Trattner, 1999). Thousands of Blacks attended schools by the late 1860s (Cruden, 1969). Although this relief was temporary and did not contribute to changing the country's economic structure, the establishment of the Freedmen's Bureau is meaningful in the U.S. history of minority workers since this was the federal government's first social welfare policy to reduce the racial gap between White and Black workers (Segal, 2010).

Despite the enactment of the Bureau, minority workers' inferior status was further reinforced by the limited range of industries in which they were involved. Blacks were further exploited for their labor, with the enactment of the Jim Crow Laws for racial segregation in 1876 (Scarpitti \& Andersen, 1992). Although Blacks in the South started working as a paid labor force, they worked predominantly in agriculture (field hands or sharecropper), heavy manual 
labor, or domestic service (Glenn, 1991). During the same period, Mexicans worked as agricultural laborers, miners, cowhands, and railroad hands in the Southwest (Glenn, 1991).

\section{World War I and $\Pi$ era}

With the development of war industries during World Wars I and II, a large number of Blacks migrated from southern to northern and urban areas in search of unskilled work in factories and homes. Residing in urban ghettos, they faced substandard living conditions, prejudice, discrimination, and racism (Franklin \& Moss, 2000). At the same time, Latino workers from Mexico, Cuba, Central and South America came to the U.S. labor market (Daniels, 2002) and filled the shortage in agricultural labor, while many Whites and Blacks looked for betterpaying factory jobs (Scarpitti \& Andersen, 1992). Latino workers suffered from their politically and socially vulnerable position. The U.S. actually recruited Latino workers in times of labor shortage. However, during the Great Depression in the 1930s when jobs were sparse, the U.S. repatriated them back to their original countries (Nelson \& Tienda, 1984; Sernau, 2001).

\section{Postindustrial era}

The civil rights movement in the 1960s substantially reduced discrimination by outlawing racial segregation in public accommodations (Allen \& Chung, 2000) and initiating affirmative action (Horne, 2001). Most importantly, the U.S. government stopped overlooking the existence of racial inequalities and started to dismantle discriminatory laws (Allen \& Chung, 2000). For instance, Congress established the Civil Rights Act in 1964 and the Equal Employment Opportunity Commission in 1976 under the Civil Rights Act, which prohibit discrimination in employment based on race, skin color, gender, and national origin (U.S. Equal Employment Opportunity Commission, 2011). Because of to the Civil Rights movement, the proportion of 
minorities in blue collar jobs has noticeably decreased over the past decades. In 1940, $96 \%$ of Black workers were concentrated in blue collar jobs, particularly as farmers and laborers, and the proportion dropped to 93\% in 1960, 84\% in 1980, and 65\% in 2000 (Farley, 1995).

Despite the enactment of the Civil Rights Act, a substantial gap between Whites and minority workers still remains. During the recession in 1973-1975, minority workers still experienced difficulty sustaining stable employment. Among many workers who were laid off, minority workers comprised 60 to $70 \%$ (Rothenberg, 2008). This difference was attributed to the fact that the layoff decision was often based on workers' seniority—length of service on the job (Bohlander \& Snell, 2010) in which minority and immigrant workers often have less of than Whites due to institutionalized discrimination (Cihon \& Castagnera, 2008). Today, minority workers are still overrepresented in service occupations and sparse in managerial and professional positions (Gilbert, 2002). Furthermore, the wage gap between Whites and Blacks remained the same in 2000 as in 1970 (Gilbert, 2002).

In conclusion, as Adams (2000) points out, racial disparity in the labor market is not only the result of personal ideology or racial prejudice, but also the result of a structural system that involves historical institutional policies and practices. In particular, the development of capitalism in the U.S. has generated the evolution of a class system which reinforces racial disparities in the U.S labor market (Andersen \& Collins, 2004).

\section{INTRODUCTION OF CUMULATIVE ADVANTAGE/DISADVANTAGE THEORY}

\section{Overview of the Theory}

CAD theory focuses on the process by which structures in society generate inequality and how unfavorable positions in early life influence the accumulation of disadvantages later in life 
(Crystal \& Shea, 1990; Shuey \& Willson, 2008). The CAD framework suggests that labor market participation in old age is not simply made by individual preference per se but by structural influences as well, reflecting underlying racial inequalities among the older population. In particular, $\mathrm{CAD}$ theory highlights the influences of four factors-financial resources for retirement, health, career patterns, and education—in explaining racial/ethnic inequality in old age. The essential tenet of CAD theory ${ }^{11}$ is that early advantage or disadvantage is critical to understanding how groups become disparate in later life (Merton, 1968).

\section{Origins}

Since the foundational work of classical theories of inequality, those theories have evolved to reflect changes in contemporary society, such as accounting for race and gender following the Civil Rights Movement in the 60s and 70s (S. M. Lynch \& Brown, 2011). CAD theory is one of the newly developed theories explaining inequality today.

CAD theory first came into being through the process of merging the life course perspective with the discovery of the trend of cumulative advantage/disadvantage. In 1965, the phenomenon of cumulative advantage was first speculated by Derek Price (1965), a science historian. While developing "bibliometrics," a system for predicting scientific citation rates, he discovered the importance of factors unrelated to the actual merit of the work, such as an author's reputation or a journal's prestige. Subsequently, Merton (1968) utilized this idea in sociology, using the term "the Matthew Effect in Science"-an effect that amplifies inequality

\footnotetext{
${ }^{11}$ The notions of CAD are sometimes called a theory (e.g., Ferraro \& Kelly-Moore, 2003), a perspective (e.g., Crystal \& Shea, 1990) or a hypothesis (e.g., O'Rand, 1996). It appears that CAD theory has been receiving recognition as an independent theory. Also, note that CAD theory is different from Cumulative Inequality (CI) theory, which merges concepts from multiple disciplines, including CAD, life course, symbolic interactionism, stress access, and chronic inflammation (Ferraro \& Shippee, 2009).
} 
within social systems. Since then, CAD theory has been applied to diverse research studies on inequality. Today, CAD theory, having been used as an independent theory (Ferraro \& KelleyMoore, 2003; George, 2000; Herd, Robert, \& House, 2011), is employed to emphasize a collective spectrum (Dannefer, 2011) and the influence of early inequalities differentiating diverse trajectories in later life (Ferraro \& Kelley-Moore, 2003; O'Rand, 1996).

\section{Main Tenets}

The main tenet of CAD theory is that in order to explain social disparity in later life, it is necessary to have an understanding of earlier advantage or disadvantage (Ferraro \& KelleyMoore, 2003; O'Rand, 1996; Street, 2007). CAD theory posits that advantages or disadvantages that occur during an earlier stage of a life course shape not only the trajectories of some outcomes in the short term but also in the long term through a compounding process (Ferraro \& Kelley-Moore, 2003).

Early advantage or disadvantage — early life experiences or conditions, such as education, gender, race/ethnicity, and social class, exists unequally across populations and over the life course (O'Rand, 2001). Unfavorable positions at an earlier age can further accelerate their negative influences across the lifespan, accelerating the growth of disadvantages among one individual or group relative to another and generating heterogeneity in later life (Dannefer, 1987; O'Rand, 1996; Ross \& Wu, 1996; Shuey \& Willson, 2008). For example, because of Blacks' early disadvantages in education, they face continual structural disadvantages in their income disparity and wealth accumulation during their entire life (O'Rand, 2001).

CAD theory emphasizes the role of social structure in understanding social inequality

(Caputo, 2004; Crystal \& Shea, 1990). It postulates that inequality between groups is a 
byproduct of the interplay between individuals' cumulative experiences over the life course and the institutional processes that regulate opportunities over time (Dannefer, 1987; O'Rand, 1996; Quadagno \& Reid, 1999). In other words, people in favorable positions in earlier life attain better positions to access resources and opportunities compared to those in a less favorable position in the stratification system (Quadagno \& Reid, 1999). Given its emphasis on social structure, empirical studies based on CAD theory highlight the role of public policies and practices which can eliminate institutional racism existing in the U.S. (Crystal \& Shea, 1990; Street, 2007).

\section{The Emergence of CAD Theory in Studies on Aging}

Around the 1990s, some gerontologists suggested the necessity of acknowledging the heterogeneity of today's older population (Rappaport \& Scheiber, 1993; Riley, Kahn, \& Foner, 1994). In an attempt to understand heterogeneity in old age, some researchers started applying CAD theory, which deals with questions of whether inequality increases over time or remains constant, and if it increases, why such inequality within a cohort increases with age (O'Rand, 1996).

The growing body of CAD research focusing on inequality in old age claims that inequality increases as an individual ages (Dannefer \& Settersten, 2010; O'Rand, 1996). This is because the initial gaps between being advantaged or disadvantaged grow over the life course (George, 2000). As a result, the level of heterogeneity becomes greater in older age than at an earlier age (McMullin, 2002), and older people are more severely affected by accumulating disadvantages.

CAD research underlines the role of social structures: the heterogeneity in old age is not a simple result of the accumulation of life decisions that individuals make but is a byproduct of the 
interconnection between aggregated individual actions and institutional arrangements which stratify the available resources and rewards (O'Rand, 1996).

\section{Significance of Race/Ethnicity in Understanding Social Inequality in the U.S.}

Each individual holds specific characteristics that offer certain advantages or disadvantages which contribute to differentiating groups over time (McMullin, 2002). The majority of studies use the concept of SES, socio-economic status-a proxy of social class which commonly includes education, income, and wealth-which is often pointed out as what differentiates groups (Shuey \& Willson, 2008). For instance, it is well established that SES, which is positively related to health outcomes (Williams \& Collins, 1995), plays a crucial role in explaining racial gaps in health (Feinstein, 1993; Hayward, Myles, Crimmins, \& Yang, 2000; Williams \& Collins, 1995).

CAD theorists, however, claim that social class or SES does not fully explain racial/ethnic differences existing in contemporary society and underline the significance of race/ethnicity in understanding social inequality in the U.S. (Crimmins, Hayward, \& Seeman, 2004; Farmer \& Ferraro, 2005; Kahn \& Fazio, 2005; Williams \& Collins, 1995). For example, how do we explain that Blacks of every level of SES strata have poorer health than Whites? (Ries, 1990; Smith \& Kington, 1997; Williams \& Jackson, 2005). This phenomenon is well explained by a study conducted by Shuey and Willson (2008). Using longitudinal data from the Panel Study of Income Dynamics, they examined whether SES equally benefits health between Blacks and Whites. They found that Blacks' poorer health is not entirely explained by SES. They

pointed out that the health gaps between Blacks and Whites are greater at higher levels of education than at lower levels. They suggested that higher SES does not offer equal health 
advantages to minorities because the cumulative effect of institutionalized racism restricts minorities' ability to gain socioeconomic resources and the benefits that SES provides to their White counterparts. Discrimination over a lifetime creates stress which negatively impacts both the physical and mental status of Blacks.

Minorities are affected by structural stratification, which affects access to health care, education, employment, social support, housing, and levels of stress (Cagney, Browning, \& Wen, 2005; Oliver \& Shapiro, 2006). Taylor (2008), for instance, conducted a study that examined the disability trajectories between Blacks and Whites, using the 1986 to 1996 datasets of the Duke Established Population for Epidemiologic Studies of the Elderly (EPESE). He found that individual-level health behaviors — such as smoking — had little impact; however, when the level of SES was controlled for, limited access to health care-such as limited access to physicians and health insurance-showed a significantly strong effect on Blacks' disability trajectories. Based on these results, he underscored the significance of structural components as the heart of cumulative disadvantage. In addition, racial discrimination exacerbates the cumulative process of disadvantages (O'Rand, 1996), and exposures to advantages or disadvantages are socially patterned by race/ethnicity and social position (Walsemann, Geronimus, \& Gee, 2008).

\section{APPLYING CAD THEORY TO RACIAL/ETHNIC INEQUALITY IN OLD AGE}

The notion of $\mathrm{CAD}$ has been applied to inequality research in many fields, including demography, economics, history, sociology, health disciplines, and psychology (DePrete \& Eirich, 2006; O'Rand, 1996; Taylor, 2008); however, it has not been empirically addressed in particular studies of older workers in a systematic manner. Nevertheless, as CAD theory can be 
applied to other sources of disparities in old age (George, 2000), it has the potential to offer useful guidance for this study. The following section provides a review on CAD research related to inequality in old age, with a focus on financial resources for retirement, health, career patterns, and education.

\section{Minorities' Cumulative Disadvantages in Financial Resources for Retirement and Health}

Individuals' work decisions in old age are often dependent on finances and health conditions for all racial groups. CAD theory does not view the differences in retirement income (Crystal \& Shea, 1990; George, 2000) and health (Hayward et al., 2000; Kahn \& Fazio, 2005; Warner \& Hayward, 2006) as sudden occurrences in older ages, but rather as the outcomes of the long term and cumulative process of disadvantages that begin early in life. Crystal and Shea (1990) stated that retirement income is predetermined by wealth accumulation before retirement. In other words, pre-retirement inequality continues even after retirement, amplifying the initial differences. For example, compared to renting, home ownership provides advantages to one's finances, which accumulate over the passage of time (Crystal \& Shea, 1990). Also, Ferraro and Kelly-Moore (2003) empirically tested how early risk factors in health develop health inequality in later life. Analyzing 4,106 individuals age 45 or above tracked for 20 years, who were from the national surveys of the National Health and Nutrition Examination Survey I (NHANES I) and its Epidemiologic Followup Study (NHEFS), they found that obesity (an early health risk factor) significantly increased comorbidity (health inequality) in adulthood. Similarly, Shuey and Willson (2008) argued that initial differences in health by race grow considerably with age through the aggregation of advantage or disadvantage, such as access to health care, neighborhood context, and levels of stress. 
The relationship between health and wealth appears to be reciprocal. Research demonstrates that the influences of financial hardship accumulating over time not only limit the economic resources to healthcare access (O'Rand, 1996), but also produce chronic stress that deteriorates physical health (J. W. Lynch, Kaplan, \& Shema, 1997; Smith \& Kington, 1997). For instance, income is closely related to mortality as it impacts the progression of disease and disability over the life course (Herd, Goesling, \& House, 2007). Also, poor health, in turn, undermines one's labor market participation, resulting in limited earnings and a drain on savings (Kahn \& Fazio, 2005; McDonough \& Berglund, 2003).

Applying the CAD framework to the older worker population, this study suggests that minorities' poorer health and lower financial resources for retirement can be understood not as sudden consequences in old age but is a result of their different life trajectories of cumulative advantage/disadvantage during a course of life.

\section{Significance of Career Patterns}

In considering inequality in old age, CAD research emphasizes the role of career patterns because of their close connection with the trajectories of 1) wealth and 2) health during the course of life. First, career patterns influence wealth accumulation during a lifetime (Crystal et al., 1992; Flippen \& Tienda, 2000; Hogan et al., 1997). Crystal, Shea, and Krishnaswami (1992) elaborated how individuals' career patterns early in the life course affect their wealth accumulation in later years. Using the 1984 panel of the Survey of Income and Program Participation and employing a path analysis, they examined determinants of economic well-being among different age groups of men. They found that privileged jobs, such as professional, technical, and managerial positions, offer more potential for compensation growth with 
employment length over the lifespan and provide increased income as retirement approaches. Moreover, these positions are more likely to provide good job security and protection from unemployment and to have a smaller risk of occupational injury or impairment, all of which enable workers to work longer and increase their opportunities for saving. Therefore, unstable employment histories - longer periods of unemployment, temporary and part-time positionsare closely associated with fewer economic resources and retirement benefits (E. Brown, 2009).

Racial gaps in pension plans accentuate the significance of career patterns. In general, the growth of pension savings are rewarded by stable employment and penalized by unstable careers (O'Rand, 1996). In other words, individuals with long-term careers are generally able to accumulate adequate pension funds (Crystal et al., 1992). Therefore, Blacks and Latinos, who are disproportionally concentrated in temporary and low-wage jobs, are less likely to accumulate pension savings (Hogan et al., 1997).

In addition to negatively affecting pension savings, poor career patterns also appear to result in some minority retirees not being eligible for Social Security benefits at all. Hogan, Kim, and Perrucci (1997) illustrated that these retirees' lifetime career patterns are often exemplified as the urban poor, struggling for day-to day survival in the temporary labor force, or as "off the books" workers who lack opportunities to build Social Security savings. Thus, along with discrimination and/or a language barrier (Hogan et al., 1997), many minorities' lifetime disadvantage in career patterns may explain the economic necessity of remaining in the labor market.

Second, one's career patterns are also linked with one's health outcomes during the life course. Research, although relatively sparse compared to studies on the relationship between 
career patterns and retirement income, shows that older people with lower occupational categories have poorer health and higher rates of disability (Gueorguieva, Sindelar, Falba, Fletcher, Keenan, Ran, \& Gallo, 2009; Herd et al., 2011). Specifically, older people with lower occupational status are more likely to have poorer health, greater disability, lower quality of life, inferior mental health, and earlier mortality than those with their higher-occupational-status counterparts (Herd et al., 2011; Luo \& Waite, 2005).

In sum, CAD theory's emphasis on career patterns is expected to expand the scope of existing studies of older workers, which primarily focused on factors in late life while paying little attention to the role of earlier work experience (Raymo et al., 2009).

\section{Significance of Education}

CAD theory frequently emphasizes education as a vital factor that shapes one's life trajectories in both short and long terms (Ferraro \& Kelley-Moore, 2003). This emphasis is important because for most Americans, education is fundamentally related to the trajectories of 1) career, 2) wealth, and 3) health in direct or indirect pathways (Shuey \& Willson, 2008). First, educational attainment profoundly affects one's career trajectory. It is well known that lower education tends to limit access to higher-paying and less physically demanding jobs (R. W. Johnson, 2000), and can make it more difficult to maintain stable employment during the life course (Lee, 2007).

Second, the CAD framework suggests that education shapes an individual's income trajectory during the course of life, affecting the accumulation of retirement income in old age (Crystal \& Shea, 1990). Higher education usually increases the chances of having higher-status jobs and stable employment in the long term, which both increase income not only in middle age 
but also in old age (Crystal et al., 1992). More importantly, CAD theory points out that the cumulative effect of education may be even greater after than before retirement due to its greater impact on financial difficulty in old age (Crystal, 2002; Crystal \& Shea, 1990).

Finally, research consistently shows that people with higher education are more likely to have higher levels of self-rated health and physical functioning, and lower levels of mortality and morbidity (Mirowsky \& Ross, 2003). This relationship between education and health is mediated by income. In other words, workers with less education tend to have less privileged jobs which impacts their health detrimentally during their course of life (R. W. Johnson, 2000; Shuey \& Willson, 2008).

In sum, this section presents the interactive influences of the four main factors-financial resources for retirement, health, career patterns, and education-explaining racial/ethnic inequality in old age. However, this review does not intend to demonstrate the causal direction of their effects. Rather, it aims to emphasize the significance of these factors, which are closely associated with labor market participation in old age. This review also highlights that racial/ethnic inequality among older workers has important implications at the society level (Dannefer, 2003).

\section{E. SUMMARY}

In understanding inequality in old age, CAD research particularly underlines the influences of four factors: financial resources for retirement, health, career patterns, and education, all of which strongly affect labor market participation in old age. Although this study applies the relatively new CAD framework to studies of older workers, the notion of CAD can be highly useful because its emphasis on the role of race/ethnicity holds for individuals' outcomes and it 
embraces the disadvantages that minorities experience in contemporary U.S. society. The racial/ethnic differences in these four factors do not suddenly appear at older ages, but rather evolve over an individual's lifetime. In other words, Whites, who are launched on comparatively more promising trajectories — as shown in U.S. history-experience early successes that lead to further advantage. On the other hand, minorities' early disadvantages accumulate throughout the lifespan, increasing with age. The literature review in Chapter 2 and the assumptions of CAD theory in Chapter 3 suggest that racial/ethnic differences significantly influence labor force participation in old age. Also, it appears that labor force participation in later life reflects underlying inequalities among members of the older population that begin at an earlier age, and are therefore, not sudden occurrences in old age, but are the outcome of a long-term and cumulative process of disadvantages that minorities have experienced throughout their lives. Thus, it is necessary to empirically test the cumulative advantage/disadvantage theory in the context of race and labor market participation in old age. Figure 1 shows the conceptual model of this study to examine labor market participation in old age, given the review of literature and CAD theory.

\section{F. RESEARCH QUESTION AND HYPOTHESES}

Within the CAD framework, the following research question and subsequent hypotheses are generated; 
Research Questions: among workers approaching retirement, what are the factors significantly explain their labor market participation after retirement age, and are there racial differences in these factors? ${ }^{12}$

Hypothesis (racial/ethnic differences)

H-1: Racial/ethnic differences exist in the factors that significantly predict older individuals' labor market participation.

Hypotheses (Retirement income)

H-2: The influence of Social Security differs by race.

H-3: The influence of employer-sponsored pension differs by race.

H-4: The effect of wealth differs by race.

H-5: The influence of the total household income differs by race.

H-6: The influence of homeownership differs by race.

Hypothesis (health)

H-7: The influence of health differs by race.

Hypothesis (career patterns)

H-8: The influence of employment stability differs by race.

H-9: The influence of job types during preretirement years differs by race.

Hypothesis (education)

${ }^{12}$ This study presents hypotheses only for theoretically important factors and excludes hypotheses dealing with control factors. 
H-10: The influence of education differs by race. 
Figure 1. The conceptual model of this study

\begin{tabular}{|l|}
\hline FACTORS OF INTEREST \\
Financial Factors \\
Social Security \\
Employer-sponsored pensions \\
Wealth \\
Household income \\
Home ownership \\
Health \\
Career Patterns \\
Employment stability \\
Occupation types \\
\hline Education
\end{tabular}
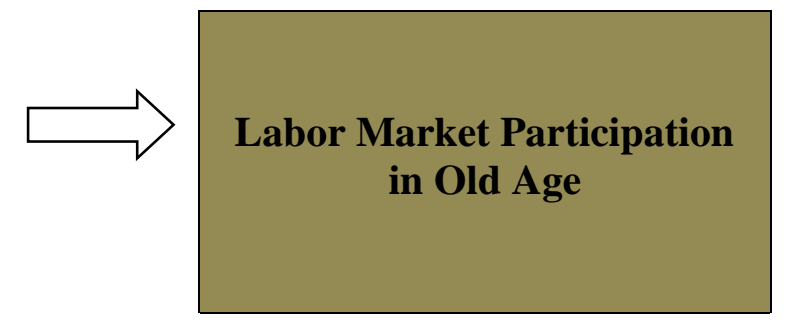

\begin{tabular}{|l|}
\hline CONTROL FACTORS \\
The Attributes of Preretirement Work \\
Job stress \\
Employers' attitudes toward older workers
\end{tabular}

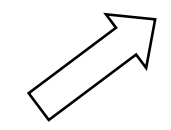

The Meaning of Work

\section{Dependents}

\section{Demography}

Age

Gender

Marital status 


\section{METHODS}

\section{A. DATA}

This study used the 2004 and 2008 datasets of the Health and Retirement Study (HRS) ${ }^{13}$ to examine racial/ethnic differences within the factors affecting labor market participation in old age. The HRS is a longitudinal dataset that has biannually surveyed more than 22,000 nationally representative Americans aged 50 or over since 1992. Funded by the National Institute on Aging and the Social Security Administration, the HRS is currently administrated by the University of Michigan. This dataset provides diverse variables, such as Social Security, pensions, health, and employment histories. Although the HRS offers both publically open and restricted data, this study only accessed the public data. All predictors (including variables of interest and control variables) were employed from the 2004 wave, though the outcome variable was taken from the $2008{ }^{14}$ wave. This four-year term was chosen for two reasons: 1) to focus on people closer to retirement and 2) to minimize the changes in health and financial status in old age, which considerably influence older people's employment ${ }^{15}$.

In addition to the HRS data files, this study also used the HRS's two ancillary data files ${ }^{16}$ : the RAND HRS data files and the Respondent Pension Data Tracker files. The RAND HRS data

\footnotetext{
${ }^{13}$ See Appendix 1 for an additional analysis examining the changes in respondents' health and wealth between 2004 and 2008.

${ }^{14}$ Although the HRS provides more a recent wave (2010), this study chose the 2008 wave in order to minimize the influence of the economic recession in 2008 on the U.S. labor market.

${ }^{15}$ A similar study (e.g. Kim \& DeVaney, (2005) used an 8-year term between their predictors and outcome, which appears somewhat remote from actual retirement. Individuals may experience a certain degree of changes in health and financial status during those 8 years, especially in old age.

${ }^{16}$ The HRS provides several ancillary data files to enhance their data users' convenience. With unique verification numbers of each participant—such as household ID numbers and personal numbers_ data users are able to merge the ancillary data files with any HRS wave files.
} 
files, supported and funded by the National Institute on Aging (NIA) and the Social Security Administration (SSA), and the RAND Center for the Study of Aging, offer cleaned variables, consistent and intuitive naming conventions, model-based imputations and imputation flags, and comparability of variables across survey waves. This study accessed the latest RAND HRS data product, the March 2011 release of Version K. Also, the Respondent Pension Data Tracker files (version 1.0) are constructed to enhance the user's ability to utilize pension information from various jobs reported by respondents from up to seven waves. These data files are especially useful for this study to analyze respondents' pension-related information, such as respondents' pension eligibility from current and previous jobs.

Of the 17 analytic variables, four variables (home ownership, employers' attitudes toward older workers, meaning of work, and dependents) were employed from the original HRS datasets, 12 variables (Social Security eligibility, wealth, total household income, health, employment stability, occupation types, job stress, age, gender, race, marital status, and the outcome variable) were employed from the 2004 RAND HRS files, and pension eligibility was taken from the 2004 wave of the Respondent Pension Data Tracker files. Other than the outcome variable extracted from the 2008 wave, all analytic variables were employed from the 2004 wave.

\section{Inclusion criteria}

This study's sample had to satisfy two criteria: work status and age. By using the HRS variable, labor force status, which identifies one's labor force status tracked from a number of variables (self-reported employment status, whether working for pay, usual hours work per week, usual weeks worked per year, second job, whether looking for work, etc.), this study included 
only respondents working either part- or full-time in 2004. Accordingly, it excluded those who were unemployed, retired, disabled, homemakers, and not in the labor force in 2004.

Furthermore, this study included only those who were aged 61 to 64 in 2004, which allowed it to examine those who are beyond the traditional retirement age of 65 in 2008 . In addition, those who died between 2004 and 2008 were deleted from the sample. The final sample size was 1,114 .

\section{B. VARIABLES}

\section{Outcome Variable}

The outcome variable is employment status ( $1=$ working, $0=$ retired). Respondents in the labor market, either full- or part-time, were categorized as 1, and those who retired were coded as 0 . This variable was generated by recoding the raw variable labor force status (1=working full-time, 2= working part-time, $3=$ unemployed, $4=$ partly retired, 5=retired, $6=$ disabled, $7=$ not in the labor force). Codes 1,2 , and 4 were recoded to the new code 1 (working), code 5 is set to 0 (retired), and 3, 6, and 7 were excluded from the analysis.

\section{Variables of Interest}

Financial resources for retirement

\section{$\underline{\text { Social Security eligibility }}{ }^{17}$}

Social Security eligibility is a binary variable (yes $=1$, no=0). This variable was made by combining two variables: one asking whether they "expect to receive Social Security benefits at

\footnotetext{
${ }^{17}$ Note that Social Security was included in the descriptive analysis and the multiple imputation process, but was excluded from the main probit analysis due to its substantially disproportional distribution. For all racial groups, those who were not eligible for Social Security were less than $1 \%$.
} 
some time in the future" and the other asking whether the respondents currently receive Social Security benefits. After combining these two variables, those who both do not expect to and do not currently receive Social Security benefits were recoded into 0 (ineligible for Social Security), and others who either expect to or currently receive Social Security benefits were recoded into 1 (eligible for Social Security).

\section{$\underline{\text { Pension plan eligibility }}$}

Pension eligibility is a binary variable for whether a respondent expects to receive any benefits from employer-sponsored pension(s) by the time they retire $(1=y e s, 0=$ no).

This variable was created by combining four variables: 1) whether the respondent has pension coverage from their current job (yes or no); 2) the total number of previous pension plans the respondent has had throughout all previous jobs (ranging from 0 to 8 ); 3 ) the number of dormant pension plans that the respondents report (ranging from 0 to 5), and 4) whether the participants currently receive pension benefits (yes or no). After summing these four variables, those with zero pensions were recoded into 0 and those with more than one pension were recoded to 1 . Combining these four variables enabled this study to account for multiple-pension eligibility from current and previous jobs. Finally, respondents who have one or more pension plans were regarded as those with pension eligibility.

\section{$\underline{\text { Total wealth }}$}

Total wealth is a continuous variable that sums up the net value of real estate, vehicles, businesses, IRA (Keogh accounts), stocks, mutual funds, investment trusts, checking, savings, or money market accounts, value of CDs (government savings bond, and T-bills), bonds and bond funds, as well as all other savings. However, the value of housing expenses (primary residence, 
mortgages, and home loans) was not included. Also, total debt was subtracted from total net value to arrive at total wealth. This formula for calculating wealth was provided by the HRS.

\section{$\underline{\text { Total household income }}{ }^{18}$}

Total household income is a continuous variable; the number presents the amount of money that each household earns annually. This variable employed the HRS RAND item that summed up 1) both the respondent's and spouse's earnings (the sum of wage/salary income, bonuses/ overtime pay/ commissions/ tips, second job or military reserve earnings, professional practice or trade income ${ }^{19}$ ), 2) household capital income (the sum of household business or farm income, self-employment earnings, business income, gross rent, dividend and interest income, trust funds or royalties, and other asset income), 3) the respondent's and spouse's combined pension/annuities income, 4) SSDI benefits, 5) Social Security benefits, 6) employment/worker's compensation, 7) government benefits (veteran's benefits/welfare/food stamps), and 8) misc. (alimony/ lump sums from insurance/ inheritance).

\section{Home ownership}

Homeownership is a binary variable (yes $=1$, no=0). This variable was created by recoding the raw variable that asks, "Do you [and your (husband/wife/partner)] own this (house and lot/apartment), do you rent?" (1=own or is buying; land contract, $2=$ pays rent, $7=$ neither owns nor rents). The response 1 remained as 1 and all other responses were recoded into 0 .

\footnotetext{
${ }^{18}$ See Appendix 2 for wealth and income pre-imputation performed by HRS

${ }^{19}$ These wages were the amount before taxes and other deductions.
} 


\section{Health}

Health is measured by self-measured health ${ }^{20}$ (1=poor, $2=$ fair, $3=$ good, $4=$ very good, $5=$ excellent). This variable was created from the raw variable, "Would you say your health is excellent, very good, good, fair, or poor?”.

\section{Career patterns}

\section{Employment stability}

Employment stability is a continuous variable; the numerical value of the response represents the participant's years of working at the longest-held job ${ }^{21}$. This study used the raw variable job tenure which provided the years of tenure at the longest-held job ${ }^{22}$ based on the information on all reported jobs ${ }^{23}$.

\footnotetext{
${ }^{20}$ There has been controversy over which health measures, subjective or objective, better capture one's health status. After carefully reviewing the literature, this study chose to use a self-rated measure of health because numerous scholars report that it is actually a good indicator of a person's medically determined health status (Dwyer \& Mitchell, 1999; McGarry, 2004; Munnell, Soto, \& Golub-Sass, 2007) and may be the best approach to determining the effects of health on work (Munnell et al., 2007). For a detailed review of the literature, see Appendix 3

${ }^{21}$ Compared to the latest-held jobs, the longest-held jobs appear to better represent workers' employment stability because older people sometimes quit a career job and get a new job in old age, which is sometimes referred to as "bridge jobs" according to Cahill and his colleagues (2006b).

${ }^{22}$ The longest job tenure was determined by comparing the tenures derived from jobs given in the retrospective job history, current job tenures from current and previous interviews, and tenure on any job that ended between interviews and the present. Thus, the longest-held job can be a current or past job (HRS, 2011a).

${ }^{23}$ Information on reported jobs came from respondents' current job in any waves and from their retrospective job history.
} 
Table 1. Coding schemes for categorizing occupations

\begin{tabular}{lll}
\hline & & New binary code \\
\hline BRS & 5= service: providing & White collar jobs \\
Occupation & household/cleaning/building service; & 1= managerial specialty operation; \\
codes & 6= service: protection; & operational/ technical support; \\
& 7= service: food preparation; & $3=$ sales; \\
8= health service; & $4=$ clerical/ administrational support \\
$9=$ personal service; & \\
$10=$ farming/ forestry/ fishing; & \\
& $13=$ precision production; & \\
$14=$ operators/ machine; & \\
$15=$ operators: transport, etc.; & \\
$16=$ operators: handlers, etc.; & \\
$11=$ mechanics/ repair; & \\
$17=$ member of Armed Forces; & \\
$12=$ constructional grade/ extractors & \\
\end{tabular}

$\underline{\text { Job types }}$

The variable of Job types is binary, asking whether respondents have primarily worked a blue- or white-collar job throughout their working lives $(0=$ white collar, $1=$ blue collar $)$. This variable was created by recoding the raw data of occupation codes with the longest tenure. The 17 categories were recoded into a binary code for this study, based on Peterson and Murphy's (2010) categorization. Table 1 summarizes how the 17 codes were recoded into the new binary code.

Education

Education is a continuous variable; the number represents the years of education the participant has received. 


\section{Control Factors}

\section{The attributes of preretirement work}

\section{$\underline{\text { Job stress }}$}

The level of job stress is assessed by the question "Thinking of your job, please indicate how much you agree or disagree with the statement. My job involves a lot of stress." The response was rated by a four-score Likert scale (1=strongly disagree, 2=disagree, 3=agree, $4=$ strongly agree).

\section{Employers' attitudes toward older workers}

Employers' attitudes toward older workers are a continuous variable; the higher the respondents score, the higher the perception that older workers are treated differently from younger workers at their workplace in a negative way. This variable was created by combining three questions: 1) "In decisions about promotion, my employer gives younger people preference over older people"; 2) "My co-workers make older workers feel that they ought to retire before age 65"; and 3) My employer would let older workers move to a less demanding job with less pay if they wanted to." All responses to these questions were rated on a four-score scale (1=strongly agree, 2=agree, $3=$ disagree, $4=$ strongly disagree). After the first and second questions were recoded in reverse, the three responses were summed up, giving a final variable ranging from 3 to 12 , with a reliability of 0.72 . 


\section{Meaning of work}

The meaning of work is measured by the question "Even if I didn't need the money, I would probably keep on working ${ }^{24}$ (1=strongly disagree, $2=$ disagree, 3=agree, 4=strongly agree)." The original responses were recoded in reverse so that the higher the scores, the higher the value placed on work $^{25}$.

\section{Dependents}

The number of dependents is a continuous variable that asks the respondents how many dependents they have. A zero value indicates that the respondent has no dependent. This variable was created by combining two items: "Were any children, parents, or other relatives dependent on you for more than half of their support?" (yes/no) and "(if yes) How many people was that?"

\section{Demography}

$\underline{\text { Age }}$

Age is a continuous variable measured at the beginning of the interview at each wave. The number represents the participant's actual age.

\section{$\underline{\text { Gender }}$}

Gender is a binary variable $(0=$ male, $1=$ female $)$. The original gender variable's responses were recoded for this study's convenience.

\footnotetext{
${ }^{24}$ This question was also used as a measure of the meaning of work in other studies, e.g., Kim \& DeVaney (2005) and Kosloski, Ekerdt, \& Deviney (2001).

${ }^{25}$ The meaning of work was employed from the 1992 wave because the HRS provides this question only in the 1992 wave and does not further include it in their later waves. Although this might be this study's limitation, personal value systems, in general, are considered to be relatively unchanging (England, 1967; Joyaux, 2001).
} 


\section{$\underline{\text { Marital status }}$}

Current marital status is a binary variable $(0=$ not married, $1=$ married $)$. The original HRS for this variable was separated into eight categories. This study combined those who are married, married but spouse absent, and separated into married(1) and those who are partnered, divorced, separated/divorced, and windowed into not married (0).

\section{$\underline{\text { Race /Ethnicity }}$}

Race/Ethnicity is a categorical variable $\left(0=\right.$ Whites, $1=$ Blacks, $2=$ Latinos $\left.^{26}\right)$. This variable was created by combining two raw variables of race: 1) primary race $(1=$ White/Caucasian, 2=Black/African American, 3=other) and 2) whether Hispanic $(1=y e s, 0=$ no $)$. Those who are not Whites, Blacks, or Latinos are excluded from the data. This variable will be used to break this study' data into three subsets of data for Whites, Blacks and Latinos.

\section{ANALYSIS PLAN}

\section{Step 1: Descriptive Analysis}

Descriptive analysis of the data

An initial descriptive analysis explored the basic characteristics of the data, including means, standard deviations, minimums, maximums, and crosstabs between the main analysis variables and demographic variables.

26 The HRS uses the terms "Hispanics" and "Latino" interchangeably throughout the waves (e.g., "Hispanic/Latino"); however, this study keeps the term "Latino" for consistency. 


\section{Racial comparison}

To assess racial differences in the factors, t-tests, chi-square tests, or ANOVA were run on the factors among Whites, Blacks, and Latinos.

\section{Step 2: Missing Value Imputation}

Missing data occurs frequently in surveys (Reiter, 2006), and HRS tends to have significant portions of missing values. Missing values appear for many reasons: participants skip questions by mistake, refuse to respond, lack the requested information, or leave the survey through attrition caused by illness or death (Patrician, 2002). Missing values are generally excluded from estimation, a default setting in most statistical programs (Allison, 2000). This exclusion method, called listwise deletion, discards cases with any missing data, restricting analysis to those cases with a full completion of values (Patrician, 2002). This method may be a reasonable approach if the deleted cases are a fairly small portion of the entire sample ${ }^{27}$. However, when a large portion of the data are missing, estimates may be seriously biased because of the loss of power (Schafer, 1999). Thus, to help adjust for potential bias coming from missing data, this study employed the multiple imputation (MI) strategy. This study selected $\mathrm{MI}^{28}$ because of its many advantages compared to other methods ${ }^{29}$. That is, MI is preferable for large and publically available surveys and censuses; allows randomly drawn imputations under more than one model (Patrician, 2002); increases estimate efficiency and minimizes standard

\footnotetext{
${ }^{27}$ There is no consensus on how much missing data is acceptable for multiple imputation (Social Science Computer Cooperative, 2013).

${ }^{28}$ See Appendix 5 to see details of a multiple imputation technique.

${ }^{29}$ See Appendix 4 to see diverse techniques available for missing value treatment.
} 
error (Rubin, 1987); adjusts for potential bias due to missing data; and incorporates random error (Little \& Rubin, 1987; Schafer, 1997).

This study's missing value imputation involved three steps: 1) checking missing values, 2) checking missing patterns, and 3) imputing data.

Step 2-1: Checking missing values

This step ran descriptive analysis to ascertain the number of missing values in each study variable.

Step 2-2: Checking missing patterns

Before imputing data, it must be verified whether patterns of missing data are missing completely at random (MCAR) or missing at random (MAR), two assumptions for missing data imputation $^{30}$. This step examined whether variables with a relatively large portion of missing values are independent of the key variables (outcome and race) and other analysis variables. As for the process, first, variables with a large portion of missing values were recoded into two values: missing (1) or not missing (0). Then, chi-square analyses were run to compare these recoded variables and the outcome. This straightforward test conveniently identifies whether the data are MCAR or MAR, given that there is no formal test to determine the missing patterns (Social Science Computer Cooperative, 2013). The nonsignificance of the chi-square test result indicates the independence of the missing patterns, either MCAR or MAR. In other words, when the chi-square test results between the missing values of variable A and variable B are not significant at $\mathrm{p}<.05$, the missing patterns of variable $\mathrm{A}$ are independent of variable $\mathrm{B}$, which gives further evidence that the data is MCAR or MAR.

\footnotetext{
${ }^{30}$ See Appendix 6 to see more about the patterns of missing data.
} 


\section{Step 2-3: Imputing data}

This final step used the multiple imputation technique. The MI specification of this study is described as follows: due to the large portion of missing values, the MI specification included 50 imputations, which is reported to produce consistent parameter estimates in direction and magnitude (Horton \& Lipsit, 2001) and is often used in many studies with large datasets (e.g., (Kamakura \& Wedel, 2000) and (Lipkovich, Duan, \& Ahmed, 2005). All study variables were entered in the imputation process to maximize all of the covariate information. Furthermore, some restrictions on minimums and maximums were applied to certain variables. For example, minimum 1 and maximum 12 (the range of this variable in the original data) were assigned to employers' attitudes in order to avoid having values out of the range of this variable in the imputed data. The final specification was a selection of a method for imputing categorical variables. This study employed both a "rounding method" and a "binary dummy variables method"31 (Ake, 2005).

The MI specification also included the Monte-Carlo Markov Chain (MCMC) procedure, designed to handle quantitative variables identified as either MCAR or MAR. MCMC works well for large complex datasets (Schunk, 2008), such as this study's HRS datasets, which combine both its original and supplemental datasets. After applying these MI specifications, each of the 50 imputed datasets was separately analyzed by probit analysis, and then results were pooled across the 50 imputed datasets to reduce bias in estimation (Saunders, MarrowHowell, Spitznagel, Doré, Proctor, \& Pescario, 2006 ).

\footnotetext{
${ }^{31}$ See Appendix 7 to see further information about these two methods.
} 


\section{Step 3: Racially Stratified Analysis}

\section{Step 3-1: Running probit models}

Step 3-1 is designed to examine the factors that significantly contribute to participation in the labor market among the three racial groups. Accordingly, Step 3 analysis involved stratifying the data by three racial groups (Blacks, Latinos, and Whites), analyzing the three datasets separately, and comparing these factors among the three racial groups.

The datasets were analyzed by probit analysis with SAS version 9.3. When the outcome variable is binary, using probit analysis is advantageous because it overcomes the problems of using the conventional method of ordinary least squares (OLS) linear regression (Long, 1997; Long \& Freese, 2006). The problems of OLS estimation for the binary outcome include: 1) being unable to produce the best linear unbiased estimator (BLUE), where the distribution of residual error becomes heteroscedastic_meaning unequal variances of the error for different observations - which leads to violating the OLS assumption; 2) producing biased standard errors due to the nonnormality of the outcome, which also results in biased results; 3) predicting the outcome below 0 or above 1 , which is out of the range of the outcome.

Probit and logit (often called logistic regression) analyses are similar in that they are both suitable for analyzing a binary outcome. Even with the similarity, the crucial difference between the two models is that probit is based on cumulative normal distribution and uses the probit transformation of the predicted scores, based on the assumption that the outcome reflects underlying quantitative variable. On the other hand, logit is based on a binominal distribution and the log transformation of the predicted scores, which are logit's reflection of an underlying qualitative variable. 
This study chooses to use probit over logit models due to the concerns over sample sizes. As long as the sample sizes are large, probit and logit models eventually produce very similar results. However, since this study's sample sizes for minorities are limited, probit analysis is preferred (Long, 1997; Long \& Freese, 2006).

To better present Step 3 analysis, equations are illustrated. Equation (1) shows the basic model for this study. The model assumes that $z$ is linearly related to the predictors, where $\alpha$ is a constant, $\beta$ is a coefficient, $x$ is the predictors, and $i$ is the nine factors of interest and the seven control variables.

$$
z=\alpha_{0}+\beta_{i} x_{i}
$$

Equations (2), (3), and (4) show how the analytic model is applied to three different racial/ethnic groups; equation (2) is the basic model applied to the White group, equation (3) to the Black group, and equation (4) to the Latino group.

$$
\begin{gathered}
z_{\text {White }}=\alpha_{\text {White }}+\beta_{i, \text { White }} x_{i} \\
z_{\text {Black }}=\alpha_{\text {Black }}+\beta_{\text {i,Black }} x_{i} \\
z_{\text {Latino }}=\alpha_{\text {Latino }}+\beta_{\text {i,Latino }} x_{i}
\end{gathered}
$$

From the three sets of results from Step 3, this study compared three points: 1) the significance of each factor, and, if significant, 2) the direction of the relationship between the factor and the outcome, and 3) the magnitude of the relationship. 


\section{Step 3-2: Comparing magnitude of significant factors across races}

To compare the magnitude of significant factors across racial groups, this study used Wald chi-square statistics (Allison, 1999) for testing the difference between coefficients across racial groups. This is the common way of comparing the magnitude of factors in probit models. The formula for this statistics is in Equation (5), where $b_{\mathrm{m}}$ is the coefficient for one group of race,

$b_{w}$ is the coefficient for another race group, and s.e. is the standard error. Each statistics has one degree of freedom.

$$
\chi^{2}=\frac{\left(b_{m}-b_{w}\right)^{2}}{\left[\text { s.e. }\left(b_{m}\right)\right]^{2}+\left[\text { s.e. }\left(b_{w}\right)\right]^{2}}
$$




\section{RESULTS}

\section{A. DESCRIPTIVE ANALYSIS RESULTS}

\section{Descriptive Analysis of the Data}

Descriptive results are available in Table 2. Among the total sample of 1,114 for this study, Whites comprised 874 (78\%), Blacks 155 (14\%), and Latinos 85 (8\%). Among workers who were working either full- or part-time in 2004, 702 (63\%) retired, and 412 (37\%) still remained in the labor market in 2008.

The variables of interest were comprised of financial factors, health, career patterns, and education. Financial factors were: 1) Social Security eligibility, 2) employer-sponsored pension eligibility, 3) total wealth, 4) total household income, and 5) home ownership. Almost all of the participants were eligible to receive Social Security benefits. Only 11 participants (1\%) were not eligible for Social Security benefits. On the other hand, the portion of people not eligible for employer-sponsored pension was relatively higher than that for Social Security. There were 228 (21\%) who were not eligible to receive any type of pension. The average total wealth was $\$ 387,000$ with a very large standard deviation of $\$ 2,419,000$, indicating this variable distributed nonnormally. While the minimum wealth was $-\$ 106,000$ (of debt), the maximum wealth was $\$ 74,300,000$. The average household income was $\$ 87,000$, ranging from $\$ 0$ to $\$ 2,876,000$. Also, there were $118(12 \%)$ individuals who did not own their home in their 60s.

The average health was 3.52 out of 5 as excellent, reflecting the relatively good health of the samples $(S D=.95, \min =1, \max =5)$. 
Career patterns include career stability and job types that the workers have had throughout their working lives. The average stability (average years of working at the same workplace) was 20.17 years $(S D=10.47, \min =.20, \max =47.60)$. The number of workers having blue-color jobs was $400(36 \%)$, meaning that more than half of the workers aged 65 or over had white-color jobs.

The mean of education was 13.08 years, demonstrating just above a high school education $(S D=2.90, \min =0, \max =17)$.

The control variables of this study include 1) attributes of preretirement work, 2) meanings of work, 3) dependents and 4) demographics. In terms of the attributes of preretirement work, participants reported an average of 2.57 job stress $(S D=.82)$, distributing from the minimum 0 to the maximum 4. Also, the mean of employers' attitudes toward older workers was $6.25(S D=1.32)$, ranging from min 3 to max 17 . The average meaning of work was $2.83(S D=$ .78 ), ranging from min 1 to $\max 4$. The average number of dependents was $0.20(S D=.66)$, ranging from 0 to 6 . In regard to demographics, the average age for the samples was 62.56 years old $(S D=1.10, \min =61, \max =64)$ in 2004 . The gender distribution was exactly half and half, meaning that older females were actively participating in the labor market as much as older male workers. Three out of four samples $(75 \%)$ were married. 
Table 2. Descriptive analysis results before imputation

$N=1,114)$

\begin{tabular}{|c|c|c|c|c|c|c|c|}
\hline \multicolumn{3}{|l|}{ Variables } & \multirow{2}{*}{$\frac{n(\%)}{874(78)}$} & \multirow[t]{2}{*}{$M$} & \multirow[t]{2}{*}{$S D$} & \multirow[t]{2}{*}{ Min } & \multirow[t]{2}{*}{$\operatorname{Max}$} \\
\hline & & Whites & & & & & \\
\hline & Race & Blacks & $155(14)$ & & & & \\
\hline & & Latinos & $85(8)$ & & & & \\
\hline \multirow{2}{*}{ Outcome } & \multirow{2}{*}{ Work status } & Not working & $412(37)$ & & & & \\
\hline & & Working & $702(63)$ & & & & \\
\hline \multirow{8}{*}{$\begin{array}{l}\text { Variables } \\
\text { of interest }\end{array}$} & \multirow{5}{*}{ Financial factors } & Social Security (no) & $11(1)$ & & & & \\
\hline & & Pension (no) & $228(20)$ & & & & \\
\hline & & Wealth (k) & & 387 & 2419 & -106 & 74300 \\
\hline & & HH income $(\mathrm{k})$ & & 87 & 149 & 0 & 2876 \\
\hline & & Home (no) & $118(12)$ & & & & \\
\hline & Health & & & 3.52 & .945 & 1 & 5 \\
\hline & Career patterns & $\begin{array}{l}\text { Stability } \\
\text { Job type (blue) }\end{array}$ & $400(36)$ & 20.17 & 10.47 & .20 & 47.60 \\
\hline & Education & & & 13.08 & 2.90 & 0 & 17 \\
\hline \multirow{7}{*}{$\begin{array}{l}\text { Control } \\
\text { variables }\end{array}$} & \multirow{2}{*}{$\begin{array}{l}\text { Attributes of } \\
\text { preretirement work }\end{array}$} & Job stress & & 2.57 & .821 & 1 & 4 \\
\hline & & Employers' attitudes & & 6.25 & 1.32 & 3 & 12 \\
\hline & Meaning of work & & & 2.83 & .77 & 1 & 4 \\
\hline & Dependents & & & 0.20 & 0.66 & 0 & 6 \\
\hline & \multirow[t]{3}{*}{ Demographics } & Age & & 62.56 & 1.10 & 61 & 64 \\
\hline & & Gender (male) & $551(49)$ & & & & \\
\hline & & Marital (yes) & $815(73)$ & & & & \\
\hline
\end{tabular}




\section{Racial Comparison}

Table 3 breaks down the descriptive results by race. Among individuals who worked either full- or part-time in 2004, $63.3 \%$ of Whites still remained in the labor market in 2008, as compared with $58.1 \%$ of Blacks and $69.4 \%$ of Latinos, which were not statistical differences.

There were stark differences by race in all of the variables of interest, however. In terms of financial factors, the proportion of individuals who were not eligible to receive pensions was almost two times higher for Latinos (38.8\%) compared to Whites (19.3\%) and Blacks (16.8\%), which were statistically significant: $\chi^{2}(2, N=1114)=19.58, p=.000$. Also, the amount of total wealth that Whites accumulated $(M=\$ 464,000, S D=2,676,000)$ was almost four times higher than that of Blacks $(M=\$ 169,000, S D=1,232,000)$ and seven times than that of Latinos $(M=$ $\$ 85,000, S D=254,000), F(2,1031)=70.35, p=.000$. The post hoc test, however, showed no statistical difference between Blacks and Latinos. The average total household income for Whites $(M=\$ 96,000, S D=166,000)$ was significantly higher than that for Blacks $(M=\$ 56,000$, $S D=39,000)$ and Latinos $(M=\$ 47,000, S D=46,000), F(2,1031)=8.287, p=.000$. The proportions of individuals who did not own their house in their 60 s were $10.4 \%$ for Whites, $13.2 \%$ for Blacks, and $22.1 \%$ for Latinos, which were statistically significant, $\chi^{2}(2, N=1007)=$ $9.58, p=.008$.

As for health, the average health for Whites (3.6) was significantly higher than that for Blacks (3.2) and Latinos (3.1), $F(2,1113)=26.68, p=.000$. However, there was no difference between Blacks' and Latinos' health.

Career patterns also showed racial disparity. The average employment stability was 20.1 years for Whites, 21.9 years for Blacks, and 18.3 years for Latinos, which were statistically 
significant, $F(2,1111)=3.35, p=.040$. The post-hoc analysis showed that while the BlackWhite difference was not significant, the Black-Latino difference was. This means that older Latino workers usually have less stable career histories than Blacks.

Furthermore, the percentages of individuals having blue-collar jobs were almost two times higher for Blacks $(56.8 \%)$ and Latinos $(67.9 \%)$ compared to Whites $(30.6 \%), \chi^{2}(2, N=$ $1078)=73.80, p=.000$.

Education levels also exhibited noticeable racial differences. The average years of education were 13.5 years for Whites, 12.4 years for Blacks, and 9.6 years for Latinos, $F(2,1108)$ $=86.36, p=.000$. The Black-White difference in education, significant according to a post-hoc analysis, might look minor, but in fact, is meaningful; older White workers on average had college education, while older Black workers on average had high school education. Furthermore, older Latino workers showed substantially lower education (even no high school diploma), which was significantly lower than for Whites and even Blacks.

The average scores of employers' attitudes toward older workers were 6.27 for Whites, 6.39 for Blacks, and 5.80 for Latinos, which were statistically significant, $F(2,708)=4.18, p$ $=.020$. Interestingly, there were no statistical differences in job stress and meaning of work. Also, the number of dependents showed racial differences, albeit minor ones. That number was significantly lower for Whites $(0.16)$ compared to Blacks $(0.39), F(2,474.04)=8.90, p=.000$.

Demographics also showed racial differences, albeit minor ones. The percentage of male workers was much higher for Latinos $(63.5 \%)$ compared to Whites $(49.9 \%)$ and Blacks (39.4\%), $\chi^{2}(2, N=1114)=13.13, p=.001$. Also, the percentage of individuals who were not 
married was $25.1 \%$ for Whites, $38.7 \%$ for Blacks, and $23.5 \%$ for Latinos, which was statistically significant, $\chi^{2}(2, N=1114)=13.10, p=.001$. 
Table 3. Racial comparison before imputation

$(\mathrm{N}=1114)$

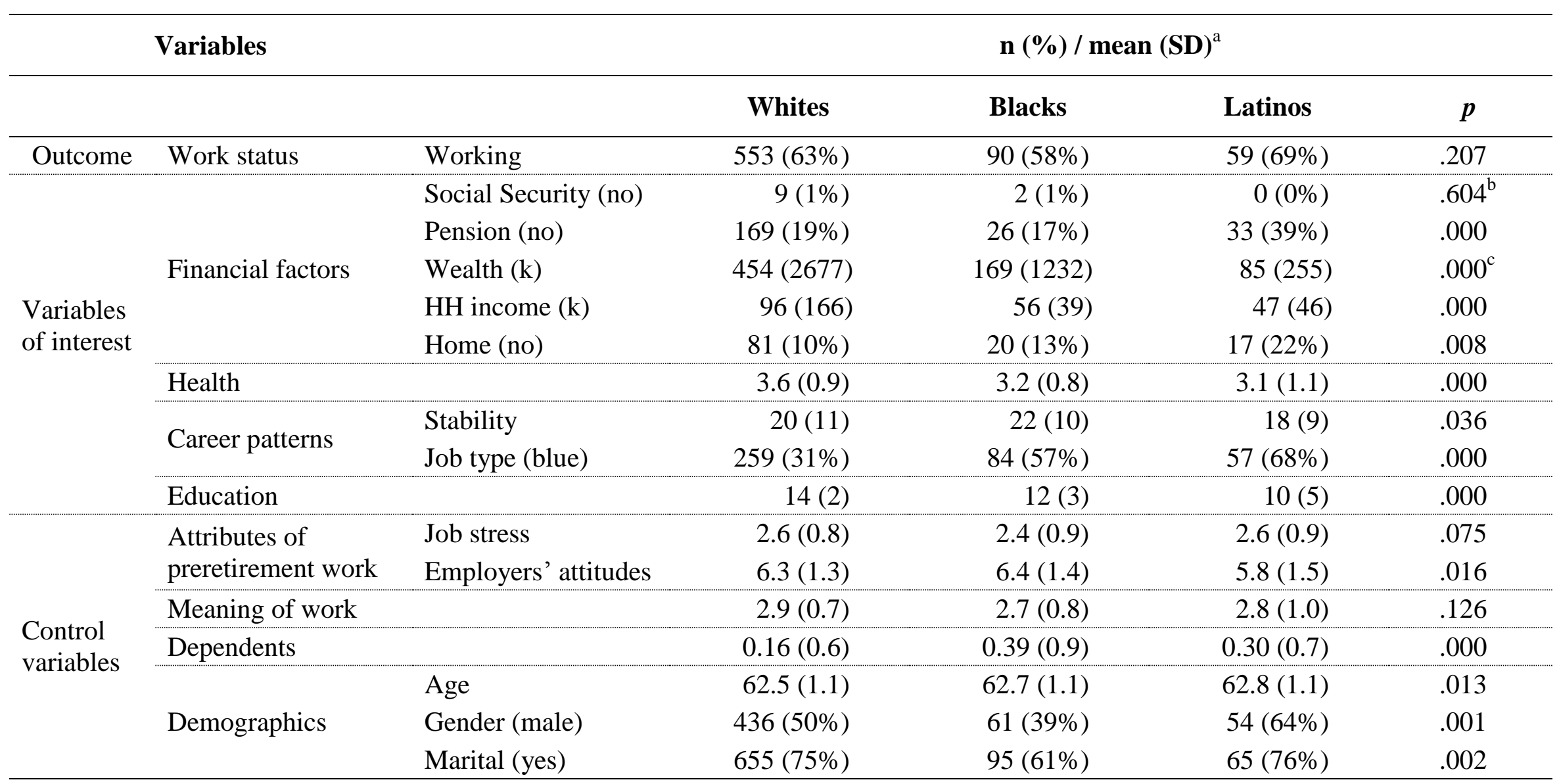

a. Chi-square analysis was conducted for the categorical variables of interest, and ANOVA was run for the continuous variables of interest. Post-hoc analysis was followed only for ANOVA analysis that was significant.

b. Chi-square analysis was not conducted because some frequencies for the "no" category in the analysis were smaller than 5, which violates the assumption of chi-square analysis

c. This ANOVA test was performed on the log-transformed wealth and income variables due to the seriously non-normality of the original wealth variable. 


\section{B. Missing Value imputation Results}

\section{Step 2-1 Results: Checking Missing Values}

Table 4 shows the frequencies of missing values among the 17 study variables. There were ten variables that do not have any missing values: race, work status, Social Security eligibility, pension eligibility, total wealth, total household income, health, age, gender, and marital status. Also, there were six variables that have a fairly small portion of missing values, which are less likely to impact the estimation of analysis results. That is, job stability had only $0.2 \%$ of missing values, $3.2 \%$ of job type, $0.4 \%$ of education, $4.8 \%$ of job stress, $9.6 \%$ of home ownership, and $0.7 \%$ of dependents. Yet, there were two variables that had significant portions of missing values; meaning of work (30.2\%), and employers' attitudes toward older workers (36.4\%). Without treating these missing values appropriately, estimates may be biased. The

following section reports the missing patterns of these two variables with large portions of missing values. 
Table 4. Missing data information

\begin{tabular}{|c|c|c|c|c|c|}
\hline & \multirow{2}{*}{\multicolumn{2}{|c|}{ Variables }} & \multirow{2}{*}{ Frequency } & \multicolumn{2}{|c|}{ Missing } \\
\hline & & & & Count & Percent (\%) \\
\hline & Race & & 1114 & 0 & 0 \\
\hline Outcome & Work status & & 1114 & 0 & 0 \\
\hline \multirow{9}{*}{$\begin{array}{l}\text { Variables } \\
\text { of interest }\end{array}$} & \multirow{5}{*}{$\begin{array}{l}\text { Financial } \\
\text { factors }\end{array}$} & Social Security & 1114 & 0 & 0 \\
\hline & & Pension & 1114 & 0 & 0 \\
\hline & & Total wealth & 1114 & 0 & 0 \\
\hline & & HH income & 1114 & 0 & 0 \\
\hline & & Home & 1007 & 107 & 9.6 \\
\hline & Health & & 1114 & 0 & 0 \\
\hline & \multirow{2}{*}{ Career patterns } & Stability & 1112 & 2 & .2 \\
\hline & & Job type & 1078 & 36 & 3.2 \\
\hline & Education & & 1109 & 5 & .5 \\
\hline \multirow{7}{*}{$\begin{array}{c}\text { Control } \\
\text { variables }\end{array}$} & \multirow{2}{*}{$\begin{array}{l}\text { Attributes of } \\
\text { preretirement } \\
\text { work }\end{array}$} & Job stress & 1060 & 54 & 4.9 \\
\hline & & $\begin{array}{l}\text { Employers' } \\
\text { attitudes }\end{array}$ & 709 & 405 & 36.4 \\
\hline & $\begin{array}{l}\text { Meaning of } \\
\text { work }\end{array}$ & & 778 & 336 & 30.2 \\
\hline & Dependents & & 1106 & 8 & 0.7 \\
\hline & \multirow{3}{*}{ Demographics } & Age & 1114 & 0 & 0 \\
\hline & & Gender & 1114 & 0 & 0 \\
\hline & & Marital status & 1114 & 0 & 0 \\
\hline
\end{tabular}




\section{Step 2-2 Results: Checking Missing Patterns}

Step 1-2 examined whether variables with a relatively large portion of missing values are independent of the key variables (the outcome and race) and other analysis variables. Table 5 shows that there were no statistically significant differences in the patterns of the missing values between meaning of work and the outcome (work status), $\chi^{2}(1, N=1114)=1.927, p=.17$. Similarly, the missing values of employers' attitudes were independent of work status, $\chi^{2}(1, N=$ $1114)=1.285, p=.26$. These results imply that whether HRS participants responded to or missed questions, their perception of work and employers' attitudes toward older workers are independent of their work status. Thus, it is evidenced that meaning of work and employers' attitudes are either MCAR or MAR.

In addition to the outcome, since race is another vital variable of this study, the patterns of missing values for the two variables - meaning of work and employers' attitudes toward older workers - were tested to determine their independence of race. As Table 5 shows, there were no statistically significant differences in the patterns of missing values for these two variables by race. The three racial groups showed similar response and missing rates, $\chi^{2}(2, N=1114)=$ $2.468, p=.29$. Thus, the missing patterns of the two variables did not appear to be affected by the respondents' race, $\chi^{2}(2, N=1114)=2.973, p=.23$. Again, these lines of results indicate that the patterns of the missing values for the two variables are MCAR either MAR. 
Table 5. Checking independence of patterns of missing for work status and race

\begin{tabular}{|c|c|c|c|c|c|c|c|}
\hline & & \multicolumn{2}{|c|}{ Work status (DV) } & \multicolumn{3}{|c|}{ Race } & \multirow{2}{*}{ Total } \\
\hline & & Retired & Working & White & Black & Latino & \\
\hline \multirow{4}{*}{$\begin{array}{l}\text { Meaning of } \\
\text { work }\end{array}$} & Non missing & $\begin{array}{c}298 \\
(38.3 \%)\end{array}$ & $\begin{array}{c}480 \\
(61.7 \%)\end{array}$ & $\begin{array}{c}601 \\
(77.3 \%)\end{array}$ & $\begin{array}{c}116 \\
(14.9 \%)\end{array}$ & $\begin{array}{c}61 \\
(7.84 \%)\end{array}$ & $\begin{array}{c}778 \\
(100 \%)\end{array}$ \\
\hline & Missing & $\begin{array}{c}114 \\
(33.9 \%)\end{array}$ & $\begin{array}{c}222 \\
(66.1 \%)\end{array}$ & $\begin{array}{c}273 \\
(81.3 \%)\end{array}$ & $\begin{array}{c}39 \\
(11.6 \%)\end{array}$ & $\begin{array}{c}24 \\
(7.1 \%)\end{array}$ & $\begin{array}{c}336 \\
(100 \%)\end{array}$ \\
\hline & Total & $\begin{array}{c}412 \\
(37.0 \%)\end{array}$ & $\begin{array}{c}702 \\
(63.0 \%)\end{array}$ & $\begin{array}{c}874 \\
(78.5 \%)\end{array}$ & $\begin{array}{c}155 \\
(13.9 \%)\end{array}$ & $\begin{array}{c}85 \\
(7.6 \%)\end{array}$ & $1114(100 \%)$ \\
\hline & Test & \multicolumn{3}{|c|}{$\chi^{2}(1, N=1114)=1.927, p=.17$} & \multicolumn{3}{|c|}{$\chi^{2}(2, N=1114)=2.973, p=.26$} \\
\hline \multirow{4}{*}{$\begin{array}{l}\text { Employer's } \\
\text { attitudes }\end{array}$} & Non missing & $\begin{array}{c}217 \\
(38.2 \%)\end{array}$ & $\begin{array}{c}438 \\
(61.8 \%)\end{array}$ & $\begin{array}{c}545 \\
(76.9 \%)\end{array}$ & $\begin{array}{c}105 \\
(14.8 \%)\end{array}$ & $\begin{array}{c}59 \\
(8.3 \%)\end{array}$ & $\begin{array}{c}709 \\
(100 \%)\end{array}$ \\
\hline & Missing & $\begin{array}{c}141 \\
(34.8 \%)\end{array}$ & $\begin{array}{c}264 \\
(65.2 \%)\end{array}$ & $\begin{array}{c}329 \\
(81.2 \%)\end{array}$ & $\begin{array}{c}50 \\
(12.4 \%)\end{array}$ & $\begin{array}{c}26 \\
(6.4 \%)\end{array}$ & $\begin{array}{c}405 \\
(100 \%)\end{array}$ \\
\hline & Total & $\begin{array}{c}412 \\
(37.0 \%)\end{array}$ & $\begin{array}{c}702 \\
(63.0 \%)\end{array}$ & $\begin{array}{c}874 \\
(78.5 \%)\end{array}$ & $\begin{array}{c}155 \\
(13.9 \%)\end{array}$ & $\begin{array}{c}85 \\
(7.6 \%)\end{array}$ & $\begin{array}{c}1114 \\
(100 \%)\end{array}$ \\
\hline & Test & \multicolumn{3}{|c|}{$\chi^{2}(2, N=1114)=2.468, p=.29$} & \multicolumn{3}{|c|}{$\chi^{2}(2, N=1114)=2.973, p=.23$} \\
\hline
\end{tabular}


To double check whether it is adequate to perform missing imputation for the study data, their missing patterns were compared between the two variables with large missing values and other study variable (Table 6). Results showed that the pattern of the missing values for meaning of work was significantly related to career stability, $t(1110)=4.06, p<.001$, and age, $t(1112)=$ $15.17, p<.001$. This means that younger HRS participants $(M=61.86, S D=1.00)$ showed more missing values for the question of the meaning of work than their older counterparts $(M=62.86$, $S D=1.01)$. Also, those with shorter career stability $(M=18.24, S D=11.03)$ showed higher missing values than those with longer career stability $(M=21.00, S D=18.24)$.

The missing pattern of employers' attitudes toward older workers appears to be influenced by two covariates: pension eligibility and gender. The percentage of those who were eligible for pensions $(86.3 \%)$ was significantly higher among those who answered this attitude question than the percentage $(67.7 \%)$ among those who missed the question, $\chi^{2}(1, N=1114)=$ 55.163, $p=.000$. Furthermore, the percentage of females (57.3\%) was slightly lower among those who responded to the attitude question than among those who missed the question (61.2\%), $\chi^{2}(1, N=1114)=35.285, p=.000$. Finally, more missing values were found among the married $(22.2 \%)$ than the unmarried $(77.8 \%), \chi^{2}(1, N=1114)=6.911, p=.009$.

These lines of results give a sense of how close the data are to also how deviated from MCAR; therefore, it is concluded that the data are either MCAR or MAR, which is the case for using multiple imputation as opposed to complete care analysis (Social Science Computer Cooperative, 2013).

In summary, among the 17 analysis variables for this study, only two variables - meaning of work and employers' attitudes toward older workers-were found to have a significant 
portion of missing values, which might distort the analysis results. The missing pattern analyses showed that the missing values of these two variables were independent of the two main variables of this study-work status (outcome) and race. Also, these two variables were relatively close to MCAR, given the comparison between these two and other study variables. These results signal that the missing patterns of the two variables were identified as MAR. Thus, this study's data satisfy the assumption of performing imputation methods. As for the next step, this study imputed the data using multiple imputation techniques to produce the complete data. 
Table 6. Comparing the missing patterns of meaning of work with other covariates

\begin{tabular}{|c|c|c|c|c|c|c|c|}
\hline & \multirow{4}{*}{ Covariates } & \multicolumn{6}{|c|}{ Missing patterns $^{a}$} \\
\hline & & \multicolumn{6}{|c|}{$p^{b}$} \\
\hline & & \multicolumn{3}{|c|}{ Meaning of work } & \multicolumn{3}{|c|}{ Employer's attitudes } \\
\hline & & $t / \chi^{2}$ & $\mathrm{df}$ & $p$ & $t / \chi^{2}$ & $\mathrm{df}$ & $p$ \\
\hline \multirow{5}{*}{ Financial factors } & Social Security & 1.23 & 1 & .267 & .00 & 1 & 999 \\
\hline & Pension & .70 & 1 & .397 & 55.16 & 1 & $.000^{* * *}$ \\
\hline & Total wealth & -1.27 & 346.09 & .207 & -1.06 & 1029.6 & .289 \\
\hline & $\mathrm{HH}$ income & -1.45 & 452.22 & .078 & 4.56 & 1112 & .152 \\
\hline & Home ownership & .426 & 1 & .514 & 3.36 & 1 & .067 \\
\hline Health & & -0.94 & 1112 & .345 & .01 & 1112 & .993 \\
\hline \multirow{2}{*}{ Career patterns } & Stability & 4.06 & 1110 & $.000^{* * * * *}$ & -1.47 & 1110 & .143 \\
\hline & Job type & .003 & 1 & .960 & 3.45 & 1 & .063 \\
\hline Education & & -1.13 & 1107 & .258 & 1.34 & 752.74 & .179 \\
\hline $\begin{array}{l}\text { Attributes of } \\
\text { preretirement work }\end{array}$ & Job stress & -0.12 & 1058 & .904 & 1.38 & 1058 & .168 \\
\hline Dependents & & -0.22 & 587.4 & .829 & 0.90 & 951.7 & .366 \\
\hline \multirow{3}{*}{ Demographics } & Age & 15.17 & 1112 & $.000^{* * * *}$ & -1.54 & 1112 & .124 \\
\hline & Gender & .79 & 1 & .374 & 35.29 & 1 & $.000^{* * *}$ \\
\hline & Marital status & 2.09 & 1 & .148 & 6.91 & 1 & $.009^{* *}$ \\
\hline
\end{tabular}

a. Like the results from Table 4 and Table 5, meaning of work was recoded into either missing (0) or not missing (1).

b. Chi-square analyses were performed for categorical covariates, and $t$ tests were performed for continuous covariates.

$* p<.05, * * p<.01, * * * p<.001$ 


\section{Step 2-3 Results: Imputing Data}

Table 7 compares the descriptive statistics of the data before and after imputations. After 50 imputations, the original sample size of 1,114 increased to 55,700. The imputed data showed almost identical characteristics in descriptive statistics in terms of their frequencies, percentages, means, standard deviations, minimums and maximums ${ }^{32}$.

The five variables in the original data with minor portions of missing values (education, job stability, job stress, home ownership, job type, and dependents) showed almost identical descriptive characteristics before and after imputation. Yet, job type and education showed slightly different distributions. The percentage of blue-collar workers is $36 \%$ in the original data, while that in the imputed is $37 \%$, a negligible difference. Also, the maximum education increased from 16 years in the original to 20 years in the imputed data.

Most importantly, the two variables with significant portions of missing valuesmeaning of work and employers' attitudes toward older workers - were imputed satisfactorily, retaining the characteristics in the original data. The descriptive characteristics of meaning of work $(M=2.83, S D=.773, \min =1, \max =4)$ were retained in the imputed data $(M=2.85, S D=$ $.764, \min =1, \max =4)$. Also, as for employers' attitudes toward older workers, the descriptive characteristics before $(M=6.25, S D=10318, \min =3, \max =12)$ and after $(M=6.24, S D=$ 1.325, $\min =3, \max =12$ ) were almost the same. In conclusion, the multiple imputation was performed adequately, filling in the missing values while keeping the characteristics of the original data. Using this imputed data, probit analyses were followed.

\footnotetext{
${ }^{32}$ The 10 variables in the original data (race, work status, Social Security eligibility, pension eligibility, total wealth, total household income, health, age, gender, and marital status) were not imputed because they do not have any missing values.
} 
Table 7. Comparing descriptive statistics before and after imputation

\begin{tabular}{|c|c|c|c|c|c|c|c|c|c|c|c|}
\hline & & \multicolumn{5}{|c|}{$\begin{array}{c}\text { Original Data } \\
(\mathrm{N}=1114)\end{array}$} & \multicolumn{5}{|c|}{$\begin{array}{c}\text { Imputed Data } \\
(\mathbf{N}=\mathbf{5 5}, 700)\end{array}$} \\
\hline & & n $(\%)$ & $\mathbf{M}$ & SD & Min & Max & n $(\%)$ & $\mathbf{M}$ & SD & Min & Max \\
\hline \multirow{3}{*}{ Race } & Whites & $874(78)$ & & & & & $43700(78)$ & & & & \\
\hline & Blacks & $155(14)$ & & & & & $7750(14)$ & & & & \\
\hline & Latinos & $85(7)$ & & & & & $4250(7)$ & & & & \\
\hline \multirow{2}{*}{ Work status } & Not working & $412(37)$ & & & & & $20600(37)$ & & & & \\
\hline & Working & $702(63)$ & & & & & $35100(63)$ & & & & \\
\hline \multirow{5}{*}{$\begin{array}{l}\text { Financial } \\
\text { factors }\end{array}$} & Social Security (no) & $11(1)$ & & & & & $550(1)$ & & & & \\
\hline & Pension (no) & $228(20)$ & & & & & $11400(20)$ & & & & \\
\hline & Wealth (k) & & 387 & 2419 & -106 & 74300 & & 387 & 2419 & -106 & 74300 \\
\hline & HH income (k) & & 87 & 149 & 0 & 2876 & & 87 & 149 & 0 & 2876 \\
\hline & Home (no) & $118(11)$ & & & & & $6603(12)$ & & & & \\
\hline Health & & & 3.52 & .945 & 1 & 5 & & 3.52 & .945 & 1 & 5 \\
\hline $\begin{array}{l}\text { Career } \\
\text { patterns }\end{array}$ & $\begin{array}{l}\text { Stability } \\
\text { Job type (blue) }\end{array}$ & $400(36)$ & 20.17 & 10.470 & .20 & 47.60 & $20665(37)$ & 20.17 & 10.463 & .20 & 47.60 \\
\hline Education & & & 13.08 & 2.896 & 0 & 17 & & 13.07 & 2.898 & 0 & 21 \\
\hline \multirow{2}{*}{$\begin{array}{l}\text { Attributes } \\
\text { of } \\
\text { preretireme } \\
\text { nt work }\end{array}$} & Job stress & & 2.57 & 0.821 & 1 & 4 & & 2.57 & 0.821 & 1 & 4 \\
\hline & Employer's attitudes & & 6.25 & 1.318 & 3 & 12 & & 6.24 & 1.325 & 3 & 12 \\
\hline $\begin{array}{l}\text { Meaning of } \\
\text { work }\end{array}$ & & & 2.83 & 0.773 & 1 & 4 & & 2.85 & 0.764 & 1 & 4 \\
\hline Dependents & & & 0.20 & 0.655 & 0 & 6 & & .20 & 654 & 0 & 6 \\
\hline \multirow{3}{*}{$\begin{array}{l}\text { Demograph } \\
\text { ics }\end{array}$} & Age & & 62.56 & 1.102 & 61 & 64 & & 62.56 & 1.102 & 61 & 64 \\
\hline & Gender (male) & $551(50)$ & & & & & $27550(49)$ & & & & \\
\hline & Marital (yes) & $815(73)$ & & & & & $40750(73)$ & & & & \\
\hline
\end{tabular}




\section{Probit Analysis Results}

\section{Step 3-1: Comparing significant factors across races ${ }^{33}$}

Table 8 shows probit analysis results ${ }^{34}$ by 1) all races, 2) Whites, 3) Blacks, and 4) Latinos. First, for all races, the factors significant at $\mathrm{p}<.05$ were found to be health, meaning of work, age, and Latinos (compared to Whites). In other words, those workers staying in the labor market after retirement age were those who had better health $(\beta=.210, S E=.045, p=.000)$, valued working more highly $(\beta=.153, S E=.060, p=.010)$, aged relatively younger $(\beta=-.081$, $S E=.036, p=.025)$, and were Whites $(\beta=-.170, S E=.083, p=.042)$.

For Whites, three variables were found to be significant: health, meaning of work, and age. In other words, among Whites, those who were more likely to stay in the labor market in 2008 were those who had better health $(\beta=.207, S E=.050, p=.000)$, valued working more highly $(\beta=.196, S E=.071, p=.006)$, and were relatively younger $(\beta=-.106, S E=.041, p$ $=.010)$.

Unlike Whites, Blacks showed one significant variable. Black workers who owned their own house before retirement age were more likely to stay in the labor market after retirement age $(\beta=.390, S E=.172, p=.023)$.

Latinos showed only one significant factor, health. Those Latinos workers who had better health tended to continue working after retirement age $(\beta=.421, S E=.192, p=.029)$.

\footnotetext{
${ }^{33}$ Social Security was not included in the probit analysis due to its extremely uneven distribution. For all racial groups, those who were not eligible for Social Security were less than $1 \%$.

${ }^{34}$ See Appendix 8 for using alternative outcome (work status) measurement - a three level outcome (retired, parttime, and full-time).
} 
Table 8 . Probit analysis results by race

\begin{tabular}{|c|c|c|c|c|c|c|c|c|}
\hline \multirow{2}{*}{ Factors } & \multicolumn{2}{|c|}{ All races } & \multicolumn{2}{|c|}{ Whites } & \multicolumn{2}{|c|}{ Blacks } & \multicolumn{2}{|c|}{ Latinos } \\
\hline & $\beta$ & $S E$ & $\boldsymbol{\beta}$ & $S E$ & $\boldsymbol{\beta}$ & $S E$ & $\boldsymbol{\beta}$ & $S E$ \\
\hline Constant & 4.768 & 2.328 & 5.905 & 2.666 & -0.300 & 6.471 & 4.404 & 10.212 \\
\hline \multicolumn{9}{|l|}{ Factors of Interest } \\
\hline \multicolumn{9}{|l|}{ Financial Factors } \\
\hline Employer-sponsored pensions & 0.059 & 0.052 & 0.071 & 0.059 & -0.036 & 0.162 & 0.039 & 0.181 \\
\hline Wealth $(\$ 10,000)$ & 0.001 & 0.001 & 0.001 & 0.001 & 0.016 & 0.010 & 0.012 & 0.012 \\
\hline $\mathrm{HH}$ income $(\$ 10,000)$ & 0.009 & 0.006 & 0.008 & 0.006 & 0.007 & 0.036 & 0.085 & 0.071 \\
\hline Home ownership & 0.056 & 0.066 & 0.040 & 0.082 & 0.390 & $0.172 *$ & 0.160 & 0.217 \\
\hline Health & 0.210 & $0.045 * * *$ & 0.207 & $0.050 * * *$ & 0.194 & 0.146 & 0.421 & $0.192 *$ \\
\hline \multicolumn{9}{|l|}{ Career Patterns } \\
\hline Employment stability & -0.002 & 0.004 & 0.000 & 0.004 & -0.011 & 0.012 & 0.001 & 0.020 \\
\hline Occupation types & -0.006 & 0.050 & -0.044 & 0.057 & 0.033 & 0.147 & 0.165 & 0.222 \\
\hline Education & -0.001 & 0.018 & 0.004 & 0.022 & 0.019 & 0.052 & -0.090 & 0.059 \\
\hline \multicolumn{9}{|l|}{ Control Factors } \\
\hline \multicolumn{9}{|l|}{ Attributes of Preretirement work } \\
\hline Job stress & -0.003 & 0.051 & 0.010 & 0.058 & -0.159 & 0.144 & -0.116 & 0.205 \\
\hline Employer's attitude toward older workers & -0.062 & 0.037 & -0.058 & 0.043 & -0.023 & 0.102 & -0.260 & 0.151 \\
\hline Meaning of Work & 0.153 & $0.060^{*}$ & 0.196 & $0.071 * *$ & 0.106 & 0.156 & -0.284 & 0.238 \\
\hline Dependents (\#) & 0.015 & 0.061 & 0.048 & 0.079 & -0.147 & 0.116 & 0.347 & 0.296 \\
\hline \multicolumn{9}{|l|}{ Demography } \\
\hline Age & -0.081 & $0.036^{*}$ & -0.106 & $0.041 *$ & -0.003 & 0.102 & -0.036 & 0.159 \\
\hline Gender & 0.043 & 0.044 & 0.019 & 0.051 & 0.064 & 0.125 & 0.188 & 0.198 \\
\hline Marital status & 0.033 & 0.050 & 0.002 & 0.058 & 0.149 & 0.136 & -0.078 & 0.207 \\
\hline Blacks & -0.022 & 0.059 & - & - & - & - & - & - \\
\hline Latinos & -0.170 & $0.083 *$ & - & - & - & - & - & - \\
\hline$N$ & \multicolumn{2}{|c|}{1114} & \multicolumn{2}{|c|}{874} & \multicolumn{2}{|c|}{155} & \multicolumn{2}{|c|}{85} \\
\hline Mean $(\min -\max )$ & \multicolumn{2}{|c|}{$.077(.067-.096)$} & \multicolumn{2}{|c|}{$.085(.073-.111)$} & \multicolumn{2}{|c|}{$.204(.186-.223)$} & \multicolumn{2}{|c|}{$.245(.164-.362)$} \\
\hline
\end{tabular}

Note: $* p<.05 ; * * p<.01 ; * * * p<.001$ 


\section{Step 3-2: Comparing magnitude of significant factors across races}

As a post-probit analysis, the magnitude of health between Whites and Latinos were compared, as shown in Equation (6) and (7), given that health was the only variable that overlaps across races and that both race groups show a positive relationship between health and the likelihood of working. The Wald Chi-square statistics for testing the difference between the coefficients for health between Whites and Latinos were calculated.

$$
\begin{gathered}
\chi^{2}=\frac{\left(b_{\text {Whites }}-b_{\text {Latinos }}\right)^{2}}{\left[\text { s.e. }\left(b_{\text {Whites }}\right)\right]^{2}+\left[\text { s.e. }\left(b_{\text {Latinos }}\right)\right]^{2}} \\
\chi^{2}=\frac{(.207-.421)^{2}}{[(.050)]^{2}+[(.192)]^{2}}=1.163
\end{gathered}
$$

The p-value with 1 degree of freedom was .281. Thus, there was no significant difference between the effect of health on Whites and Latinos' probability of working after retirement age. 


\section{Summary of Results}

This chapter presented study results examining whether there are racial differences in the factors that significantly influence workers' labor market participation after retirement age. As expected, after adjusting for all covariates, significant factors differed across the three racial groups, which supported $\mathrm{H}_{1}$.

The influence of homeownership differed by race, supporting $\mathrm{H}_{6}$; homeownership was a significant determinant to Blacks, but not to Whites and Latinos. Those Blacks who owned their own house were more likely to continue working after retirement age.

Health was a significant determinant to Whites and Latinos, but not to Blacks, supporting $\mathrm{H}_{7}$. In addition, the post probit analysis showed that the direction and magnitude of the relationship between health and the probability of working after retirement age were not statistically different between Whites and Latinos.

On the other hand, regardless of race, pensions $\left(\mathrm{H}_{3}\right)$, wealth $\left(\mathrm{H}_{4}\right)$, household income $\left(\mathrm{H}_{5}\right)^{35}$, employment stability $\left(\mathrm{H}_{8}\right)$, job types $\left(\mathrm{H}_{9}\right)$, and education $\left(\mathrm{H}_{10}\right)$ did not significantly influence workers' labor market participation after retirement age, providing no support for those six hypotheses.

In addition, meaning of work was only significant to Whites, not to Blacks and Latinos, even though there was no statistical difference in meaning of work across racial groups.

\footnotetext{
${ }^{35}$ See Appendix 9 for supplemental analysis on multicollinearity.
} 


\section{DISCUSSION}

Based on the study findings, this chapter discusses the study results in depth, acknowledges the limitations of the study, and discusses implications for theory, future research, older worker policies, and social work practice.

\section{A. RACIAL/ETHNIC INEQUALITY AMONG OLDER WORKERS}

\section{Racial Inequality in Pre-retirement Conditions}

As the descriptive analysis results showed in Chapter 5 (see Table 2), there were racial differences among workers facing retirement. Older minority workers usually were not as financially prepared for retirement as their White counterparts. Older minorities were less likely to be eligible to receive employer-sponsored pensions, accumulated less wealth, earned lower household income, and did not own their own housing in their 60s. Not owning housing in one's 60s in particular implies serious financial disadvantages since home ownership is a primary means for establishing and maintaining wealth status (Marsh, 2008). These disadvantages in financial resources for retirement indicate that minorities may have greater financial difficulty in retirement than Whites and may need to continue working to afford retirement.

In addition to finances, older minorities also showed poorer health than older White workers. Furthermore, the racial difference in job types was particularly striking; the percentage of workers with blue-collar jobs was almost two times higher for older minorities compared to older Whites. This result is further supported by AARP's nationally representative survey in 
2011 reporting that the top five occupations among Blacks aged 50 to 69 were truck drivers, janitors, security guards, laborers, and bus drivers (AARP, 2011).

Racial inequality in education might exacerbate minorities' disadvantage in finance, health, and career patterns. Older minority workers showed significantly lower levels of education than Whites. As CAD theory frequently emphasizes, education vitally shapes one's life trajectory in both the short and long term (Ferraro \& Kelley-Moore, 2003). Given CAD theory's support, older minority workers with limited education can experience further disadvantages in their careers, wealth accumulation, and health (Shuey \& Willson, 2008).

In sum, stark racial disparities exist in many aspects among workers facing retirement, including finances, health, career patterns (especially job types), and education. These results are congruent with existing findings and the CAD notions. The next section discusses how these different preretirement conditions affect retirement.

\section{Racial Differences in Factors Affecting Labor Market Participation after Retirement Age}

Results showed that factors influencing individuals' labor market participation after retirement age are conditioned by race. This finding provides compelling implications for understanding older workers and racial inequality in the labor market. This section discusses the importance of race in understanding factors explaining older people's labor market participation. 


\section{Older White workers}

\section{$\underline{\text { Significance of the meaning of work }}$}

This study revealed that, among Whites, those likely to work after retirement age had better health, were relatively young, and value work more highly. This may mean that as long as their health allows, Whites usually stay employed after retirement age because they value the intrinsic reward of working. These findings suggest that behaviors of older White workers fit the perspective of productive aging; working after retirement age is a matter of personal preference, and individuals voluntarily choose to work based on their need for and interest in personal growth as well as their willingness to contribute to society (Butler \& Gleason, 1994; Friedan, 1993; Hinterlong et al., 2001). Given that none of the financial factors were significant, the study results reinforce the notion that older Whites' main determinant to work is generally influenced primarily by how they perceive work, rather than financial necessity.

\section{Older Black workers}

\section{$\underline{\text { Homeowners working longer }}$}

The descriptive analysis of this study showed that minorities have greater financial difficulty, which may indicate their need to stay employed. From probit results, however, homeownership was the only significant factor; among black workers approaching retirement, homeowners were the ones who were likely to continue working after age 65 . This finding also implies that those renters among older black workers, perhaps at the lower end of economic spectrum, tend to have poorer education and lower paying jobs. In fact, as shown in Chapter 2, the influence of financial factors, while garnering the most attention from researchers on older 
workers, are controversial. This study's findings on older Black workers conflict with existing research reporting that those with higher education and occupational attainment are more likely to receive higher pension benefits and greater retirement assets, all of which motivate them to leave the labor market early (Flippen \& Tienda, 2000). Thus, the findings of this study can be particularly compelling in that those older Black workers who stay employed after retirement age are not those with greater financial difficulty (renters), but those with less financial difficulty (homeowners).

\section{Potential explanations for the findings}

Perhaps older Black workers without homeownership retire earlier or retire as soon as they are eligible to receive Social Security benefits or pensions or Medicare because they usually are in the lower economic strata and often have jobs that are physically taxing, low-paid, boring, and make them feel less useful, and valued. Or their compromised health status may produce a higher level of physical or psychological exhaustion. On the other hand, older Black homeowners, many of whom could afford retirement and usually have higher SES than their counterparts, often choose to continue working to keep their higher financial rewards (Cahill et al., 2006). Or their meaning they attach to work may mirror that of White middle class.

Furthermore, this study's findings may suggest a greater vulnerability to involuntary labor market exit among older Black workers with lower SES. Black workers in the lower economic strata, many of whom need to work out of financial difficulty, might have to leave the labor market earlier than their counterparts due to layoff or work disability. This study's findings are reinforced by others suggesting that poorly educated and low skilled workers exit the labor

market earlier than their counterparts (Hardy, 1991; Mutchler et al., 1999; Ruhm, 1990a), and 
that precursors to involuntary job separation include having low SES, unstable employment histories, service/labor-intense occupations, low education, functional limitations, and lack of finances for retirement (Belgrave, 1988; T. H. Brown \& Warner, 2008; Burr et al., 1996; Flippen \& Tienda, 2000; Gibson, 1987; Hayward et al., 1996). Combined with the age barrier, those laid off Black workers who need to work out of financial necessity may experience further difficulty finding reemployment, causing great earnings reduction or leading to permanent labor market withdrawal (Bound et al., 1996; Flippen \& Tienda, 2000; Hayward et al., 1998).

In addition, the findings potentially point out class differences among older Black workers. One study posits that Blacks are not a homogeneous group because there is increasing diversity within the Black community (Hwang, Fitzpatrick, \& Helms, 1998). This diversity, in fact, has resulted from the emergence of a Black middle class, which began to appear after the Civil Rights Movement of the 1960s (W. J. Wilson, 1987). The emergence of a Black middle class also indicates improved social mobility among many Blacks. Policies such as Affirmative Action programs have helped to dismantle many social structures discriminating against Blacks as well as White women since the 1960s. However, not all Blacks have benefited from the changes facilitated by the Great Society era.

In sum, the physically taxing nature of jobs, barriers to staying in the workforce due to layoff or work disability, and class differences among older Black workers may potentially explain this study's results of why Black workers with homeownership are more likely to stay in the labor market after retirement age. 


\section{Older Latino Workers}

\section{Perhaps more disadvantaged than older Blacks}

The findings of this study showed that older Latino workers are more disadvantaged in many aspects, than their Black counterparts. To illustrate, the descriptive results of this study (see Table 2) presented that compared to older Black workers, older Latinos were less likely to have employer-sponsored pension coverage, to own their own housing, but more likely to have unstable career histories.

The most noticeable disadvantages of older Latino workers, even worse than their Black counterparts, appear to be job types and educational attainment. This study showed that around $68 \%$ had blue-collar jobs, compared to around $57 \%$ of older Black workers. The average education of older Latino workers in this study was barely 10 years. According to Bound and his colleagues (2003), the influence of education is so powerful that comparatively speaking, health disparities accounted for relatively little of the racial gaps in income.

Immigration seems to be the major factor behind older Latinos' disadvantages in preretirement conditions. Immigration status is responsible for many older Latinos' lifetime of lower earnings, translating into lower retirement saving than U.S.-born individuals (AARP, 2009). Older Latinos are predominantly immigrants, and foreign-born Latinos have much less education than those born in the U.S. Furthermore, many foreign-born Latinos, especially those with limited education, are not fluent in English, limiting their employment options. 


\section{Central role of health due to tenuous jobs}

This study's findings showed that health appears to be the only significant factor affecting older Latinos' employment after retirement age. Health status is an important factor for employment in general, particularly in older ages, but it appears to play a more central role for older Latino workers. Older Latinos' health is generally poorer than that of Whites but not significantly different from older Blacks'. But why was health found to be a significant factor for Latinos but not Blacks? The reason can be found from the nature of the jobs that older Latino workers usually have. It is well known that older Latino workers are overrepresented in strenuous jobs, which require good health to perform (Bound et al., 1996). Although both older Blacks and Latinos are concentrated in blue-collar jobs, Latinos are disproportionally represented in agriculture or construction. Thus, even though a lifetime of low pay and few benefits threatens many Latinos' later-life financial security, they may be forced out of the labor market because even relatively minor work disability would not sustain their arduous jobs during the years preceding traditional retirement age.

\section{B. STUDY LIMITATIONS}

The findings presented in this study should be viewed in light of several limitations. The following discussion of the study limitations focuses on data, measurement, and analysis.

\section{Data limitations}

\section{Limited Sample Size for Blacks and Latinos}

Even with HRS's over-sampling on minorities, this study's sample sizes for older Blacks and Latinos were relatively smaller than that for Whites, which might have left little room to 
examine the factors for minorities. This may mean that the small sample size employed in this study could have precluded the detection of additional factors that may significantly impact on minority older workers and the results may not represent the population.

\section{Omitting illegal Latino immigrants}

It is likely that HRS Latinos participants are legal immigrants in the U.S. Therefore, the findings of this study for older Latino workers may call into question whether the results can reflect illegal Latino immigrants in the labor market.

\section{Excluding Social Security and Supplemental Security Income variables}

Although this study's analytic model was supposed to test the influence of Social Security (SS) income and Social Security's Supplemental Security Income (SSI), those sources of income were excluded from the model due to their severely uneven distribution. Regardless of race, those ineligible for Social Security comprised less than $1 \%$ of the 1,114 total sample size. Moreover, there was no one who received or was eligible for SSI benefits among the study samples.

\section{Measurement Limitations}

\section{Meaning of work}

Examining the effect of the meaning of work was limited in this study because the HRS did not provide variables that directly ask about how respondents perceive the intrinsic reward of working. Given this limitation, this study employed the one-item measure, "I would probably keep on working even if I did not need money," which was only included in the 1992 HRS data. 
Although the portion of this variable's missing (38\%) was not negligible, the carefully conducted multiple imputation process overcame the issue of losing a substantial number of the total sample. Notwithstanding the limitations, considering the meaning of work in the model is a substantial social work contribution to studies of older workers.

Outcome measure for work status

A second measurement limitation regards the outcome variable for work status-either working or being retired. This binary outcome measure ignores retirement transitions that might have occurred during the study timeframe between 2004 and 2008. Multiple transitions may occur between working and full retirement; among those who were working in 2004, some might have become unemployed and then employed again, while others might have retired but gone back to the labor market with a part-time job.

Furthermore, this study's outcome measure did not account for certain workers with parttime jobs, sometimes called "bridge jobs", who reduced hours of work, changed to less demanding positions, or found new jobs before fully retiring (Borland 2005; Cahill et al., 2006). Distinguishing among these part-time workers is significant because retirement today is no longer two dimensional. Compared to the previous retirement pattern-leaving the labor market all at once-, Americans today tend to retire gradually, moving from full-time employment to part-time jobs and then eventually withdrawing from the labor market altogether ${ }^{36}$ (Cahill et al., 2006; Dendinger, Adams, \& Jacobson, 2005). As a result of the changes in retirement trends, the

\footnotetext{
${ }^{36}$ Appendix 8 shows the supplemental analysis results using the three-level outcome (work status: retired, part-time, and full-time).
} 
concept of retirement has become more complex, and it is difficult for researchers of older workers to find a universal measure for retirement (Denton \& Spencer, 2009).

\section{Pensions}

Employer-sponsored pension in this study was measured eligibility (yes/no), not the amount of benefits (continuous measure). This measurement may explain why the factor of pensions in this study was not significant, unlike some existing findings (e.g., French, 2005; Munnell, Triest, \& Jivan 2004; Pienta \& Hayward, 2003).

\section{Analysis Limitations}

Survey weights

The HRS provides the household level and respondent level weights that are post stratified to the March Current Population Survey (CPS) for the year of data collection. This post-stratification is conducted on the basis of factors that reflect all the major characteristics of the sample design, such as the birth cohorts of the respondent and spouse, and on the basis of respondent gender and race/ethnicity, which provides consistent adjustments for sample attrition and mortality (HRS, 2011b). However, this study did not incorporate the HRS weighting variable into the multiple imputation procedure due to a concern over complex process as well as possible overestimation.

\section{Impact of the Great Recession}

Another analysis limitation stems from the potential effect that the Great Recession, which began in December 2007 and ended in June 2009, might have on this study's internal 
validity since this study used the 2008 HRS dataset, collected between February 2008 and February 2009 (Health and Retirement Study, 2012). This economic downturn exacerbated the labor market challenges to minority workers; i.e., the unemployment rate of the construction section more than tripled during the recession, impacting Latino workers especially (AARP, 2009).

\section{Limited generalizability of study findings}

It should be noted that this study's samples were limited to individuals who were working, regardless how many hours they worked, and were aged between 60 and 64 in 2004 . Thus, this study's results can only be applied to workers approaching retirement and cannot be applied to those who are not in this age criterion, those who already retired before age 60, or those who were unemployed or disabled because those groups differ in many respects, in particular, finance health, career patterns, and education ${ }^{37}$. These restrictions in age and work status in the study samples might have caused an underestimation of the influence of health and finances, especially because the study samples were relatively healthier and wealthier than those unemployed/disabled. Consequently, this study's results may not reflect the heterogeneity among older Americans.

Furthermore, because minorities are more likely to have a work disability and to involuntarily leave the labor market, the proportion of minority workers surviving to age 60 and older might be much smaller than the proportion of their White counterparts, meaning that the survivors may be members of a somewhat elite population. Given these reasons, the generalizability of this study's findings is limited.

\footnotetext{
${ }^{37}$ See Appendix 10 for the statistical comparison between this study's sample and those unemployed and disabled.
} 


\section{Early disadvantages not fully explored}

While the CAD framework highlights the impact of early advantage/disadvantage on racial inequality in old age, this study explored a narrow subset of factors within that framework, such as education and career patterns. CAD theory itself does not conceptualize early advantage/disadvantage clearly and lists a limited range of examples. Thus, this study's design may not be able to fully test the usefulness of the CAD framework on older worker studies.

\section{IMPLICATIONS}

\section{Implications for Future Research}

Findings of this study offer a road map for future studies interested in building upon this important line of research of older workers. First, class differences within older Black workers merit future research. Existing studies of older minority workers primarily focused on differences across races, particularly between Blacks and Whites, but not within minorities. Future research might identify standards that distinguish upper class blacks from lower class Blacks as well as the differences in their lifetime career patterns. Also, future research should further recognize differences between the involuntary nature of retirement of older Blacks, as opposed to the voluntary nature of older Whites. These lines of inquiry raise critical issues for the next logical step of understanding older minority workers.

A second research implication is to further examine the role of health to older Black workers. Perhaps the most surprising finding of theoretical relevance was the lack of a significant relationship between health and labor force participation. Given the theoretical importance of health, future research may need to use work disability as an alternative health 
measure, rather than using a self-rated scale that subjectively measures how respondents evaluate their overall health condition. This approach may better capture how health affects older Blacks' labor market participation.

Third, there is still a great deal to be learned about the different perceptions of the meaning of work ${ }^{38}$ among racially diverse groups. For example, while the meaning of work was significant to older White workers regardless of their finance or job types, it was not to older Blacks and Latino workers. These results do not match with the descriptive analysis of this study, which shows that the average level of meaning of work was statistically not different across the three racial groups. This may mean that older minorities, even with their more disadvantaged preretirement circumstances, value the intrinsic reward of working as much as their White counterparts do. Furthermore, Latino workers are known for their strong work ethic (AARP, 2009). Yet, with more valid and reliable measurement tools, researchers can further examine how the meaning of work differs by race and/or different class.

The final implication for future research is to expand the scope of the research to full- and part-time employment. As the aforementioned limitations regarding the outcome measurement acknowledged, distinguishing types of employment between part- and full-time can provide a better understanding of the behaviors of older workers.

\section{Implications for Theories}

CAD theory provided a theoretical framework for this study in the context of race and labor market participation in old age, and the conceptual model presented in Chapter 3 (see Figure 1) was built on the CAD framework of racial disparity in old age.

\footnotetext{
${ }^{38}$ See Appendix 11 for supplementary correlation analyses between meaning of work and selected study variables.
} 
This study's support for the CAD framework

First, this study's findings support the CAD framework, which highlights the significance of four factors-financial resources for retirement, health, career patterns, and education-in explaining racial/ethnic inequality in old age. The results demonstrated that Black and Latino workers are significantly more disadvantaged than Whites in all four conditions.

The cohort effect, in particular, should be noted in understanding older minority's disadvantage in education. This study's samples, the pre-Civil Rights Movement cohort, had historically limited access to education in racially segregated institutions. In 1960, only $3 \%$ of Blacks age 25 or older had a college degree, compared to $16.5 \%$ in 2000 . Similarly, in 1970 , only $4.5 \%$ of Latinos age 25 or older earned a Bachelor's degree, compared to $11 \%$ in 2000 (Shavit, Arum, Gamoran, \& Menachem, 2007). Even in the late 1970s, after the 1964 Civil Rights Act was enacted and affirmative action policies were adopted, most of Black students in higher education attended historically Black institutions (R. Wilson, 1994). This cohort effect in education further hindered minorities' labor market outcomes (Bowen \& Bok, 1998)

Second, this study also supports the CAD postulation that beyond preretirement conditions, understanding earlier advantage/disadvantage is necessary to grasp racial differences among older workers approaching retirement. For example, this study found that homeownership, offering substantial and compounding advantages to one's finances over the lifetime, significantly impacts older Black workers whether or not they stay employed after retirement age.

Finally, this study's findings support the role of social structures that CAD highlights. Workers who reach retirement age may choose to stay employed or retire, but this decision is not 
simply based on individual preference, but also on social structure, reflecting underlying racial inequalities in the older population. However, this study's support for the significance of social structure is limited because the analytic model did not empirically test variables of social structure in a systematic manner.

In sum, while the CAD framework has been applied to inequality research in many fields, it has not been applied to older worker research. However, this study's findings provide significant evidence for "a goodness of fit" for the CAD framework to understanding racial differences among older workers.

This study's lack of evidence for discrimination

Although this study's findings overall supported the CAD framework, they did not explicitly support CAD's usefulness in ascertaining whether institutionalized discrimination still restricts minorities from gaining resources and benefits. This is because this study did not examine the impact of racism directly in the analytic model. Thus, this study did not provide any overt support for whether or not racism exacerbates the cumulative process of disadvantage.

Even with no empirical evidence, this study addresses the question of whether racial discrimination still exists in the labor market. This is very difficult to answer because contemporary forms of discrimination can be so subtle and covert as to be difficult to measure, unlike during the pre-civil rights era, when racial prejudice was more overt and pervasive (Pager $\&$ Shepherd, 2008).

Some argue that discrimination in the contemporary labor market has disappeared and that the Black-White differences in earnings result from differences in level of skill, not 
discrimination (Heckman 1998; from pager 2009). In fact, more than half of Whites, Latinos, and even Blacks share the belief that Blacks who have not gotten ahead in life are behind due to personal reasons (Pew Research Center, 2007).

Research, however, argues that even though racial discrimination has decreased since the Civil Rights Movement, many minorities today are still treated unequally on the basis of their race/ethnicity (Cagney et al., 2005), which appears in the labor market in particular as the most enduring form of discrimination (Pager, Western, \& Bonikowski, 2009). A 2007 survey based on 3,086 nationally representative samples of the U.S. population reported that $67 \%$ of Blacks commonly encounter discrimination in hiring, compared to $20 \%$ of Whites and $36 \%$ of Latinos (Pew Research Center, 2007). Furthermore, numerous studies have produced strong and consistent evidence of how discrimination generates wage differentials by race (Darity \& Mason, 1998) and unfair hiring decisions (Bendick, Jackson, \& Reinoso, 1994). For example, employers tend to negatively stereotype young minority men as being unreliable and dishonest, and are therefore reluctant to hire them (Moss \& Tilly, 2001). In addition, although the 2000 Housing Discrimination Study showed that discrimination against Blacks and Latinos in both rentals and sales decreased since 1989, discrimination remains an important barrier to residential opportunities (Pager \& Shepherd, 2008). Blacks and Latinos still are more likely to get rejected outright (Munnell, Tootell, Browne, \& McEneaney, 1996) or to pay more than 0.5\% higher interest rates on home mortgages than Whites with similar credit (Oliver \& Shapiro, 2006). Furthermore, discrimination in housing implies a substantial disadvantage to Latinos since home ownership is a primary means of establishing and maintaining wealth (Marsh, 2008). Perhaps discrimination explains why well-educated Latinos often work at jobs for which they are overqualified, a common finding for college-educated Latino immigrants. Moreover, Blacks' 118 
poor health is reported as not solely explained by SES because institutionalized discrimination prevents health equality (Shuey \& Willson, 2008).

Discrimination can be particularly relevant for these participants of this study, the preCivil Rights Movement cohort, given the historical context of overt racism that they may have endured since birth, including racial segregation in education, barriers to labor market entry, persistent segregation in occupation, and unequal treatment in housing. Younger generations of minorities might benefit from social changes and new policies against racial discrimination; however, these older minorities might have lived with the nation's legacy of discrimination and segregation, including a lack of family inheritance (Shapiro \& Kenty-Drane, 2005), as illustrated in Chapter 2 ("Historical context of minority workers in the U.S."). Even in the absence of ongoing discrimination, the legacy of past discrimination still continues, leading many to miss out on intergenerational advantages, including accumulated wealth, quality education (Oliver \& Shapiro, 2006), and equal employment opportunities.

In conclusion, although this study provided no empirical support for the existence of racism, discrimination still exists persistently in contemporary U.S. society; it is not solely responsible for racial disparities in the U.S. (Pager \& Shepherd, 2008), but still creates obvious disadvantages for older minority workers.

\section{Limitations of the CAD framework}

To better understand older minority workers, the influences of education and career patterns should be further articulated as one of the early advantages/disadvantages. Although this study's results showed that racial differences appear in education and career patterns 
(particularly in job types), these factors were not significant in the model predicting labor market participation after retirement age.

Perhaps, education and career patterns might indirectly impact older people's labor market participation, as opposed to retirement assets and health impacting directly. A need exist for continued theoretical research on constructing the model with education and career patterns as indirect factors (e.g., a structural equation modeling approach) and empirically testing their effects on labor market participation.

A second limitation of CAD theory for framing the studies of older workers is a failure to mention those barriers that make it more difficult to access the labor market. Several statistics and literature suggest that older minorities usually work out of financial necessity, not to gain personal growth or to make a productive contribution to society; however, this study found that the labor market pushes out many minorities in great financial hardship. Staying employed after retirement age seems to be not a simple personal choice but an opportunity where many minorities with disadvantages are prevented from pursuing. Therefore, future theoretical research on CAD might investigate what barriers older individuals face in staying in the labor market and how these barriers may differ by race. The elucidation of such barriers will provide fertile ground for not only developing theories for older workers, but also for shaping future programs and policies that could substantially reduce racial gaps among older workers, ultimately serving to improve the lives of many older workers.

A third limitation of the CAD framework is its insufficient attention to lack of family wealth as an early disadvantage to minorities. As mentioned in the historical background, even though racial/ethnic minorities have made substantial gains in both occupation and income since 
the beginning of the 1960 s, they have been unable to accumulate assets due to their meager inheritance. Family wealth, often accumulating in families over years or even generations, is important because people without wealth are more disadvantaged by loss of income and their financial progress may be halting or uncertain (Beteille, 2003). Thus, to fully reflect the historical context of minority workers in the U.S., CAD theory needs to highlight the importance of family wealth as an early disadvantage.

Finally, although CAD helps this study understand such racial differences among older workers and why different racial groups are influenced by different factors, it does not explain the mechanism by which those factors differently impact labor market participation after retirement. As this study is one of the first attempt at applying CAD to older worker studies, clearly, more studies are necessary.

In conclusion, $\mathrm{CAD}$ theory appears to be a useful framework that provides insight into the cumulative effect of racial inequality in employment over the lifespan. However, more research is needed to further develop this theoretical framework.

\section{Implications for Older Worker Policies}

Given CAD theory's emphasis on the social system, the role of public policies and practices is vital in reducing racial inequality among workers in both the short and long-term policy perspective. This section discusses detailed policy initiatives for older Black and Latino workers, particularly in terms of finance, health, career patterns, and education.

To reduce racial gaps in finance and health, promoting minority workers' career patterns and education are fundamental. This section first discusses short and long-term ways to improve 
older minority workers' education. Suggestions on promoting minorities' career patterns follow, listing policy suggestions for current government workforce programs for older people. This study also discusses the age eligibility requirements for Social Security. Finally, a brief discussion follows on different approaches between "want to" and "need to" older workers.

\section{Promote older minorities' education}

\section{$\underline{\text { Utilize Community College }}$}

Community colleges, by providing part-time classes, can be a useful resource to find or advance the employment credentials of older Black and Latino workers (AARP, 2011), many of whom must keep on working to gain additional financial resources for retirement or were laid off during the economic recession. In particular, The "Plus 50" Initiative, funded by the Atlantic Philanthropies from 2008 to 2012 and organized by the American Association of Community Colleges, is a pilot program ${ }^{39}$ that supports 13 national community colleges as a way to create or expand postsecondary education for individuals age 50 or older-mainly the baby boomers (The American Association of Community Colleges, 2013). In the academic year 2009 and 2010, Plus 50 provided 1,093 courses to 15,000 older students (American Association of Community Colleges, 2012). Although the Initiative provided a variety of courses (workforce training, volunteering, and knowledge), its workforce program is of particular interest for older Blacks and Latinos. The Plus 50 program can help older minorities improve their employment prospects in many ways, including: enriching current or new job skills; or obtaining a license or certificate (American Association of Community Colleges, 2012).

\footnotetext{
${ }^{39}$ After the pilot funding ended in 2008,12 out of the 13 participating community colleges have continued the Plus 50 Initiative, by sustaining their finances through tuition or course fees, the college's annual budget, and outside funding (American Association of Community Colleges, 2012).
} 


\section{$\underline{\text { Promote Early Education as Long-term Solution }}$}

As racial inequality among older workers begins early in life, early education is a fundamental way to combat racial inequality in the labor market for the long-term. Throughout American history, as shown in Chapter 2, minorities have had unequal access to education. Many Blacks and Latinos still receive lower quality education. i.e. urban schools with limited classroom facilities and curricula, and higher dropout rates (Williams \& Collins, 2002). Supporting the education of younger minorities, especially of Latinos, would potentially boost employment outcomes at younger ages, eventually enabling minorities to reach their full potential and enjoy a more economically stable retirement when they get older.

\section{Improve minorities' career patterns}

This section discusses policy options that aim to bolster the employment prospects of older minorities, particularly how to lower employment barriers and boost earning among older workers. Given the fact that minority older workers already possess diverse disadvantages, particular emphasis is given to how to lower employment barriers and how to create protected employment for older minorities.

\section{Promote Employment in Growing Industries}

Because of programs like the Plus 50 Initiative, older minorities have a higher possibility of finding work in the rapidly growing healthcare and social assistant industries because these positions only require a postsecondary education; moreover, the areas of healthcare and social assistance tend to pay relatively well. It is predicted that $30 \%$ of the fastest-growing industries in the U.S. will be filled by individuals without Bachelor's degrees (AARP, 2011). 


\section{$\underline{\text { Utilize Workforce Development Programs }}$}

Older minority workers can benefit from participating in the three types of workforce development programs that the U.S. government currently provides: Mature Worker Program, American Job Center, and Senior Community Service Employment Program.

Mature Worker Program, funded by a \$13 million Department of Labor grant and administrated by the National Urban League, helps to restart the careers of low-income adults age 55 or older; it also provides subsidized employment through six Urban League grantees. Its job-training program includes counseling services, assessments, computer literacy, and job placement. Partnering with local employers and job placement agencies, Mature Worker Program has served 1,400 jobless older individuals in economically depressed areas.

American Job Centers, formerly called One-Step Career Centers, funded by the Workforce Investment Act (WIA) of 1998 and administrated by the Department of U.S. Department of Labor (DOL)'s Employment and Training Administration (ETA), offers a full range of employment and training services, including job training and finding additional state and local government support for employment (U.S. Department of Labor, 2013). American Job Centers can benefit Blacks, Latinos, women, and manufacturing workers to gain higher earnings (Greenberg, Michalopoulos, \& Robins, 2003) and to promote their job prospects, especially for workers trying to transfer to fast growing industries.

To better serve older minorities, American Job Centers should increase their outreach to minorities with low education. To better serve the Latino population in particular, the Centers 
must make a special effort to hire Spanish-Speaking counselors and to implement English acquisition programs (AARP, 2009).

Another policy recommendation for American Job Centers is that their clients' English language proficiency should be accounted for the performance appraisal standards of the Centers, defined by the Department of Labor (Thomas-Breitfeld \& Liu, 2003). Although designed to serve workers of all ages, American Job Centers tend to invest little time into serving Latinos because clients with limited English language skills often perform poorly against standard benchmarks (General Accounting Office, 2003). Thus, the evaluation incentive can minimize the Centers' reluctance towards helping the Latino population.

Senior Community Service Employment Program (SCSEP), authorized under Title V of the Older Americans Act (OAA) of 1965 Amendments, promotes part-time opportunities in subsidized minimum-wage jobs in community service positions in public and nonprofit organization settings. It targets unemployed individuals who are at least 55 years old and whose income level is no more than $125 \%$ of the poverty level. The legislation of the SCSEP has three objectives: (1) to enable older Americans to earn additional income, (2) to provide participants with an opportunity to engage in purposeful activity, and (3) to provide needed services in communities where aged persons reside. Administered by the Department of Labor for over 30 years, the program operates in every state, including Puerto Rico. SCSEP is administered through grants awarded to national organizations and to state and territorial agencies. SCSEP has served some of the most disadvantaged persons in society, particularly minorities and those with poverty income and limited educational attainment. In the program year 2011, the number of SCSEP participants was 76,864 , with $65 \%$ females and $47 \%$ minorities, and $44 \%$ of the 
participants were placed with unsubsidized employers (DOL Employment and Training Administration, 2013).

To better serve older minority workers, this study offers three suggestions. A first suggestion is that the Department of Labor eases SCSEP's eligibility requirements. Since 2005, Social Security income has been included in calculating the individual's income level to assure targeting of services to those with the greatest economic need (DOL Employment and Training Administration, 2006). The inclusion of Social Security benefits may be erroneous because many financially disadvantaged older minorities have Social Security benefits as a single source of income. Furthermore, the 2005 new eligibility criteria exclude people who already have any kind of employment, such as baby-sitting. This regulation might restrict the participation of those older minorities who have poor employment prospects but need to continue working.

Second, the new performance measures, which increased the number of participants transitioning from subsidized to unsubsidized sectors, might give a disadvantage to older minorities. These provisions will push local SCSEP agencies to increase their number of client placements in the private sector because their performance score will affect their future funding. Given this study's results that older minorities have poor employment prospects, the SCSEP requirements should differ from other employment programs that the Department of Labor operates for younger populations.

Third, the increase in the age eligibility from 55 to 60 can harm older minorities. The age 55 criterion was determined in 1965, but the Department of Labor intends to increase this age as a reflection of the longer life expectancy in the U.S. However, low-income older minorities 
between the ages of 55 and 64 are a particularly vulnerable population due to their ineligibility for Medicare or full Social Security benefits.

A final suggestion for SCSEP is to explore ways to gain more funding. The potential demand for SCSEP services substantially exceeds the available program slot. In 2007, about 9.2 million adults ages 55 to 74 were eligible for SCSEP, but the program served only 80,000 (Sum, Khatiwada, McLaughlin, \& Palma, 2008). With more financial backing, SCSEP can reach a larger population.

Reconsider the Increase in Social Security Eligibility Age

Raising Social Security's early entitlement age beyond 62 may negatively affect some minorities who have unstable jobs and who may be unable to continue working into their mid60s. Although this increase in the eligibility age, the first change since Social Security was established in 1935, is necessary given the increasing life expectancy, the new Social Security regulations should reflect the challenging circumstances of the minority populations.

Differentiate approaches between "want to" and "need to" older workers

It is inevitable that the number of older workers will continue to grow, given the prolonged life expectancy, better health, and the increasing insolvency of retirement income systems. In building policies for older workers, therefore, a different approach is necessary for those individuals who "want to" work and "need to" work. Policy makers also should create meaningful jobs that acknowledge the skills and experience of older workers, maximize both the financial and non-financial rewards of working, and benefit society. 


\section{Implications for Social Work Practice}

Given the findings of this study, implications for social work practice are limited compared to policy implications. Nevertheless, the study does suggest some important implications for social work practice.

Due to the continuous increase in the number of older workers, it is important for social work practitioners who provide services to older people to recognize that the expectations and needs of older individuals have changed. Some older clients are physically dependent and need support services; others with relatively better health may either choose or need to continue working beyond retirement age. Gerontological social workers working for older adults must be skilled in their ability to understand both groups of older people.

This study also highlights the necessity of social workers who work with older Latinos to do culturally competence practice. Many older Latinos are immigrants who, despite limited education and language challenges, must work to support their families. In addition, social workers need to become advocates for their older Latino clients by highlighting this population's strong work ethic, loyalty, and low rate of absenteeism—all qualities that employers value.

The most essential implication for social work practice evidenced by this study is that social workers serving older minorities need to be aware of the availability of workforce programs and post-secondary education within their communities - such as the Plus 50 program, SCSEP, Mature Worker Program, and American Job Centers - and must be adept at connecting those programs with their minority clients who are in need. This knowledge could provide clinicians and program developers with critical insights into how to best help older minorities 
who are involuntarily unemployed and experience substantial labor market obstacles in finding a job arising from their poor employment prospects.

\section{CONCLUSION}

In conclusion, this study aimed to investigate factors determining the labor market participation of older people. Based upon the findings, this study has enriched the existing body of knowledge. In particular, it explicitly emphasized the role of race, suggesting that one universal model does not fully explain older individuals' labor market participation among different racial/ethnic groups. Also, this study provided insight into how the labor market participation of older minorities differs from that of their White counterparts. Because of racial inequality in preretirement conditions, factors influencing the individual's labor market participation differ by race. Whereas health and the meaning of work influence Whites, financial resources (home ownership) affect Blacks, and health concerns Latinos. This study discussed that availability of access to the labor market—not personal preference, financial necessity, or job dissatisfactionmost influences the labor market participation of minorities. As Hayward and colleagues (1996) stated, retirement may be more of a White experience.

Furthermore, this study included the Latino population to expand the scope of the existing literature, finding that although both Blacks and Latinos experience a lifetime accumulation of disadvantages, their employment experiences significantly differ. Due to different historical backgrounds, Blacks exhibit class differences in the workplace, while Latinos face substantial barriers of education and language in the workplace. 
Pointing out the theoretical limitations in studies of older workers, this study made an important theoretical contribution by employing and testing the CAD framework. CAD helped this study to frame fragmentary knowledge from existing studies and build a conceptual model with four essential factors - finance, health, career patterns, and education. CAD theory also contributed to this study by demonstrating that racial inequality should be understood not as a simple product of old age, but as a byproduct of the interplay between the individual's lifetime experiences in the labor market and the social structures that impose cumulative advantages/disadvantages on the individual.

This study made a methodological contribution by separately estimating the models by the three racial groups to better capture the racial differences that exist. This estimation approach treated race-associated differences as key elements, providing insight into the role of race in the analysis.

Finally, this study contributed to the field of social work by stressing the importance of considering both financial and non-financial factors when explaining the labor market participation of older people.

Therefore, this study provided a cornerstone work that 1) shed insight on the status of older minority workers and 2) identified the racial inequality that exists among older workers. As a result, this study supports policy initiatives, such as the Plus 50 program, to reduce barriers that restrict minorities' opportunity to remain employed and to reduce racial inequality among older workers. 


\section{Appendix 1.}

\section{Supplemental analysis— health and finance changes between 2004 and 2008}

The respondents' health and finances between 2004 and 2008 were compared to account for changes because this study's data came from the two different waves (the study factors from the 2004 wave and outcome from the 2008 wave).

During the four-year time lapse, the respondents' health significantly decreased from $3.52(S D=.95)$ to $3.37(S D=1.00), t(1113)=-5.495, p<.001$. This change appears credible since one's health gradually declines as one ages.

The respondents' total wealth also decreased from $\$ 387,000$ in 2004 to $\$ 366,000$ in 2008; however, this change was not statistically significant $t(1113)=.308, p<.758$. Finally, there was no significant change in the average total household income between 2004 and in 2008, $t$ (1113) $=.911, p<.362$. These lines of results may suggest that the four-year time lapse of this study is rigorous.

Table 9. Health and finance changes between 2004 and 2008

\begin{tabular}{lccc}
\hline \multirow{2}{*}{ Variables } & \multicolumn{2}{c}{$\boldsymbol{M ( S D )}$} & $\boldsymbol{p}^{\mathbf{a}}$ \\
\cline { 2 - 4 } & $\mathbf{2 0 0 4}$ & $\mathbf{2 0 0 8}$ & .000 \\
\hline Health & $3.52(.95)$ & $3.37(1.00)$ & .758 \\
\hline Total wealth $(\mathrm{k})$ & $387(2419)$ & $366(858)$ & .362 \\
\hline Total household income $(\mathrm{k})$ & $87(149)$ & $83(96)$ & \\
\hline
\end{tabular}

a. Paired t-tests were performed to compare the conditions between 2004 and 2008 


\section{Appendix 2.}

\section{Wealth and income pre-imputations}

The RAND Center for the Study of Aging pre-imputed the HRS wealth and income variables, including the wealth and household variables of this study. The Center used a consistent method that has been extensively tested. Using a liner regression model with the nearest neighbor technique, they built model specification for imputation that is parsimonious and consistent across asset and income types. Based on the sample of households that reported exact continuous values, wealth and income were imputed. For income, the covariates included in the imputation model consist of husband and wife's employment status, education, health status, race, marital status, occupation class, cognition, and bequest motive. For wealth, the same set of covariates were used, but instead of employment status, a number of income amounts and indicators of pension or government benefit receipts were included (HRS, 2011a). 


\section{Appendix 3.}

\section{Measurement issues in capturing health}

There has been controversy between subjective and objective health measures regarding which one better captures one's health status. After carefully reviewing literature, I chose to use a self-rated measure of health because numerous scholars report that it is actually a good indicator of a person's medically determined health status (Dwyer \& Mitchell, 1999; McGarry, 2004; Munnell et al., 2007) and may be the best approach in determining the effects of health on work (Munnell et al., 2007).

It should be noted that although subjective health measures - such as self-rated health or questions of health limitations - are popularly used in studies of older workers (Munnell et al., 2007), their validity is questionable for two reasons: 1) sensitivity to other circumstances and 2) justification bias.

First, self-rated health is sensitive to personal circumstances (Anderson \& Burkhauser, 1985; Bound, 1991; Munnell et al., 2007). For example, some older adults who like their work often downplay their health problems; conversely, others—who dislike their work, were laid off, are eligible for government benefits, have high incomes, or look for more medical care—often overestimate their health conditions (Munnell et al., 2007). Self-reported health can be easily affected by the availability and generosity of government-provided health and retirement benefits in particular compared to an objective measure in estimating the probability of working in old age (Anderson \& Burkhauser, 1985). 
Second, self-rated health cannot be free of justification bias (Anderson \& Burkhauser, 1985; Bound, 1991; McGarry, 2004; Munnell et al., 2007). Individuals' deteriorating health can lead them to exit the labor force; however, there is a concern that workers might use failing health as a socially justifiable excuse for early retirement (McGarry, 2004). Thus, as Anderson and Burkhauser (1985) argued, self-reported health may not be a perfect measure of health to use in studies of older workers.

In attempting to overcome these limitations of subjective health measures, researchers of older workers have employed various types of objective measures, such as ADL (activities of daily living) and the presence of chronic conditions. However, objective health measures may not be a good alternative either because they do not capture one's ability to work (Bound, 1991; Dwyer \& Mitchell, 1999; McGarry, 2004; Munnell et al., 2007). Physical exams may not control for the specific demands of an individual's job environment or the interaction between their skills and health limitations (Bound, 1991). For example, difficulty walking up stairs may have little impact on a person's ability to work as a computer programmer (Munnell et al., 2007)

More recent research reevaluated a self-reported measure of health. In elaborating the association between health and the labor force participation of older people, the landmark study by McGarry (2004) paid special attention to health measurement. To better deal with the issues of health measures, she used two strategies: 1) statistically controlling for self-rated health's justification bias and 2) employing both self-reported and objective instruments of health, such as chronic conditions, ADLs, and the probability of living to 85 . The results showed that a strong correlation between self-rated health and older people's work was not a simple result of the justification bias. Moreover, the effects of self-rated health remained large even when the model 
included objective instruments. Thus, given the literature review on the controversy between subjective and objective health measures, this study chose to use a subjective health measure. 


\section{Appendix 4.}

\section{Diverse methods for missing value treatment}

There are several types of imputation techniques: case deletion, single imputation, and multiple imputation.

First, case deletion includes listwise and pairwise deletion. Pairwise deletion eliminates a whole case if any single value is unavailable (Patrician, 2002). Frequencies, means, and standard deviations are computed separately for each pair. The pairwise method can be advantageous since correlations and covariances for two variables do not depend on other variables' missing values (SPSS Inc., 2010). However, the estimates of case deletion can be seriously biased when data violate the assumption of missing completely at random (MCAR); that is, the discarded cases do not differ systematically from the rest, and the probabilities of response do not depend on missing subsamples or any data values observed (Allison, 2000). Even though the data are MCAR, case deletion may yield larger standard errors due to the reduced sample size (Schafer, 1999).

Second, single imputations - mean imputation, regression, and hot deck imputation - are another alternative that gives a value to a missing data cell based on the values of other variables, and it substitutes a reasonable estimate for absent data elements (Little \& Rubin, 1989). Single imputations are fairly accurate when the amount of missing information is small; however, only one imputed value from single imputation methods may be unable to account for variability (Schafer, 1999). In other words, although mean imputation is the most common technique to reconcile missing data, it is limited mainly in that it decreases variability between responses and 
biases correlations with other variables. For example, persons with very high and low SES often do not report their income. Treating this case with mean imputation may result in producing incorrect statistical inferences (Tacachnick \& Fidell, 2000). The other drawback of mean imputation is the ignorance of nonresponse bias (Rubin, 1987). Researchers should not overlook nonresponse because participants usually do not respond to certain questions for reasons (Patrician, 2002). Also, regression, which computes predictive equations in order to generate imputed values using information from complete cases, works well when predictors are strong. However, when sufficient variability is absent, this method may underestimate standard errors, leading to biased imputation (Little \& Rubin, 1989). Moreover, hot deck, which matches respondents having missing data with other respondents having similar values in a set of other variables and imputes the known value into the missing data cell (Patrician, 2002) may underestimate variability and assume no difference between respondents and nonrespondents (Patrician, 2002; Rubin, 1987). 


\section{Appendix 5.}

\section{Multiple imputation}

To improve the drawbacks of case deletions and single imputations described earlier, Rubin (1987) developed a new imputation method, multiple imputation (MI), which is primarily suitable for large and publically available surveys and censuses. Allison (2000) and Schafer (1997, 1999) further advanced Rubin's method (Patrician, 2002). MI has become increasingly attractive to researchers in diverse disciplines, including biomedical, behavioral, and social sciences (Schafer, 1999). This method deals with various types of variables (e.g., quantitative, ordered categorical, and nominal, etc.) with all roles (e.g., outcome, predictor, and confounder, etc.) (White, Wood, \& Royston, 2007). Also, this method assumes that the data are missing at random (MAR); that is, the case where missingness of a certain variable may be related to other variables, but not to the underlying values of the missing variable (White et al., 2007). Therefore, given the drawbacks and advantages of various imputation methods, this study chose to use multiple imputation.

The process of MI involves specifying an imputation model, imputing several datasets, analyzing them separately, and finally combining results. This method creates a multiple number of datasets (usually five imputations) imputed by using all variable information, with each respondent's data treated as an independent data vector (or predictor) ${ }^{40} \quad$ (Little \& Rubin, 1987;

\footnotetext{
${ }^{40}$ MI usually uses all analysis variables, both a dependent and predictors, in the imputation model. However, to make the analytic model more compact, researchers can set certain variables as "predictor only" to turn off imputation or exclude some variables to use as "impute only" (SPSS Inc., 2010). Accordingly, this study did not impute three variables - total wealth, total household income, and work status (DV) - which were only included in the imputation process as predictors. This is because the wealth and income variables were pre-imputed by the HRS or RAND (e.g., Szinovacz, 2005). Also, this study avoided imputing an outcome variable (e.g., Koike, 2002; Unutzer, 2011).
} 
Reiter, 2006). Five sets of imputation are practically regarded as sufficient in most settings (Longford, 2005). In other words, comparing $m$ imputations to an infinite number of imputations, the estimate efficiency is around $(1+\lambda / m)^{-1}$, where $\lambda$ is the rate of missing information. For example, with 50\% missing information, an estimate with five imputations has a standard deviation of only around 5\% wider, based on $m=\infty$ because $\sqrt{1+0.5 / 5}=1.049$ (Rubin, 1987).

The predictions across five imputed datasets are averaged, and standard errors are adjusted to reflect both within-imputation variability and between-imputation variability (Rubin, 1987, 1996; Schafer, 1997). Five MI datasets produce output for each "complete" dataset as well as "pooled" output, which estimates to obtain a single set of results.

An MI strategy is advantageous in many ways ${ }^{41}$. Filling each missing value with not a single value but multiple values, a MI strategy helps adjust for potential bias from missing data (Little \& Rubin, 1987; Schafer, 1997). Moreover, MI can incorporate random error, given its calculation of random variation in the imputation process. MI can also increase estimate efficiency as it minimizes standard error (Rubin, 1987) and allows randomly drawn imputations under more than one model (Patrician, 2002).

This study's MI process involves three specifications. First, it uses maximum likelihood (ML) estimation, which is based on the EM (expectation-maximization) algorithm (Longford, 2005). Second, the MI is performed by a fully conditional specification (FCS, also called Markov Chain Monte Carlo; MCMC) method, which is useful when the data does not show a monotone pattern of missing values. This technique continues the estimation until it reaches the

\footnotetext{
${ }^{41}$ Even with its popularity, it should be noted that MI is not a perfect method for treating missing values. The major criticism of MI is that the reproductivity of exact results may be questionable because each data set imputed will yield slightly different estimates and standard errors (Patrician, 2002).
} 
maximum number of iterations and saves the imputed values at the maximum iteration to the imputed dataset (Judkins, 2008; Kenward \& Carpenter, 2007). Finally, the MI contains constraints, such as the minimum and maximum of imputed values ${ }^{42}$.

\footnotetext{
${ }^{42}$ For example, the variable of job stress in this study ranged from 1 to 4 ; accordingly, the imputed job stress was constrained to a minimum of 1 and a maximum of 4 .
} 


\section{Appendix 6.}

\section{Patterns of missing data}

Before imputing data, one must verify patterns of the missing data. There are three types of missing data patterns: missing completely at random (MCAR), missing at random (MAR), and missing not at random (MNAR). The data are MCAR when the missing data are independent of both the observed and missing values (Heitjan \& Basu, 1996), which is rare in nature. Little's MCAR test can be useful for determining whether the data are MCAR (SPSS Inc., 2010).

On the other hand, the data are MAR when missing patterns of the observed data are related to other observed variables, but not to the values of the unobserved variables, i.e., when information from other variables may be used to help predict why the values of the variable are missing (White et al., 2007). For example, if people with higher incomes tend to skip the question of their income, the data are not MCAR. However, the data still can be MAR ${ }^{43}$ if there are no missing values in other variables and the subgroups of occupation and education are independent of income (Ake, 2012). Unfortunately, it is impossible to verify if the data satisfy the MAR assumption from the observed data alone (Ake, 2012). Also, MNAR occurs when the unobserved variable predicts why it is missing, but there is no formal test available to check MNAR (Social Science Computer Cooperative, 2013).

When the missing patterns are identified as either MCAR or MAR, researchers can use imputation methods that help fill in the missing data.

\footnotetext{
${ }^{43}$ Although MCAR and MAR are widely discussed as missing patterns, the distinctions between them are not clearly explained (Heitjan \& Basu, 1996).
} 


\section{Appendix 7.}

\section{Methods for imputing categorical variables}

For categorical variables measured with a Likert Scale, two imputation methods can be used. The first imputation method for categorical variables is a "rounding method." This method treats the categorical variables with missing data as quantitative with bounds. For example, the variable of job stress is measured on a four-point Likert Scale, ranging from 1 to 4 . After imputing, imputed values are rounded to the nearest whole number, filling in the missing values with plausible values (Ake, 2005). For instance, an imputed value of 2.7 will be rounded to 3 , which will be used for the missing value for job stress.

The second imputation method for categorical variables is a "binary dummy variables method." This method creates an indicator (binary dummy) variable for each level of the categorical variable. For example, for a four-level categorical variable, four binary dummy variables are created. The values are imputed as binary with strict bounds of 0 and 1 . After the multiple imputation is performed, the dummy that has the highest imputed value is assigned to 1 and the rest of the dummies to 0 (Ake, 2005).

To choose a better method for imputing categorical variables in this study, Chi-square tests of independence were run to compare the original and the imputed data after applying each method. Ideally, the imputed and original values should show the same distribution. The insignificant difference from the Chi-square statistics indicates that the two sets of data distribute the same, meaning the data are imputed inadequately. Based on the results, between the rounding 
and the binary dummy variables methods, this study selected an imputation method that shows the most insignificant test results. 


\section{Appendix 8.}

\section{Supplemental Analysis—using alternative outcome (three-level work status)}

In addition to the binary outcome measuring work status (retired and working), this study also used an alternative outcome, three-level work status (retired, part-time, full-time) ${ }^{44}$ for supplemental analysis that compared the results between the binary and three-level measures to predict work status.

Using multinomial logit analysis, the results between the binary and three-level measures basically identical, showing the same factors significant for the three racial groups, except for two factors: dependents and education. To illustrate, the results using the three-level outcome showed that Whites had an additional factor, dependents, that was significant; compared to retirees, full-time workers had a higher number of dependents $(\beta=.278, S E=.140, p=.047)$. Furthermore, among Latinos, education appeared to be another significant factor; among nearretirement aged Latino workers, those with lower education were more likely to stay in the labor market as full-timers, while those with higher education were more likely to retire after age 65 ( $\beta$ $=-.030, S E=.085, p=.029)$. Yet, there was no statistical difference in education between Latino retirees and part-time workers. Future studies need to further clarify how education impacts older Latinos' labor market participation.

Even with its potential usefulness, the three-level outcome measure was not chosen because of the HRS variables regarding work status provide unclear distinction between parttime and bridge jobs; some workers might have had mostly part-time jobs involuntarily during

\footnotetext{
44 This variable was created from the same HRS raw variable, labor force status, which this study used to create the binary outcome.
} 
their working lives, while other workers — sometimes referred to as bridge job workers - might have reduced work hours voluntarily to prepare for full retirement, a distinction which is simply not clear yet in the current literature. Thus, it can be ambiguous to discuss racial inequality between part-time and full-time workers. Future research needs to further examine the nature of part-timers and bridge-job takers among older workers. 
Table 10. Multinomial logit analysis results using three-level outcome (retired, part-time, and full-time)

\begin{tabular}{|c|c|c|c|c|c|c|c|c|c|}
\hline \multirow{2}{*}{ Coefficients } & \multicolumn{3}{|c|}{ All races } & \multicolumn{2}{|c|}{ Whites } & \multicolumn{2}{|c|}{ Blacks } & \multicolumn{2}{|c|}{ Latinos } \\
\hline & Part-time & Full-tim & & Part-time & Full-time & Part-time & Full-time & Part-time & Full-time \\
\hline Constant & 8.487 & 2.836 & & 2.163 & 15.330 & -4.995 & 1.058 & 10.085 & -4.361 \\
\hline \multicolumn{10}{|l|}{ Factors of Interest } \\
\hline \multicolumn{10}{|l|}{ Financial Factors } \\
\hline Employer-sponsored pensions & -0.055 & 0.242 & & 0.144 & 0.076 & 0.116 & -0.438 & -0.165 & 0.337 \\
\hline Wealth $(\$ 10,000)$ & 0.002 & 0.002 & & 0.001 & 0.001 & 0.022 & 0.024 & 0.026 & 0.019 \\
\hline HH income $(\$ 10,000)$ & 0.009 & 0.021 & & 0.009 & 0.020 & -0.007 & 0.025 & 0.018 & 0.230 \\
\hline Home ownership & 0.169 & 0.006 & & -0.074 & 0.291 & 0.551 & $0.881 *$ & 0.014 & -0.600 \\
\hline Health & $0.403 * *$ & 0.284 & * & $0.436 *$ & 0.226 & 0.218 & 0.499 & 0.492 & $0.785 *$ \\
\hline \multicolumn{10}{|l|}{ Career Patterns } \\
\hline Employment stability & -0.006 & 0.001 & & -0.004 & 0.004 & -0.004 & -0.033 & -0.026 & -0.000 \\
\hline Occupation types & -0.119 & 0.102 & & -0.094 & -0.023 & -0.562 & 0.421 & 0.223 & 0.354 \\
\hline Education & 0.034 & -0.020 & & 0.015 & 0.011 & 0.194 & -0.088 & -0.030 & $-0.239 *$ \\
\hline \multicolumn{10}{|l|}{ Control Factors } \\
\hline \multicolumn{10}{|l|}{ Attributes of Preretirement work } \\
\hline Job stress & -0.122 & 0.096 & & 0.010 & 0.102 & -0.488 & 0.082 & -0.151 & -0.127 \\
\hline Employer's attitude toward older workers & -0.085 & -0.013 & & -0.107 & -0.019 & -0.118 & 0.102 & -0.220 & -0.312 \\
\hline Meaning of Work & $0.226 * *$ & 0.217 & * & $0.272 *$ & 0.341 & $* * \quad 0.244$ & 0.105 & -0.586 & -0.740 \\
\hline Dependents (\#) & -0.198 & 0.158 & & -0.313 & 0.280 & * $\quad-0.237$ & -0.229 & 0.425 & 0.488 \\
\hline \multicolumn{10}{|l|}{ Demography } \\
\hline Age & -0.044 & -0.211 & * & -0.064 & -0.284 & 0.037 & -0.056 & -0.127 & 0.116 \\
\hline Gender & -0.065 & 0.198 & & -0.074 & 0.146 & -0.003 & 0.238 & 0.567 & 0.567 \\
\hline Marital status & 0.069 & -0.001 & & 0.033 & -0.086 & 0.287 & 0.221 & -0.082 & -0.060 \\
\hline Blacks & 0.038 & -0.114 & & - & - & - & - & - & - \\
\hline Latinos & -0.148 & -0.419 & $*$ & - & - & - & - & - & - \\
\hline$N$ & \multicolumn{3}{|c|}{1114} & \multicolumn{2}{|r|}{874} & \multicolumn{2}{|c|}{155} & \multicolumn{2}{|c|}{85} \\
\hline Max-rescaled $\mathbf{R}^{2}$ & \multicolumn{3}{|c|}{.112} & \multicolumn{2}{|r|}{.126} & \multicolumn{2}{|c|}{.296} & \multicolumn{2}{|c|}{.354} \\
\hline
\end{tabular}




\section{Appendix 9.}

\section{Supplemental Analyses-checking multicollinearity}

Health and financial factors, known to be the most influential, played only partial roles for older Blacks and Latinos in this study, calling into question whether multicollinearity might have distorted the analysis results. Multicollinearity describes a situation in a multiple regression model where a strong correlation appears among some of the independent variables (Belsley, Kuh, \& Welsch, 1976). This correlation can occur between some pairs of the independent variables on a simpler level, or among three or more variables in a more complex level (Toossi, 2011). Because the variables of interests in this study are associated with each other, the effect of health on older Black workers might not have shown up. Multicollinearity is not a violation of statistical assumptions of a regression analysis, given that most multiple regressions show some level of multicollinearity; however, identifying multicollinearity can be helpful to better understand the analysis results (Goldberger, 1991) ${ }^{45}$.

This study ran an additional analysis to check whether multicollinearity might have affected the analytical results (Table 10). One way to detect whether high multicollinearity affected the analysis of this study ${ }^{46}$ is to calculate the Variance Inflation Factor (VIF) ${ }^{47}$ (Tacq,

\footnotetext{
${ }^{45}$ Note that correction is rarely necessary when multicollinearity is detected (Goldberger, 1991). The main problem, which has long been an issue in social science, is that high multicollinearity causes larger standard errors and wider confidence intervals, affecting the significance of an individual variable (Tacq, 2004).

${ }^{46}$ Another way to check multicollinearity is to run the correlation between the independent variables (Goldberger, 1991). However, some researchers argue that this method is not recommended as proof because multicollinearity should be investigated in a multivariate context, such as spurious relations or suppressor variables (Tacq, 2004).

${ }^{47}$ The IVF values were calculated by running OLS regression on this study's model, using the SAS commends, tol Collin vif, were used. This is a commonly recommended method for calculating VIF, given the fact that the concern 
2004). As a rule of thumb, a VIF greater than 10 indicates significant multicollinearity (Der \&

Everitt, 2009). All of the VIF values ranged around 1 or 2 , detecting no multicollinearity issue ${ }^{48}$.

Thus, it is concluded that multicollinearity did not bias the estimation results of this study.

Table 11. VIF information for imputed data by race

\begin{tabular}{|c|c|c|c|c|c|c|}
\hline & \multicolumn{2}{|c|}{ Variables } & All & White & Blacks & Latinos \\
\hline \multirow{8}{*}{$\begin{array}{c}\text { Variables } \\
\text { of } \\
\text { interest }\end{array}$} & \multirow{4}{*}{$\begin{array}{l}\text { Financial } \\
\text { factors }\end{array}$} & Pension & 1.092 & 1.072 & 1.254 & 1.218 \\
\hline & & Wealth & 1.039 & 1.036 & 1.240 & 1.366 \\
\hline & & $\mathrm{HH}$ income & 1.090 & 1.076 & 1.660 & 1.585 \\
\hline & & Home & 1.113 & 1.143 & 1.143 & 1.189 \\
\hline & \multicolumn{2}{|l|}{ Health } & 1.140 & 1.082 & 1.252 & 1.362 \\
\hline & \multirow{2}{*}{$\begin{array}{l}\text { Career } \\
\text { patterns }\end{array}$} & Stability & 1.512 & 1.390 & 1.634 & 2.376 \\
\hline & & Job type & 1.110 & 1.136 & 1.140 & 1.169 \\
\hline & \multicolumn{2}{|l|}{ Education } & 1.440 & 1.357 & 1.731 & 1.680 \\
\hline \multirow{7}{*}{$\begin{array}{c}\text { Control } \\
\text { variables }\end{array}$} & \multirow{2}{*}{$\begin{array}{l}\text { Attributes of } \\
\text { work }\end{array}$} & Job stress & 1.050 & 1.057 & 1.197 & 1.267 \\
\hline & & Attitudes & 1.052 & 1.056 & 1.170 & 1.236 \\
\hline & \multicolumn{2}{|l|}{$\begin{array}{l}\text { Meaning of } \\
\text { work }\end{array}$} & 1.027 & 1.033 & 1.112 & 1.189 \\
\hline & \multicolumn{2}{|l|}{ Dependents } & 1.015 & 1.017 & 1.059 & 1.208 \\
\hline & \multirow{3}{*}{ Demographics } & Age & 1.020 & 1.020 & 1.134 & 1.189 \\
\hline & & Gender & 1.227 & 1.288 & 1.273 & 1.483 \\
\hline & & Marital & 1.215 & 1.242 & 1.381 & 1.266 \\
\hline
\end{tabular}

is with the relationship among the independent variables, but not the functional form of the model for the dependent variable in estimating collinearity (Tacq, 2004).

${ }^{48}$ In the presence of multicollinearity, researchers can correct it in a number of ways. First, one can acknowledge but ignore its presence (Tacq, 2004). Second, one obvious solution is to delete one of these highly correlated variables (Goldberger, 1991). However, researchers often find this method unsatisfactory (Toossi, 2011) because of a theoretical framework; each variable included in the model offers a distinct explanation for the outcome, even if they are statistically correlated (Tacq, 2004). As for a third solution, econometricians suggest obtaining more data, which is impractical given time and financial limitations (Tacq, 2004). The final solution is to remove the collinear variable (Tacq, 2004). 


\section{Appendix 10.}

\section{Supplemental Analyses-comparison between this study's samples (workers) and those excluded from the study (the unemployed and disabled)}

Older individuals in the labor market are composed of those who are currently working, part-/full-time, retirees, and disabled/unemployed. It should be noted that this study's results may only apply to workers approaching retirement and may not reflect those unemployed and disabled because these two groups differ in many respects.

Table 12. Comparisons between this study's sample and those excluded from this study

\begin{tabular}{|c|c|c|c|c|c|}
\hline & & & $n($ & mean $(S D)^{\mathrm{a}}$ & \\
\hline & Vari & & $\begin{array}{l}\text { Study sample } \\
\quad(\mathrm{n}=1114)\end{array}$ & $\begin{array}{c}\text { Unemployed \& } \\
\text { disabled } \\
(\mathbf{n}=\mathbf{1 2 6})\end{array}$ & $p$ \\
\hline Prce & & Blacks & $155(14 \%)$ & $25(21 \%)$ & .000 \\
\hline Kace & & Latinos & $85(7 \%)$ & $23(19)$ & .000 \\
\hline & & Pension (no) & $228(20 \%)$ & $73(58 \%)$ & .000 \\
\hline & Financial & Wealth $(\mathrm{k})$ & 387 (2419) & $79(265)$ & $.000^{c}$ \\
\hline & factors & HH income (k) & 87 (149) & $4(14)$ & .000 \\
\hline Variables & & Home (no) & $118(11 \%)$ & $50(48 \%)$ & .000 \\
\hline of interest & Health & & $3.52(.95)$ & $2.13(1.12)$ & .000 \\
\hline & Career & Stability & $20.17(10.47)$ & $12.23(9.51)$ & .000 \\
\hline & patterns & Job type (blue) & $400(36 \%)$ & $61(61 \%)$ & .000 \\
\hline & Education & & $13.08(2.90)$ & 10.85 & .000 \\
\hline
\end{tabular}

a. Chi-square analysis was conducted for the categorical variables of interest, and ANOVA was run for the continuous variables of interest. Post-hoc analysis was followed for only ANOVA analysis results that showed statistical differences. 
Table 11 compares racial composition, finances, health, and career patterns between the sample of this study (workers) and the disabled/unemployed. There were statistically significant group differences in all covariates, suggesting that the unemployed and disabled were more disadvantaged than workers. For instance, the average health was significantly lower for the unemployed and disabled $(M=2.13, \mathrm{SD}=1.12)$, compared to this study's sample $(M=3.52$, SD $=.95), t(1238)=11.210, p<.001$.

Additional analyses were performed to compare how individuals aged from 61 to 64 in 2004 differ in their work status - retired, working, and disabled/unemployed (Table 12). Note that the worker group is the samples of this study, and the retired and disabled/unemployed are those excluded from this study.

The results from multinomial logit analysis showed that compared to retirees (reference group), workers were in general more advantaged; older workers had higher total household income and better health than retirees, which appeared in the results of all three races. For example, for one score increased in health, one's chance of delaying retirement and staying in the labor market increased by $31 \%$ for Whites $(\beta=.272, S E=.057, O R=1.313, p<.000), 87 \%$ for Blacks $(\beta=.625, S E=.146, O R=1.869, p<.000)$, and $71 \%$ for Latinos $(\beta=.535, S E$ $=.193, O R=1.707, p=.006)$. Also, compared to retirees, workers were more likely to be Whites than Latinos $(\beta=-.227, S E=.094, O R=.635, p=.016)$.

Furthermore, Latino workers, unlike White and Black workers, showed two additional variables that significantly distinguished them from Latino retirees. First, Latino workers had longer employment tenure throughout their working lives than their retired counterparts $(\beta=.044$, $S E=.023, O R=1.045, p=.048)$. Second, there was a fascinating statistical difference in 
education between Latino workers and retirees $(\beta=-.129, S E=.055, O R=.879, p=.020)$. To illustrate, on average, older workers of all races (13.02 years) had significantly higher education than retirees (12.45 years) or the disabled/unemployed (10.85 years), $F(2,2451)=35.294, p$ $=.000$, (table not presented); however, for Latinos, there was no statistical differences in education among the three groups, $F(2,208)=2.075, p=.128$, (table not shown), and after controlling for covariates, older Latinos with less education were more likely to stay working. This may suggest that the nature of older Latino workers may differ from that of White and Black workers, a finding which calls for future research.

In regard to the disabled/unemployed, it was not surprising that they exhibited poorer health than retirees regardless of race. However, the Latino disabled/unemployed, unlike their Whites and Blacks counterparts, showed two additional variables that were statistically significant. The Latino disabled/unemployed were less likely to be eligible for private pensions $(\beta=-1.281, S E=.513, O R=.077, p=.013)$ and to own their own house $(\beta=-.838, S E=.411$, $O R=.187, p=.041)$ compared to their retired counterparts.

In sum, the descriptive and multinomial logit analyses showed that, even when they are in the same age groups, the three groups - workers, retirees, and the disabled/unemployed noticeably differ in many respects. Thus, the results of this study, which focused on workers approaching retirement, can only be applied to workers. 
Table 13. Multinomial logit analysis results comparing retirees, workers, and the disabled/employed.

\begin{tabular}{|c|c|c|c|c|c|c|c|c|c|c|}
\hline \multirow[b]{2}{*}{ Coefficients } & \multicolumn{3}{|c|}{ All races } & \multicolumn{3}{|c|}{ Whites } & \multicolumn{2}{|c|}{ Blacks } & \multicolumn{2}{|c|}{ Latinos } \\
\hline & Workers & \multicolumn{2}{|c|}{$\begin{array}{l}\text { Disabled/ } \\
\text { unempl. }\end{array}$} & \multicolumn{2}{|c|}{ Workers } & $\begin{array}{l}\text { Disabled/ } \\
\text { unempl. }\end{array}$ & \multirow{2}{*}{$\begin{array}{c}\text { Workers } \\
6.623\end{array}$} & \multirow{2}{*}{$\begin{array}{c}\begin{array}{l}\text { Disabled/ } \\
\text { unempl. }\end{array} \\
0.927\end{array}$} & Workers & $\begin{array}{l}\text { Disabled/ } \\
\text { unempl. }\end{array}$ \\
\hline Constant & 8.487 & 21.350 & & 8.632 & & 24.370 & & & 6.459 & 45.917 \\
\hline \multicolumn{11}{|l|}{ Factors of Interest } \\
\hline \multicolumn{11}{|l|}{ Financial Factors } \\
\hline Employer-sponsored pensions & -0.055 & 0.242 & & -0.066 & & 0.019 & -0.093 & 0.515 & -0.160 & $-1.281 *$ \\
\hline Wealth $(\$ 10,000)$ & 0.000 & 0.000 & & -0.000 & & 0.000 & 0.000 & -0.003 & -0.000 & -0.005 \\
\hline $\mathrm{HH}$ income $(\$ 10,000)$ & $0.008 * * *$ & 0.006 & & 0.007 & $* * *$ & -0.004 & $0.012 * *$ & -0.020 & $0.018 *$ & -0.010 \\
\hline Home ownership & -0.041 & -0.415 & $k *$ & 0.069 & & 0.195 & 0.092 & -0.569 & -0.402 & $-0.838 *$ \\
\hline Health & $0.339 * * *$ & -0.550 & $* * *$ & 0.272 & $* * *$ & $-0.783 * * *$ & $0.625^{* * *}$ & -0.051 & $0.535 * *$ & -0.209 \\
\hline \multicolumn{11}{|c|}{ 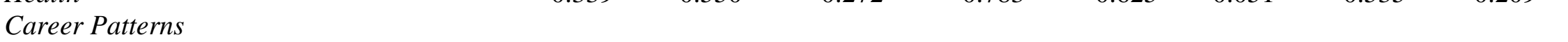 } \\
\hline Employment stability & 0.008 & -0.026 & & -0.004 & & 0.003 & 0.022 & -0.033 & $0.044 *$ & 0.029 \\
\hline Occupation types & 0.038 & -0.097 & & -0.094 & & 0.058 & -0.139 & 0.459 & 0.054 & 0.190 \\
\hline \multirow{2}{*}{\multicolumn{11}{|c|}{ Control Factors ${ }^{1}$}} \\
\hline & & & & & & & & & & \\
\hline Dependents (\#) & 0.129 & 0.387 & $*$ & 0.036 & & 0.181 & 0.284 & $0.741 *$ & 0.486 & $1.092 *$ \\
\hline \multicolumn{11}{|l|}{ Demography } \\
\hline Age & $-0.147 * *$ & -0.351 & $* *$ & -0.156 & $* *$ & $-0.409 * *$ & -0.133 & -0.016 & -0.120 & $-0.782 *$ \\
\hline Gender & 0.066 & -0.005 & & 0.102 & & -0.203 & -0.181 & -0.115 & 0.020 & 0.721 \\
\hline Marital status & $0.018 * *$ & -0.118 & & 0.207 & $* *$ & 0.049 & 0.118 & -0.443 & -0.147 & -0.546 \\
\hline Blacks & -0.061 & -0.022 & & - & & - & - & - & - & - \\
\hline Latinos & $-0.227 *$ & -0.220 & & - & & - & - & - & - & - \\
\hline$N$ & \multicolumn{3}{|c|}{1995} & \multicolumn{3}{|c|}{1496} & \multicolumn{2}{|c|}{325} & \multicolumn{2}{|c|}{174} \\
\hline Max-rescaled $\mathbf{R}^{2}$ & \multicolumn{3}{|c|}{.185} & \multicolumn{3}{|c|}{.170} & \multicolumn{2}{|c|}{.288} & \multicolumn{2}{|c|}{.373} \\
\hline
\end{tabular}

Note: $* p<.05 ; * * p<.01 ; * * * p<.001$ (outcome reference: retirees)

1. Job stress, employers' attitude toward older workers, and the meaning of work were excluded from the model because the disabled/unemployed did not have data in these three variables. 


\title{
Appendix 11.
}

\section{Supplementary analysis—correlation between meaning of work and selected study variables}

\begin{abstract}
Although the results of this study did not include any interaction effects on meaning of work, which is beyond the scope of this study, supplementary analyses were conducted to better understand how older individuals value the intrinsic reward of working.

Table 13 demonstrates the correlations between meaning of work and selected variables in the study. Regardless of race, there were in general very small but significant correlations between meaning of work and all selected covariates (finances, health, job type, education, and gender); workers who more highly valued the meaning of work tended to be those who had more wealth, higher household income, better health, white-collar jobs, higher education, and were males. However, interestingly, exceptions were found among older Blacks. Unlike older Whites and Latinos, older Black workers' meaning of work was not significantly correlated with their health and job types. These results may suggest that, by and large, older people with higher privileges more strongly value the intrinsic rewards of working than their counterparts, yet more research is necessary to draw a conclusion given the exceptions.
\end{abstract}


Table 14. Correlations between meaning of work and selected study variables

\begin{tabular}{lcccc}
\hline & All & Whites & Blacks & Latinos \\
\cline { 2 - 5 } & \multicolumn{1}{c}{$r$} & $p$ & $r$ & $p$ \\
\hline Wealth & $0.028 * * *$ & $0.023 * * *$ & $0.056 * * *$ & $0.171 * * *$ \\
HH income & $0.073 * * *$ & $0.073^{* * *}$ & $0.116 * * *$ & $0.128 * * *$ \\
Health & $0.065 * * *$ & $0.065 * * *$ & 0.008 & $0.045 * *$ \\
Job type & $-0.083 * * *$ & $-0.090 * * *$ & 0.003 & $-0.061 * * *$ \\
Education & $-0.012 * *$ & $0.028 * * *$ & $-0.109 * * *$ & $-0.168 * * *$ \\
Gender & $0.084 * * *$ & $0.073 * * *$ & $0.092 * * *$ & $0.084 * * *$ \\
\hline Note: $* p<.05 ; * * p .01 ; * * p<.001$ &
\end{tabular}




\section{BIBLIOGRAPHY}

AARP. (2008). Staying ahead of the curve 2007: The AARP work and career study. Washington, DC: AARP.

AARP. (2009). 50+ Hispanic workers: A growing segment of the U.S. workforce. Washington, DC: AARP.

AARP. (2011). 50+ African American workers: A status report, implications, and recommendations. Washington, DC.

Adams, S. J. (2000). Three essays on the Economics of aging. Michigan State University.

Adams, S. J. (2002). Passed over promotion because of age: An empirical analysis of the consequences. Journal of Labor Research, 23(3), 446-461.

Ake, C. F. (2005) Rounding Aater multiple imputation with non-binary categorical covariates. SAS® Users Group International Conference (SUGI) 30. Focus Session Paper 112-30.

Ake, C. F. (2012) Rounding after multiple impuation with non-binary categorical covariates. SUGI 30 Focus Session.

Allen, W. R., \& Chung, A. Y. (2000). "Your blues ain't like my blues": Race, ethnicity, and social inequality in America. Contemporary Sociology, 29(6), 796-805.

Allison, P. D. (1999). Comparing Logit and Probit Coefficients Across Groups. Sociological Methods \& Research, 28(2), 186-208. doi: 10.1177/0049124199028002003

Allison, P. D. (2000). Missing data. Thousand Oaks, CA: Sage Publications. 
American Association of Community Colleges. (2012). The Plus 50 Initative Evaluation: Initiative Impact. Washington: DC.

Andersen, M. L., \& Collins, P. H. (2004). Conceptualizing race, class, and gender. In M. L. Andersen \& P. H. Collins (Eds.), Race, Class, and Gender (pp. 75-98). Belmont, CA: Thomson Wardsworth.

Anderson, K. H., \& Burkhauser, R. V. (1985). The retirement-health nexus: A new measure of an old puzzle. Journal of Human Resources, 20(3), 315-330.

Atchley, R. C. (1982). Retirement as a social institution. Annual Review of Sociology, 8, 263287.

Au, A., Mitchell, O. A., \& Phillops, J. (2005) Saving shortfalls and delayed retirement. Working Paper. Ann Arbor, MI: University of Michigan Retirement Research Center.

Au, A., Mitchell, O. S., \& Phillips, J. W. (2005). Modeling Lifetime Earnings Paths: Hypothetical versus Actual Workers: SSRN.

Baker, R. L. (2003). The Social Work Dictionary (5th ed.). Washington, DC. : NASW Press. Barocas, V. (1994). Rethinking retirement income. New York: Conference Board.

Baugh, S. G., \& Sullivan, S. E. (2009). Maintaining Focus, Energy, and Options Over the Career. Charlotte, NC Information Age Publishing, Inc. .

Belgrave, L. L. (1988). The Effects of Race Differences in Work History, Work Attitudes, Economic Resources, and Health on Women ' Retirement. Research on Aging, 10(3), 383-398. doi: 10.1177/0164027588103005

Belsley, D., Kuh, E., \& Welsch, R. E. (1976). Regression diagnistics Idendifying Influential data and sources of collinearity. New York: Wiley. 
Bendick, M., Jackson, C., \& Reinoso, V. (1994). Measuring employment discrimination through controlled experiments. The Review of Black Political Economy 23, 25-48.

Beteille, A. (2003). Poverty and Inequality. Economic and Political Weekly, 38(42), 4455-4463.

Biggs, A. G., Sarney, M., \& Tamborini, C. R. (2009) A Progressivity Index for Social Security. Vol. No. 2009-01 January: Office of Retirement and Disability Policy, U.S. Social Security Administration.

Bohlander, G., \& Snell, S. (2010). Managing human resources. Mason, OH: South-Western Cengage Learning.

Borland , J. (2005). Transitions to retirement: A review Melbourne Institute Working Paper (Vol. 3, pp. 1-34): University of Melbourne

Bould, S. (1980). Unemployment as a Factor in Early Retirement Decisions. American Journal of Economics and Sociology, 39(2), 123-136.

Bound, J. (1991). Self-reported versus objective measures of health in retirement models. Journal of Human Resources, 26(1), 106-138.

Bound, J., Schoenbaum, M., \& Waidmann, T. (1995). Race and educational differences in disability status and labor force attachment in the health and retirement survey. Journal of Human Resources, 30, S227-S267.

Bound, J., Schoenbaum, M., \& Waidmann, T. (1996). Race differences in labor force attachment and disability status. Gerontologist, 36(3), 311-321.

Bowen, W. G., \& Bok, D. C. (1998). The Shape of the River: Long-Term Consequences of Considering Race in College and University Admissions. Princeton, N.J.: Princeton University Press. 
Brown, E. (2009). Work, retirement, race, and health disparities. In T. C. Antonucci \& J. S. Jackson (Eds.), Life-course perspectives on late-life health inequalities (pp. 233-249). New York: Springer Pub.

Brown, M. C., \& Yates, T. (2005). Toward an empirical corpus of literature on historically black colleges and universities. American Journal of Education, 112(1), 129-137.

Brown, T. H., \& Warner, D. F. (2008). Divergent Pathways? Racial/Ethnic Differences in Older Women's Labor Force Withdrawal. J Gerontol B Psychol Sci Soc Sci, 63(3), S122-134.

Burr, J. A., Massagli, M. P., Mutchler, N. E., \& Pienta, A. M. (1996). Labor force transitions among older African American and White men. Social Forces, 74(3).

Burtless, G., \& Quinn, J. F. (2000). Retirement trends and policies to encourage work among older Americans Economics Deparment Working Papers in Economics: Boston College.

Butler, R. N., \& Gleason, H. P. (1994). Productive aging: Enhancing vitality in later life. New York: Springer.

Butrica, B. A., \& Johnson, R. W. (2010). Racial, Ethnic, and gender differentials in employersponsored pensions. Washington, DC: Urban Institute.

Cagney, K. A., Browning, C. R., \& Wen, M. (2005). Race disparities in self-rated health at older ages: What difference does the neighborhood make? The Journals of Gerontology Series B: Psychological Sciences and Social Sciences, 60,181S-190S.

Cahill, K. E., Giandrea, M. D., \& Quinn, J. F. (2006). Retirement patterns from career employment. The Gerontologist, 46(4), 514-523.

Cai, L., \& Kalb, G. (2006). Health status and labour force participation: evidence from Australia. Health Econ, 15(3), 241-261. doi: 10.1002/hec.1053 
Caputo, R. K. (2004). Women who die young: The cumulative disadvantage of race. Affilia, 19(1), 10-23. doi: 10.1177/0886109903260666

Choi, N. G. (1994). Racial differences in timing and factors associated with retirement. Journal of Sociology and Social Welfare, 21(3), 31-52.

Choi, N. G. (1997). Racial differences in retirement income: the roles of public and private income sources. Journal of Aging and Social Policy, 9(3), 21-42.

Choi, N. G. (2001). Relationship between life satisfaction and postretirement employment among older women. International Journal of Aging and Human Development, 52(1), 4570.

Choudhury, S., \& Bridges, B. (2009). Examining Social Security Benefits as a Retirement Resource for Near-Retirees, by Race and Ethnicity, Nativity, and Disability Status. Social Security Bulletin, 69(1), 19-44.

Cihon, P. J., \& Castagnera, J. O. (2008). Employment \& Labor Law (6 ed.). Mason, OH: SouthWeatern Cengage Learning.

Clark, R. L., \& Quinn, J. F. (2002). Patterns of Work and retirement for a New Century. Generations, 26(2), 17-24.

Costa, D. (1998). The evolution of retirement: An American economic history, 1880-1990. Chicago: University of Chicago Press.

Crenshaw, A. B. (2004). The benefits bust. Washington Post National Weekly Edition, 21(34), 20-21.

Crimmins, E. M., Hayward, M. D., \& Seeman, T. E. (2004). Race/ethnicity, socioeconomic status, and health. In N. B. Anderson, R. A. Bulatao \& B. Cohen (Eds.), Critical 
perspective on racial and ethnic differences in health in later life. Washington, DC: National Academy Press.

Cruden, R. (1969). The Negro in reconstruction. Englewood Cliffs, NJ: Prentice-Hall.

Crystal, S. (2002). Poverty. In D. J. Ekerdt \& I. NetLibrary (Eds.), Encyclopedia of aging (pp. 1116-1121). New York: Macmillan Reference USA.

Crystal, S., \& Shea, D. (1990). Cumulative advantage, cumulative disadvantage, and inequality among elderly people. The Gerontologist, 30(4), 437-443.

Crystal, S., Shea, D., \& Krishnaswami, S. (1992). Educational attainment, occupational history, and stratification: Determinants of later-life economic outcomes. The Journals of Gerontology Series B: Psychological Sciences and Social Sciences, 47, S213-S221.

Cumming, E., \& Henry, W. E. (1961). Growing old: The process of disengagement. New York: Basic Books.

Curl, A. L., \& Hokenstad, M. C., Jr. (2006). Reshaping retirement policies in post-industrial nations: the need for flexibility. Journal of Sociology and Social Welfare, 33(2), 85-106.

Currie, J., \& Madrian, B. (1999). Health, health insurance, and the labor market JCPR Working Papers: Northwestern University/University of Chicago Joint Center for Poverty Research.

Daniels, R. (2002). Coming to America: A history of immigration and ethnicity in American life. New York: Parennial.

Dannefer, D. (1987). Aging as intracohort differentiation: Accuntuation, the Matthew Effect, and the life course. Sociological Forum, 2, 211-236. 
Dannefer, D. (2003). Cumulative advantage/disadvantage and the life Course: Cross-fertilizing age and social science theory. The Journals of Gerontology Series B: Psychological Sciences and Social Sciences, 58(6), S327-S337. doi: 10.1093/geronb/58.6.S327

Dannefer, D. (2011). Age, the life course, and the sociological imagination: Prospects for theory. In R. H. Binstock, L. K. George, S. J. Cutler, J. Hendricks \& J. H. Schulz (Eds.), Handbook of aging and the social sciences (pp. 3-16). Amsterdam, Boston: Elsevier/Academic Press.

Dannefer, D., \& Settersten, R. A. J. (2010). The study of the life course: Implications for social Gerontology. In C. Phillipson \& D. Dannefer (Eds.), The SAGE handbook of social gerontology. London: SAGE.

Darity, W. A., Jr., \& Mason, P. L. (1998). Evidence on discrimination in employment: Codes of color, code of gender. Journal of Economic Perspectives 12(2), 63-90.

Davis, K., \& Moore, W. (1945). Some principles of stratification. American Sociological Review, $10,242-249$.

DeNavas-Walt, C., Proctor, B. D., \& Smith, J. C. (2008). Income, poverty, and health insurance coverage in the United States:2007 Current Population Reports (pp. 60-235). Washington, DC.

Dendinger, V. M., Adams, G. A., \& Jacobson, J. D. (2005). Reasons for working and their relationship to retirement attidudes, job satisfaction and occupational self-efficacy of bridge employees.(Author Abstract). International Journal of Aging \&amp; Human Development, 61(1), 21(15).

Denton, F. T., \& Spencer, B. G. (2009). What is retirement? A review and assessment of alternative concepts and measures. Canadian Journal on Aging, 28(1), 63-76. 
DePrete, T. A., \& Eirich, G. M. (2006). Cumulative advantage as a mechanism for inequality: A review of theoretical and emprical developments. Annual Review of Sociology, 32(1), 271-297.

Der, G., \& Everitt, B. (2009). A handbook of statistical analyses using SAS (3rd ed.). Boca Raton: CRC Press.

Deschryvere, M. (2004). Health and retirement decisions: Un update of the literature (Vol. No. 932). Helsinki, Finland: The Research Institutue of the Finnish Economy.

DeViney, S., \& O'Rand, A. M. (1988). Gender-cohort succession and retirement among older men and women, 1951 to 1984. The Sociological Quaterly, 29(4), 525-540.

DOL Employment and Training Administration. (2006). Revised income inclusions and exclusions and procedures for determining Senior Community Service Employment Program (SCSEP) eligibility Retrieved May 14, 2013, from http://www.doleta.gov/seniors/other_docs/TEGL12-06.pdf

DOL Employment and Training Administration. (2013). About SCSEO Retrieved May 14, 2013, from http://www.doleta.gov/seniors/html_docs/AboutSCSEP.cfm

Doling, J., \& Horsewood, N. (2003). Home ownership and early retirement: European experience in the 1990s. Journal of Housing and the Built Environment, 18(4), 289-308. doi: 10.1023/b:joho.0000005755.62225.54

Donoghue, C. (2008). Disengagement Theory. In V. Parrillo (Ed.), Encyclopedia of Social Problems (pp. 247-248). Thousand Oaks, CA: SAGE Publications, Inc.

DuBois, W. E. B. (1903). The souls of black folk. New York: Dover.

Durkheim, É. (1893/1960). The division of labor in society. Glencoe, Ill.: Free Press. 
Dwyer, D., \& Mitchell, O. (1999). Health problems as determinants of retirement: Are self-rated measures endogenous? Journal of Health Econmics. 18, 2(173-193).

Ekerdt, D. J. (2002). Retirement, Transision. In D. J. Ekerdt \& G. Gale (Eds.), Encyclopedia of aging (Vol. 4, pp. p1217-1222). New York: Macmillan Reference USA.

Ekerdt, D. J., Kosloski, K., \& DeViney, S. (2000). The normative anticipation of retirement by older workers. Research on Aging, 22(1), 3-22.

Employee Benefit Research Institute. (2007). Retirement trends in the United States over the past quater-centry. Washington, DC: Author.

England, G. W. (1967). Peronal value systems of American managers. The Academy of Management Journal, 10(1), 53-68.

Erickson, E. (1975). Life history and the historical mmoment. New York: Norton.

Ettner, S. (1997). Is working good for you? Evidence on the endogneity of mental and physical health to female employment. Harvard School of Public Health.

Even, W. E., \& Macpherson, D. A. (1994). Why did male pension coverage deline in the 1980 ? Industrial \& Labor Relations Review, 47 (April), 439-453.

Farley, R. (1995). State of the Union: American in the 1990s. (Vol. 2). New York: Russel Sage Foundation.

Farmer, M. M., \& Ferraro, K. F. (2005). Are racial disparities in health conditions on socioeconomic status? Social Science \& Medicine, 60, 191-204.

Federal Interagency Forum on Aging-Related Statistics. (2010). Older Americans 2010: Key indicators of well-being. Washington, DC: U.S. Government Printing Office.

Feinstein, J. S. (1993). The relationship between socioeconomic status and health: A review of the literature. The Milbank Quarterly, 71, 279-322. 
Feldman, D. C. (2007). Carrer mobility and career stability among older workers. In K. S. Shultz \& G. A. Adams (Eds.), Aging and work in the 21st century. Mahwah, N.J. London: L. Erlbaum Assocciates.

Ferraro, K. F., \& Farmer, M. (1996). Double jeopardy, aging as leveler, or persistent health inequality? A longitudinal analysis of white and black Americans. The Journals of Gerontology Series B: Psychological Sciences and Social Sciences, 51B(6), S319-S328.

Ferraro, K. F., \& Kelley-Moore, J. A. (2003). Cumulative disadvantage and health: Long-term consequences of obesity? American Sociological Review, 68(5), 707-729.

Ferraro, K. F., \& Shippee, P. T. (2009). Aging and cumulative inequality: How does inequality get under the skin? The Gerontologist, 49(3).

Filer, R. K., \& Petri, P. A. (1988). A Job-Characteristics Theory of Retirement. The Review of Economics and Statistics, 70(1), 123-128.

Flippen, C., \& Tienda, M. (2000). Pathways to retirement: Patterns of labor force participation and labor market exit among the pre-retirement population by race, Hispanic origin, and sex. Journals of Gerontology Series B: Psychological Sciences \& Social Sciences, $55 B(1)$, S14-S27.

Franklin, J. H., \& Moss, A. A. (2000). From slavery to freedom: A history of African-Americans (8 ed.). Boston: McGraw-Hill.

French, E. (2005). The effects of health, wealth, and wages on labour supply and retirement behaviour. Review of Economic Studies, 72(251), 395(333).

Friedan, B. (1993). The fountain of age. New York: Simon \& Schuster Glass, TA.

Friedberg, L., \& Webb, Anthony. (2005). Retirement and the evolution of pension structure. The Journal of Human Resources, XL(2), 281-308. 
General Accounting Office. (2003) Older workers: Employment assistance focuses on subsidized jobs and job search, but revised eperformance measures could improve access to other services. GAO-03-350. Washington, DC: General Accounting Office.

George, L. K. (1993). Sociological perspectives on life transitions. Annual Review of Sociology, 19, 353-373.

George, L. K. (2000). Aging and the life course. In E. F. Borgatta, R. J. V. Montgomery \& I. NetLibrary (Eds.), Encyclopedia of sociology (pp. 78-86). New York: Macmillan Reference USA.

Gibson, R. (1987). Reconceptualizing retirement for Black-Americans. Gerontologist, 27(6), 691-698.

Gilbert, D. (2002). Social class, occupation, and social change. In J. A. Kahl (Ed.), The American class structure : In an age of growing inequality (pp. 45-82). Belmont, Calif.: Thomson Wadsworth Pub. Co.

Ginn, J., \& Arber, S. (1998). How does part-time work lead to low pension income? In J. O'Reilly \& C. Fagan (Eds.), Part-time prospects: An international comparison of parttime work in Europe, North American and the Pacific Rim (pp. 156-173). New York: Routledge.

Glenn, E. N. (1991). Cleaning up/kept down: A historical perspective on racial inequality in "Women's work". Standford Law Review, 43(6), 1333-1356.

Goldberger, A. S. (1991). A Course in Econometrics. Cambridge, MA: Harvard University Press. Greenberg, D. H., Michalopoulos, C., \& Robins, P. K. (2003). A meta-analysis of governmentsponsered training programs. Industrial \& Labor Relations Review, 57(1), 31-53. 
Griffin, B., \& Beryl, H. (2008). Post-retirement work: The individual determinants of paid and volunteer work. Journal of Occupational \& Organizational Psychology, 81(1), 101-121.

Gueorguieva, R., Sindelar, J. L., Falba, T. A., Fletcher, J. M., Keenan, P., Ran, W., \& Gallo, W. T. (Writers). (2009). The Impact of Occupation on Self-Rated Health: Cross-Sectional and Longitudinal Evidence from the Health and Retirement Survey [Article], Journals of Gerontology Series B: Psychological Sciences \& Social Sciences.

Gustman, A. L., \& Steinmeier, T. (2009). How Changes in Social Security Affect Recent Retirement Trends. Research on Aging, 31(2), 261-290.

Halpern, S. (1995). On the limits of the law: The ironic legacy of title IV of the 1964 Civil Rights Act. Baltimore: John Hopkins University Press.

Han, S. K., \& Moen, P. (1999). Clocking Out: Temporal Patterning of Retirement. The American Journal of Sociology, 105(1), 191-236.

Hardy, M. A. (1991). Employment after Retirement. Research on Aging, 13(3), 267-288. doi: $10.1177 / 0164027591133001$

Havighurst, R. J. (1968). Personality and patterns of aging. Gerontologist, 38(20-23).

Hayward, M. D. (1986). The influence of occupational characteristics on men's early retirement. Social Forces, 64(4), 1032-1045.

Hayward, M. D., Friedman, S., \& Chen, H. (1996). Race inequities in men's retirement. The Journals of Gerontology Series B: Psychological Sciences and Social Sciences, 51(1), S1-S10.

Hayward, M. D., Friedman, S., \& Chen, H. (1998). Career trajectories and older men's retirement. The Journals of Gerontology Series B: Psychological Sciences and Social Sciences, 53B(2), S91-S103. doi: 10.1093/geronb/53B.2.S91 
Hayward, M. D., Myles, T. P., Crimmins, E. M., \& Yang, Y. (2000). The significance of socioeconomic status in explaing the racial gap in chronic health conditions. American Sociological Review, 65, 910-930.

Health and Retirement Study. (2012). Health and Retirement Study: 2008 Core Final, Version 2.0 data description and usage Retrieved May 24, 2013, from http://hrsonline.isr.umich.edu/modules/meta/2008/core/desc/h08dd.pdf

Heitjan, D. F., \& Basu, S. (1996). Distinguishing "Missing at Random" and "Missing Completely at Random". The American Statistician, 50(3), 207-213. doi: $10.2307 / 2684656$

Henretta, J. C. (1992). Uniformity and diversity: Life course institutionalization and late life work exit. Sociological Quarterly, 33, 265-279.

Henretta, J. C., O'Rand, A. M., \& Chan, C. G. (1993). Joint role investments and synchronization of retirement: a sequential approach to couples' retirement timing. Social Forces, 71(4), 981-1000.

Herd, P., Goesling, B., \& House, J. S. (2007). Socioeconomic position and health: The differential effects of education versus income on the onset versus progression of health problems. Journal of Health and Social Behavior, 48(3), 223-238.

Herd, P., Robert, S. A., \& House, J. S. (2011). Health disparities among older adults: Life course influences and policy solutions. In R. H. Binstock, L. K. George, S. J. Cutler, J.

Hendricks \& J. H. Schulz (Eds.), Handbook of aging and the social sciences. Amsterdam, Boston: Elsevier/Academic Press.

Herz, D., Meisenheimer, J., \& Weinstein, H. (2000). Health and retirement benefits: Data from two BLS surveys. Monthly Labor Review, 123(3), 3-20. 
Herzog, A. R., House, J. S., \& Morgan, J. N. (1991). Relation of work and retirement to health and well-being in older age. Psychology and Aging, 6(2), 202-211.

Hinterlong, J., Morrow-Howell, N., \& Sherraden, M. W. (2001). Productive aging: Principles and perspectives. In N. Morrow-Howell, J. Hinterlong, M. W. Sherraden \& I. ebrary (Eds.), Productive aging: Concepts and challenges. Baltimore, MD: Johns Hopkins University Press.

Hochschild, A. R. (1975). Disengagement theory: A critique and proposal. American Sociological Review, 40(5), 553-569.

Hoetker, G. (2007). The use of logit and probit models in strategic management research: Critical issues. Strategic Management Journal, 28(4), 331-343. doi: 10.1002/smj.582

Hogan, R., Kim, M., \& Perrucci, C. C. (1997). Racial inequality in men's employment and retirement earnings. Sociological Quarterly, 38(3), 431-438.

Holder, K. A., \& Clark, S. L. (2008a). Working beyond retirement-age. Paper presented at the The American Sociological Association Annual Conference, Boston, MA.

Holder, K. A., \& Clark, S. L. (2008b). Working beyond retirement-age. Paper presented at the The Amercian Sociological Association Annual Conference, Boston, MA.

Holzer, H., \& Lalonde, R. (2005). Can we improve job retention and advacement among lowincome working parents? Discussion Paper. Madison, WI: Institute for Research on Poverty.

Horne, G. (2001). Whither affirmative action? Historical and political perspectives. In C. Stokes, T. Melendez \& G. Rhodes-Reed (Eds.), Race in 21 th century American (pp. 313-318). East Lansing, Michigan: Michigan State University Press. 
Horton, N. J., \& Lipsit, S. R. (2001). Multiple imputation in practice: Comparison of software packages for regression models with missing variables. The American Statistician, 55(3), 244-254.

HRS. (2011a). RAND HRS data documentation, Version K, from http://hrsonline.isr.umich.edu/

HRS. (2011b). Sampling weights: Revised for Tacker 2.0 and beyond Retrieved November 11, 2011, from http://hrsonline.isr.umich.edu/sitedocs/wghtdoc.pdf

Hwang, S.-S., Fitzpatrick, K. M., \& Helms, D. (1998). Class Differences in Racial Attitudes: A Divided Black America? Sociological Perspectives, 41(2), 367-380. doi:

$10.2307 / 1389482$

Jacobs, J. (1983). Industrial Sector and Career Mobility Reconsidered. American Sociological Review, 48(3), 415-421.

Jacoby, S. (1985). Employing bureaucracy: Managers, unions and the transformation of work, 1900-1945. . New York: Culumbia University Press.

Johnson, K. V., \& Watson, E. D. (1993). The Journal of technology studies a refereed publication of Epsilon Pi Tau, the international Honorary for Professions in Technology. The Journal of Technology Studies, 81-93.

Johnson, R. W. (2000). Trends in job demands among older workers, 1992-2000. Monthly Labor Review, 48(127).

Johnson, R. W. (2004). Trends in job demands among older workers, 1992-2002. Monthly Labor Review, 127(7), 48-56.

Jones, C. P. (2001). Invited Commentary: "Race," Racism, and the Practice of Epidemiology. American Journal of Epidemiology, 154(4), 299-304. 
Joyaux, S. P. (2001). Stragetic fund development: Building profitable relationships that last (2nd ed.). Gairtherburg, Maryland: An Aspen Publication.

Judkins, D. R. (2008). Multiple Imputation Encyclopedia of Survey Research Methods: SAGE Publications.

Kahn, J. R., \& Fazio, E. M. (2005). Economic status over the life course and racial disparities in health. The Journals of Gerontology Series B: Psychological Sciences and Social Sciences, 60(Special Issue 2), S76-S84. doi: 10.1093/geronb/60.Special_Issue_2.S76

Kamakura, W. A., \& Wedel, M. (2000). Factor Analysis and Missing Data. Journal of Marketing Research, 37(4), 490-498. doi: 10.2307/1558517

Kaufman, J. S., \& Cooper, R. S. (2001). Commentary: Considerations for Use of Racial/Ethnic Classification in Etiologic Research. American Journal of Epidemiology, 154(4), 291298. doi: 10.1093/aje/154.4.291

Kenward, M. G., \& Carpenter, J. (2007). Multiple imputation: current perspectives. Statistical Methods in Medical Research, 16(3), 199-218. doi: 10.1177/0962280206075304

Kilty, K. M., \& Berling, J. H. (1985). Predicting the retirement intensions and attitudes of professional workers. The Journals of Gerontology Series B: Psychological Sciences and Social Sciences, 40(219-227).

Kim, H., \& DeVaney, S. (2005). The selection of partial or full retirement by older workers. Journal of Family and Economic Issues, 26(3), 371-394.

Kim, S., \& Feldman, D. C. (2000). Working in retirement: The antecedents of bridge employment and its consequences for quality of life in retirement. Academy of Management Journal, 43(6), 1195-1210. 
Knapp, J. (2009). Disengagement Theory. . In D. P. C. Bryant (Ed.), Encyclopedia of death and the human experience (pp. 382-383). Thousand Oaks, CA: SAGE Publications, Inc.

Kosloski, K., Ekerdt, D. J., \& Deviney, S. (2001). The role of job-related rewards in retirement plannin. The Journal of Gerontology: Social Sciences, 56B(3), 160.

LaVeist, T. A. (1994). Beyond dummy variables and sample selection: What health services researchers ought to know about race as a variable. . Health Services Research, 29(1-16).

LaVeist, T. A. (2002). Beyond dummy variables and sample selection: What health services researchers ought to know about race as a variable. In T. A. LaVeist (Ed.), Race, Ethnicity, and Health : A Public Health Reader (pp. 115-128). San Francisco: JosseyBass.

Lee, S. (2007). Keeping moms on the job: The impacts of health insurance and child care on job retention and mobility among low-income mothers. Washington, DC: Institute for Women's Policy Research.

Levine, R. F. (2006). Social class and stratification : classic statements and theoretical debates. Lanham: Rowman \& Littlefield Publishers.

Lindberg, C., \& Carstensen, L. (2007). Emotions and emotional stability. In K. Markides (Ed.), Encyclopedia of Health \& Aging (pp. 191-193). Thousand Oaks, CA: SAGE Publications, Inc.

Lipkovich, I., Duan, Y., \& Ahmed, S. (2005). Multiple imputation compared with restricted pseudo-likelihood and generalized estimating equations for analysis of binary repeated measures in clinical studies. Pharmaceutical Statistics, 4(4), 267-285. doi: $10.1002 /$ pst. 188

Little, R. J. A., \& Rubin, D. B. (1987). Statistical analysis with missing data. New York: Wiley. 
Little, R. J. A., \& Rubin, D. B. (1989). The analysis of social science data with missing data values. Sociological Methods and Research, 18, 292-592.

Long, J. S. (1997). Regression Models for Categorical and Limited Dependent Variables. Thousand Oaks, CA: Sage Publications

Long, J. S., \& Freese, J. (2006). Regression Models for Categorical Dependent Variables Using Stata: Stata Press.

Longford, N. (2005). Multiple imputation: Missing Data and Small-Area Estimation (pp. 59-95): Springer London.

Luo, Y., \& Waite, L. J. (2005). The impact of childhood and adult SES on physical, mental, and cognitive well-being in later life. The Journals of Gerontology Series B: Psychological Sciences and Social Sciences, 60(2), S93-S101. doi: 10.1093/geronb/60.2.S93

Lynch, J. W., Kaplan, G. A., \& Shema, S. J. (1997). Cumulative impact of sustained economic hardship on physical, cognitive, psychological, and social functioning. New England Journal of Medicine, 337, 1889-1895.

Lynch, S. M., \& Brown, S. (2011). Stratification and inequality over the life course. In R. H. Binstock, L. K. George, S. J. Cutler, J. Hendricks \& J. H. Schulz (Eds.), Handbook of aging and the social sciences. Amsterdam, Boston: Elsevier/Academic Press.

Lynott, P. P., \& Lynott, R. J. (2002). Disengagement. In D. J. Ekerdt (Ed.), Encyclopedia of Aging (Vol. 1, pp. 357-360). New York: Macmillan Reference USA.

Marsh, K. (2008). Black Middle Class. In W. A. Darity, Jr. (Ed.), International Encyclopedia of the Social Sciences (2nd ed. ed., Vol. 1, pp. 313-315). Detroit: Macmillan Reference USA. 
Martin, P. P., \& Weaver, D. A. (2005). Social Security: A program and policy history. Social Security Bulletin, 66(1), 1-15.

Marx, K. (1848/2002). The Communist manifesto. London New York: Penguin Books.

Maurer, S. (2001). Disengagement theory. Reader's Guide to the Social Sciences: Routledge.

McDonough, P., \& Berglund, P. (2003). Histories of poverty and self-rated health trajectories. Journal of Health and Social Behavior, 44, 198-217.

McGarry, K. (2004). Health and Retirement: Do Changes in Health Affect Retirement Expectations? J. Human Resources, XXXIX(3), 624-648. doi: 10.3368/jhr.XXXIX.3.624

McMullin, J. A. (2002). Inequality. In D. J. Ekerdt \& I. NetLibrary (Eds.), Encyclopedia of aging (pp. 706-711). New York: Macmillan Reference USA.

Mein, G., Martikainen, P., Stansfeld, S. A., Brunner, E. J., Fuhrer, R., \& Marmot, M. G. (2000). Predictors of early retirement in British civil servants. Age and Ageing, 29(6), 529-536. doi: 10.1093/ageing/29.6.529

Merton, R. K. (1968). The Matthew Effect in Science. Science, 159(3810), 56-63.

Mirowsky, J., \& Ross, C. E. (2003). Education, Social Status, and Health. New York: Aldine de Druyter.

Molm, L. D. (2005). George Homans Encyclopedia of Social Theory. Thousand Oaks, CA: SAGE Publications, Inc.

Mor-Barak, M. E. (1995). The meaning of work for older adults seeking employment: The generativity factor. International Journal of Aging \& Human Development, 41(4), 325344.

Morrison, K. (2006). Marx, Durkheim, Weber : formations of modern social thought. London, Thousand Oaks, CA: SAGE Publications. 
Morse, N. C., \& Weiss, R. S. (1955). THE FUNCTION AND MEANING OF WORK AND THE JOB. American Sociological Review, 20(2), 191-198.

Moss, P., \& Tilly, C. (2001). Stories Employers Tell: Race, Skill and Hiring in America. New York: Russell Sage Found.

Munnell, A. H., Cahill, K. E., \& Jivan, N. A. (2003) How has the shift to 401(k)s affected the retirement age? , An Issue in Brief. Chestnut Hill, MA: Center for Retirement Research at Boston College.

Munnell, A. H., \& Sass, S. A. (2008a). Will older men want to work longer? Working longer: The solution to the retirement income challenge. . Washington, DC: Brookings Institution Press.

Munnell, A. H., \& Sass, S. A. (2008b). Working longer: The solution to the retirement income challenge. . Washington, DC: Brookings Institution Press.

Munnell, A. H., Soto, M., \& Golub-Sass, A. (2007) Will people be healthy enough to work longer? , An Issue in Brief: Center for Retirement Research at Boston College.

Munnell, A. H., Tootell, G. B., Browne, L. E., \& McEneaney, J. (1996). Mortgage lending in Boston: Interpreting HMDA data. American Economic Review 86(1), 25-53.

Munnell, A. H., Triest, R. K., \& Jivan, N. A. (2004) How do pensions affect expected and actual retirement ages? , Center for Retirement Reearch Working Paper: Boston College.

Mutchler, J. E. (2002). Employment of older workers. In D. J. Ekerdt \& G. Gale (Eds.), Encyclopedia of aging (Vol. 2, pp. 433-439). New York: Macmillan Reference USA.

Mutchler, J. E., Burr, J. A., Massagli, M. P., \& Pienta, A. (1999). Work transitions and health in later life. The Journals of Gerontology Series B: Psychological Sciences and Social Sciences, 54B(5), S252-S261. doi: 10.1093/geronb/54B.5.S252 
Mutchler, J. E., Burr, J. A., Pienta, A. M., \& Massagli, M. P. (1997). Pathways to labor force exit: work transitions and work instability. The Journals of Gerontology Series B: Psychological Sciences and Social Sciences, 52(1), S4-12.

National Center for Health Statistics. (2011). Health, United States, 2010: With special feature on death and dying. Hyattsville, MD: U.S. Government Printing Office.

National Institute on Aging. (2007). Growing older in American: The Health \& Retirement Study. Bethesda, MD: National Institute on Aging.

Nelson, C., \& Tienda, M. (1984) The structuring of Hispanic ethnicity: Historical and contemporary perspectives. CDE working paper (pp. 27-84): Center for Demography and Ecology, University of Wisconsin-Medison.

Noonan, A. E. (2005). "At this point now": older workers' reflections on their current employment experiences.(rapidly changing workplaces affect)(Author Abstract). International Journal of Aging \& Human Development, 61(3), 211(231).

O'Rand, A. M. (1996). The precious and the precocious: Understanding cumulative disadvantage and cumulative advantage over the life course. The Gerontologist, 36(2), 230-238. doi: $10.1093 /$ geront/36.2.230

O'Rand, A. M. (2001). Stratification and the life course: The forms of life course capital and their interdependence. In R. H. Binstock \& L. K. George (Eds.), Handbook on aging and the social sciences (Vol. 5th ed, pp. 197-213). San Diego, CA: Academic Press.

O’Rand, A. M. (2002). Retirement, Transitions. In D. J. Ekerdt \& G. Gale (Eds.), Encyclopedia of aging (Vol. 4, pp. p1201-1207). New York: Macmillan Reference USA.

Oliver, M., \& Shapiro, T. (2006). Black Wealth, White Wealth: A New Perspective on Racial Inequality. (2nd ed.). New York Routledge. 
Omi, M., \& Winant, H. (2006). Racial foundation. In R. F. Levine (Ed.), Social class and stratification : classic statements and theoretical debates. Lanham: Rowman \& Littlefield Publishers.

Pager, D., \& Shepherd, H. (2008). The Sociology of Discrimination: Racial Discrimination in Employment, Housing, Credit, and Consumer Markets. Annual Review of Sociology, 34(1), 181-209. doi: doi:10.1146/annurev.soc.33.040406.131740

Pager, D., Western, B., \& Bonikowski, B. (2009). Discrimination in a Low-Wage Labor Market: A Field Experiment. American Sociological Review, 74(5), 777-799. doi: $10.1177 / 000312240907400505$

Parsons, D. O. (1982). The male labor force participation decision: health, reported health and economic incentives. Economica, 49, 81-91.

Patrician, P. A. (2002). Multiple imputation for missing data $\uparrow$. Research in Nursing \& Health, 25(1), 76-84. doi: 10.1002/nur.10015

Peterson, C. L., \& Murphy, G. (2010). Transition from the labor market: Older workers and retirement. International Journal of Health Services, 40(4).

Pew Research Center. (2007). Optimism about Black progress delines: Blacks see growing balues gap between poor and middel class A Social \& Demographic Trend Report

Pienta, A. M., \& Hayward, M. D. (2002). Who expects to continue working after age 62 ? The retirement plans of couples.(Abstract). The Journals of Gerontology, Series B, 57(4), S199(110).

Porell, F., \& Almeida, B. (2009). The pension factor: Assessing the role of defined benefit plans in reducing elder hardships: National Institute on Retirement Security.

Price, D. J. D. S. (1965). Networks of Scientific Papers. Science, 149(3683), 510-515. 
Purcell, P. (2009a). Older worekrs: Employment and retirement trends Congressional Research Service.

Purcell, P. (2009b). Pension sponsorship and participation: Summary of recent trends Congressional Research Service (Vol. 7-5700): Congressional Research Service.

Quadagno, J., \& Reid, J. (1999). The political economy perspective in aging. In V. L. Bengtson \& K. W. Schaie (Eds.), Handbook of theories of aging (pp. 344-358). New York: Springer.

Quinn, J., \& Kozy, M. (1996). The role of bridge jobs in the retirement transition: Gender, race, and ethnicity. Gerontologist, 36(3), 363.

Rappaport, A. M., \& Scheiber, S. J. (1993). Demography and retirement: The twenty-first centry. Westport, CT: Praeger.

Raymo, J. M., Warren, J. R., Sweeney, M. M., Hauser, R. M., \& Ho, J.-H. (2009). Later-life employment preferences and outcomes: The role of midlife work experiences. Research on Aging, 32(4), 419-466. doi: 10.1177/0164027510361462

Reiter, J. (2006). Multiple Imputation For Missing Data. Encyclopedia of Measurement and Statistics. SAGE Publications. Thousand Oaks, USA: SAGE Publications.

Reitzes, D. C., Mutran, E. J., \& Fernandez, M. E. (1996). Does retirement hurt well-being? Factors influencing self-esteem and depression among retirees and workers.

Reynolds, S. J., Reidley, N., \& Van Horn, C. E. (2005). A work-filled retirement: Workers' chaning views on employment and leisure. John J. Heldrich Center for Workforce Development. Retrieved from http://www.heldrich.rutgers.edu/uploadedFiles/Publications/WT16.pdf 
Ries, P. (1990). Health of Black and White Americans, 1985-1987. Vital Health Statistics, 10, 9-

10.

Riley, M. W., Kahn, R. L., \& Foner, A. (1994). Age and structural lag: Society's failture to provide meaningful opportunities in work, family, and leisure. New York: WileyInterscience.

Robins, J. M., Hernan, M. A., \& Brumback, B. (2000). Marginal structural models and causal inference in epidemiology. Epidemiology, 11(550-560).

RoperASW. (2002). Staying ahead of the curve: The AARP work and career study. Washington, DC: AARP.

Ross, C. E., \& Wu, C.-L. (1996). Education, age and the cumulative advantage in health. Journal of Health and Social Behavior, 37, 104-120.

Rothenberg, P. S. (2008). White privilege: Essential readings on the other side of racism. New York: Catherine Woods.

Rubin, D. B. (1987). Multiple imputation for nonresponse in sample surveys. New York: Wiley.

Rubin, D. B. (1996). Multiple imputation after 18 years. Journal of American Statistics Association, 91, 473-489.

Ruhm, C. J. (1990a). Bridge jobs and partial retirement. Journal of Labor Economcis, 8, 482501.

Ruhm, C. J. (1990b). Career jobs, bridge employment, and retirement. In P. B. Doeringer (Ed.), Bridges to retirement : older workers in a changing labor market. Ithaca, NY: ILR Press, School of Industrial and Labor Relations, Cornell University. 
Ruhm, C. J. (1992). The effects of physical and mental health on female labor supply. In R. Frank \& W. M. Jr (Eds.), Economics and Mental Health (pp. 152-181). Baltimore, MD: Johns Hopkins University Press.

Ruhm, C. J. (1996). Gender differences in employment behavior during late middle life. The Journal of Gerontology: Social Sciences, 51B(S11-S17).

Sapozhnikov, M., \& Triest, R. K. (2007). Population Aging, Labor Demand, and the Structure of Wages. Research Review(8), 11-14.

Saunders, J., Marrow-Howell, N., Spitznagel, E., Doré, P., Proctor, E. K., \& Pescario, R. (2006 ). Imputing missing data: A comparison of methods for social work researchers. Social Work Research, 30(1), 19-31.

Scarpitti, F. R., \& Andersen, M. L. (1992). Social Problems. New York, NY: Harper Collins Publishers.

Schafer, J. L. (1997). Analysis of incomplete multivariate data. London: Chapman \& Hall.

Schafer, J. L. (1999). Multiple imputation: a primer. Statistical Methods in Medical Research, 8(1), 3-15. doi: 10.1177/096228029900800102

Schochet, P., \& Rangarajan, A. (2004). Characteristics and experiences of low-wage workers in the mid-to-late 1990. Report submitted to U.S. Department of Health and Human Services. Princeton, NJ.

Schunk, D. (2008). A Markov chain Monte Carlo algorithm for multiple imputation in large surveys. Advances in Statistical Analysis, 92(1), 101-114. doi: doi:10.1007/s10182-0080053-6

Scocpol, T. M. (1992). Protecting soldiers and mothers: The political origins of social policy in the United States. Cambridge Mass: Belknap. 
Scott, C. G. (1999). Identifying the race of ethnicity of SSI recipients. Social Security Bulletin, 62(4), 9-20.

Segal, E. A. (2010). Social welfare policy and social programs : a values perspective. Belmont, CA: Thomson Brooks/Cole.

Sernau, S. (2001). Worlds apart: social inequalities in a new century. Thousand Oaks, Calif: Pine Forge Press.

Shapiro, T. M., \& Kenty-Drane, J. L. (2005). The racial wealth gap In C. Conrad (Ed.), African Americans in the U.S. economy (pp. 175-181). Lanham, MD: Rowman \& Littlefield.

Shavit, Y., Arum, R., Gamoran, A., \& Menachem, G. (2007). Stratification in higher education: a comparative study. Stanford, Calif: Stanford University Press.

Shaw, L., \& Hill, C. (2002). Retirement, decision making. In D. J. Ekerdt \& G. Gale (Eds.), Encyclopedia of aging (Vol. 4, pp. p1190-1197). New York: Macmillan Reference USA.

Shuey, K. M., \& Willson, A. E. (2008). Cumulative disadvantage and black-white disparities in life-course health trajectories. Research on Aging, 30(2), 200-225. doi: $10.1177 / 0164027507311151$

Singh, G., \& DeNoble, A. (2003). Early Retirees As the Next Generation of Entrepreneurs. Entrepreneurship Theory and Practice, 27(3), 207-226. doi: 10.1111/1540-8520.t01-100001

Singh, G., \& Verma, A. (2003). Work history and later-life labor force participation: evidence from a large telecommunications firm.(Author Abstract). Industrial and Labor Relations Review, 56(4), 699(617).

Smith, J. P., \& Kington, R. (1997). Demographic and economic corrleates of health in old age. Demography, 34, 159-170. 
Smyer, M. A., \& Pitt-Catsouphes, M. (2007). The meaning of work for older workers. Generations, Spring, 23-30.

Social Science Computer Cooperative. (2013). Multiple imputation in Stata: Deciding to impute. Providing computer services for the Social Sciences at UW-Madison Retrieved May 19, 2013, from http://www.ssc.wisc.edu/sscc/pubs/stata_mi_decide.htm

Social Security Administration. (2008). Annual Statistical Supplement. Washington, DC: Social Security Administration.

Social Security Online. (2011). Age to receive full Social Security retirement benefits Retrieved June 30, 2011, from http://ssa.gov/pubs/retirechart.htm

Song, J. G., \& Manchester, J. (2007). How have people responded to changes in the retirement earnings test in 2000? Social Security Bulletin, 67(1).

SPSS Inc. (2010). IBM SPSS missing values 19. Retrieved from ftp://public.dhe.ibm.com/software/analytics/spss/documentation/statistics/20.0/en/client/ Manuals/IBM_SPSS_Missing_Values.pdf

Stern, S. (1989). Measuring the effect of disability on labor force participation. Journal of Human Resources, 24, 361-395.

Street, D. A. (2007). Sociological approaches to understanding age and aging. In J. A. P. D. Blackburn \& C. N. Dulmus (Eds.), Handbook of gerontology : evidence-based approaches to theory, practice, and policy (pp. 143-168). Hoboken, N.J.: Wiley.

Sum, A., Khatiwada, I., McLaughlin, J., \& Palma, S. (2008). Identifying the national pool of older workers eligible for Senior Community Service Employment Programs and their current and projected unmet service needs: Senior Service America. 
Szinovacz, M. E., \& Deviney, S. (2000). Marital Characteristics and Retirement Decisions. Research on Aging, 22(5), 470-498. doi: 10.1177/0164027500225002

Tacachnick, B. G., \& Fidell, L. S. (2000). Using multivariable statistics (4th ed.). New York: HarperCollins College Publishers.

Tacq, J. (2004). Multicollinearity. Encyclopedia of Social Science Research Methods. SAGE Publications, Inc. In A. B. M. Lewis-Beck, \& T. Liao (Ed.), Encyclopedia of social science research methods. (pp. 668-670). Thousand Oaks, CA: SAGE Publications, Inc.

Taylor, M. G. (2008). Timing, accumulation, and the Black/White disability gap in later life. Research on Aging, 30(2), 226-250. doi: 10.1177/0164027507311838

The American Association of Community Colleges. (2013). About Plus 50 Intiative Retrieved May 13, 2013, from http://plus50.aacc.nche.edu/aboutplus50/Pages/default.aspx

The U.S. Social Security Administration. (2011a). Social Security Fact Sheet: Delayed retirement credits Retrieved April 27, 2011, from http://www.ssa.gov/pressoffice/IncRetAge.html

The U.S. Social Security Administration. (2011b). Social Security Fact Sheet: Increase in retirement age Retrieved April 27, 2011, from http://www.ssa.gov/pressoffice/IncRetAge.html

Thomas-Breitfeld, S., \& Liu, S. (2003). Workforce Investment Act (WIA) reauthorization: Building a better job training system for Hispanic workers. Washington, DC: National Council of La Raza.

Tiryakian, E. A. (1975). Neither Marx nor Durkheim . . Perhaps Weber. The American Journal of Sociology, 81(1), 1-33. 
Toossi, M. (2011). A behavioral model for projecting the labor force participation rate. Monthly Labor Review, 134(5), 25-42.

Total Merrill. (2006). The 2006 Merrill Lynch New Retirement Study: A perspective from individuals and employers. from Merrill Lynch http://www.ml.com/media/66482.pdf

Trattner, W. I. (1999). From poor law to welfare state : a history of social welfare in America. New York: The Free Press.

Tunceli, K., Bradley, C. J., Nerenz, D., Williams, L. K., Pladevall, M., \& Elston Lafata, J. (2005). The Impact of Diabetes on Employment and Work Productivity. Diabetes Care, 28(11), 2662-2667. doi: 10.2337/diacare.28.11.2662

U.S. Bureau of Labor Statistics. (2011). Labor force statistics from the Current Population Survey. Retrieved November 11, 2011, from http://data.bls.gov:8080/PDQ/outside.jsp?survey=ln

U.S. Census Bureau. (2004). Current Population Survey Annual Social and Economics Supplement Retrieved May 5, 2011, from http://www.census.gov/hhes/www/poverty/publications/pubs-cps.html

U.S. Department of Commerce Bereau of Economic Analysis. (2005). National income and product accounts, from Retrieved July 25, 2008, from http://www.bea.doc.gov/bea/dn/nipaweb/SelectTable.asp?Selected=N.

U.S. Department of Labor. (2013). One-Stop Career Centers Retrieved May 14, 2013, from http://www.dol.gov/dol/topic/training/onestop.htm

U.S. Equal Employment Opportunity Commission. (2011). History: 35 years of ensuring the promise of opportunity Retrieved April 2, 2011, from http://www.eeoc.gov/eeoc/history/35th/history/index.html 
Wacker, R. R., Roberto, K. A., \& Piper, L. E. (2002). Income programs Community resources for older adults : programs and services in an era of change (2nd ed.). Thousand Oaks, Calif.: Pine Forge Press.

Walsemann, K. M., Geronimus, A. T., \& Gee, G. C. (2008). Accumulating disadvantage over the life course. Research on Aging, 30(2), 169-199. doi: 10.1177/0164027507311149

Walsh, M. (2001, Febuary 26). Reversing decades-long trend, Amercian retiring later in life. . New York Times.

Warner, D. F., \& Hayward, M. D. (2006). Early-life origins of the race gap in men's mortality. Journal of Health and Social Behavior, 47(3), 209-226. doi:

$10.1177 / 002214650604700302$

Weber, M. (1922/1978). Economy and society : an outline of interpretive sociology. Berkeley: University of California Press.

Weckerle, J. R., \& Shultz, K. S. (1999). Influences on the bridge employment decision among older USA workers. Journal of Occupational and Organizational Psychology, 72(3), 317-329. doi: 10.1348/096317999166707

White, I. R., Wood, A., \& Royston, P. (2007). Editorial. Statistical Methods in Medical Research, 16(3), 195-197. doi: 10.1177/0962280206074452

Williams, D. R., \& Collins, C. (1995). US socioeconomic and racial differences in health: Patterns and expectations. Annual Review of Sociology, 21, 349-396.

Williams, D. R., \& Collins, C. (2002). Racial residentail segregation: A fundamental cause of racial disparities in health. In T. A. Laveist (Ed.), Race, Ethnicitiy, and Health. San Francisco, CA: Jossey-Bass A wiley Imprint. 
Williams, D. R., Costa, M. W., Odunlami, A. O., \& Mahammed, S. A. (2008). Moving upstream: How interventions that address that social determinations of health can improve health and reduce disparities. Journal of Public Health Management and Practice, 14 (Suppl.), S8-S17.

Williams, D. R., \& Jackson, P. B. (2005). Social sources of racial disparities in health. Health Affairs, 24(2), 325-334.

Williamson, J. B., \& McNamara, T. K. (2004). Race, gender, and the retirement decisions of people aged 60 to 80: Prospects for age integration in employment. International journal of aging \& human development, 59(3), 255-286. doi: 10.2190/ge24-03mx-u34p-amnh

Wilson, R. (1994). The participation of African Americans in American higher education. In M. J. Justiz, R. Wilson \& L. G. Bjork (Eds.), Minorities in higher education (pp. 195-211). Phoenix, AZ: Oryx Press.

Wilson, W. J. (1987). The Truly Disadvantaged: The Inner City, the Underclass, and Public Policy. . Chicago: University of Chicago Press.

Wu, C. (2011). Long-term employment and earnings among low-income families with children. Children and Youth Services Review, 33(1), 91-101. doi:

10.1016/j.childyouth.2010.08.017

Zsembik, B. A., \& Singer, A. (1990). The problem of defining retirement among Minorities: the Mexican Americans. The Gerontologist, 30(749-757). 